\title{
Cytoprotective and toxic functions of the prion protein family
}

\author{
Antal Nyeste \\ Ph.D. Thesis
}

\author{
Supervisor: \\ Ervin Welker, D.Sc. \\ INSTITUTE OF BIOCHEMISTRY \\ BIOLOGICAL RESEARCH CENTER \\ HUNGARIAN ACADEMY OF SCIENCE \\ INSTITUTE OF ENZYMOLOGY \\ RESEARCH CENTRE FOR NATURAL SCIENCES \\ HUNGARIAN ACADEMY OF SCIENCE
}

Szeged

2016 


\section{List of Publications}

\section{Publications related to the thesis}

I. Nyeste, A., Bencsura, P., Vida, I., Hegyi, Z., Homolya, L., Fodor, E., and Welker, E. (2016) Expression of the Prion Protein Family Member Shadoo Causes Drug Hypersensitivity That Is Diminished by the Coexpression of the Wild Type Prion Protein. J. Biol. Chem. 291, 4473-86

II. Cingaram, P. K. R., Nyeste, A., Dondapati, D. T., Fodor, E., and Welker, E. (2015) Prion Protein Does Not Confer Resistance to Hippocampus-Derived Zpl Cells against the Toxic Effects of $\mathrm{Cu} 2+, \mathrm{Mn} 2+, \mathrm{Zn} 2+$ and Co2+ Not Supporting a General Protective Role for PrP in Transition Metal Induced Toxicity. PLoS One. 10, e0139219

\section{Unrelated publications}

III. Schäfer, B., Orbán, E., Borics, A., Huszár, K., Nyeste, A., Welker, E., and Tömböly, C. (2013) Preparation of semisynthetic lipoproteins with fluorescent cholesterol anchor and their introduction to the cell membrane with minimal disruption of the membrane. Bioconjug. Chem. $24,1684-1697$

IV. Tóth, E., Huszár, K., Bencsura, P., Kulcsár, P. I., Vodicska, B., Nyeste, A., Welker, Z., Tóth, S., and Welker, E. (2014) Restriction enzyme body doubles and PCR cloning: on the general use of type IIs restriction enzymes for cloning. PLoS One. 9, e90896 


\section{Conference abstracts}

V. Nyeste A., Ayaydin F., Fodor E., Tóth E., Tusnády G. E., Simon I., Welker E. Alternative translation initiation may alter the cellular distribution of GFP-tagged proteins. Prion 5(2011):70 Prion 2011: New World Congress (2011, Montreal, Canada)

VI. Vodicska B., Nyeste A., Tóth E., Welker E. A membrane protein in the nucleus. Hungarian Molecular Life Sciences 2013 (2013, Siófok, Hungary)

VII. Tóth E., Huszár K., Bencsura P., Kulcsár P. I., Vodicska B., Nyeste A., Welker Zs., Tóth Sz., Welker E. Restrikciós enzim dublörök: a Type IIS restrikciós endonukleázok általános alkalmazása. 44. Membrán-Transzport Konferencia (2014, Sümeg, Hungary)

VIII. Tóth E., Huszár K., Bencsura P., Kulcsár P. I., Vodicska B., Nyeste A., Welker Zs., Tóth Sz., Welker E. Cloning the Shadoo and Prion proteins: Restriction Enzyme Body Doubles and PCR cloning. Prion 8(2014): 43. Prion 2014: Shaping the future of prion research (2014, Trieste, Italy)

IX. Nyeste A., Bencsura P.G., Welker E. Rescuing the drug hypersensitivity phenotype of $\operatorname{PrP} \Delta 105$ 125 by the co-expression of the Shadoo protein. Prion 8(2014): 41. Prion 2014: Shaping the future of prion research (2014, Trieste, Italy) 


\section{Table of Contents}

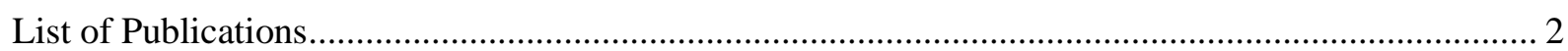

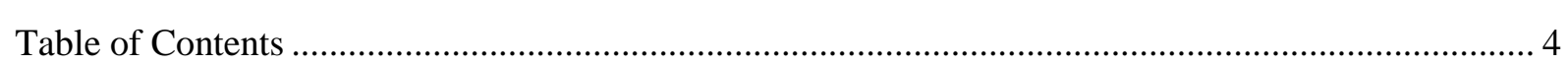

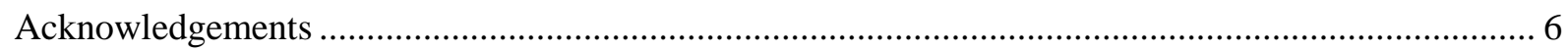

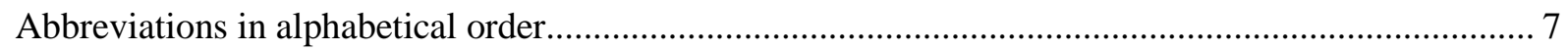

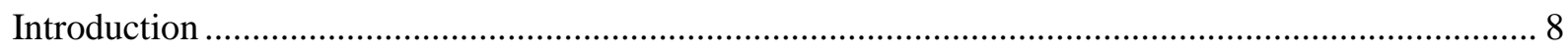

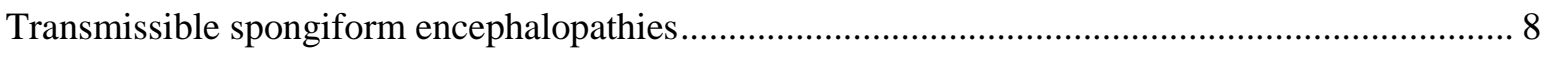

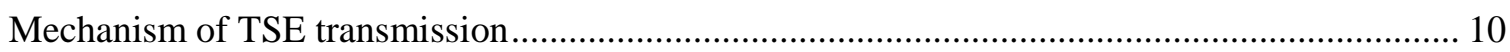

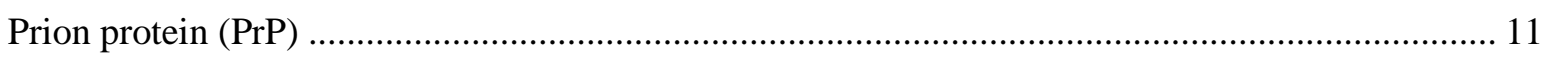

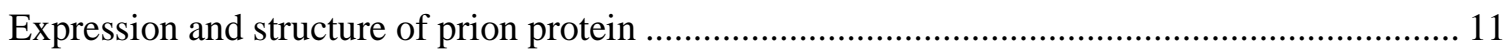

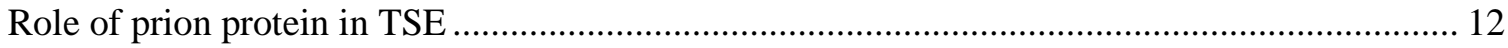

Physiological functions of the prion protein family members .................................................... 13

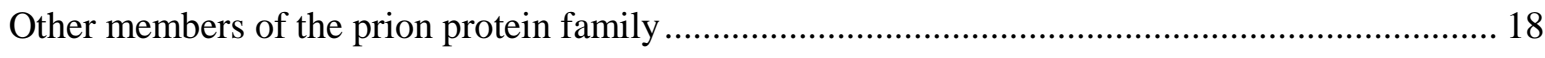

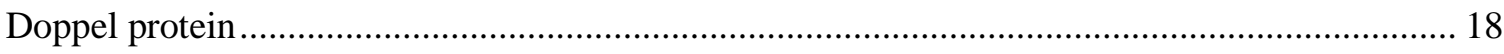

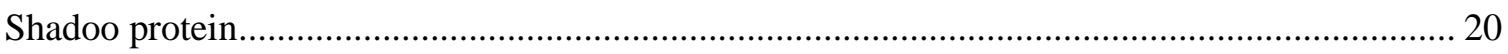

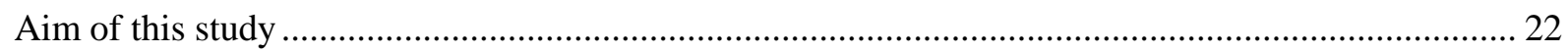

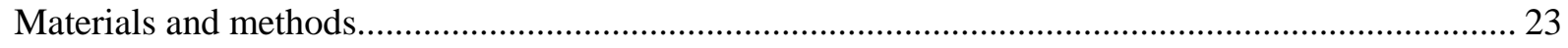

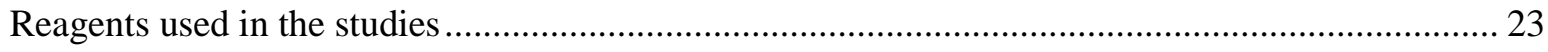

Antibodies used in immunocytochemistry (ICC) and immunoblotting (WB) ................................ 23

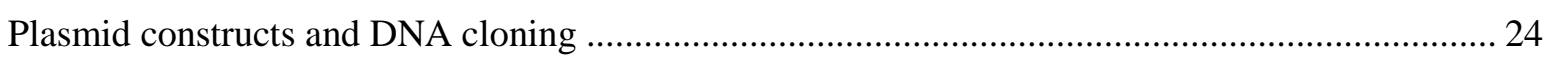

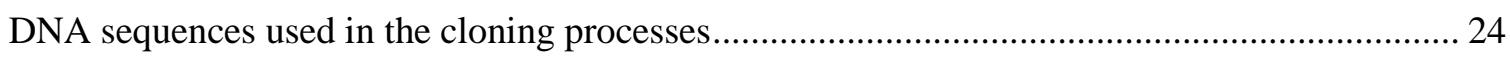

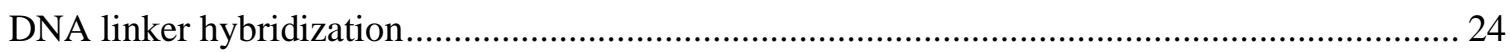

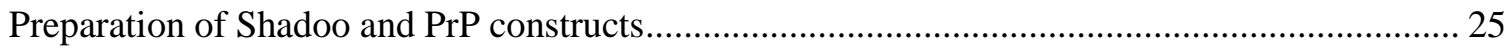

Preparation of Sleeping Beauty plasmid constructs ..................................................................... 25

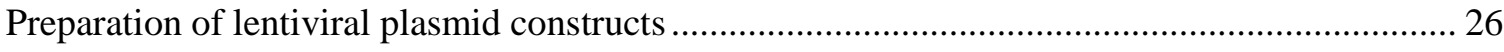

Cloning of the recombinant Sho-PrP (rSho-PrP) fusion polypeptide........................................ 27

Expression, purification and refolding of the recombinant Sho-PrP fusion protein......................... 28

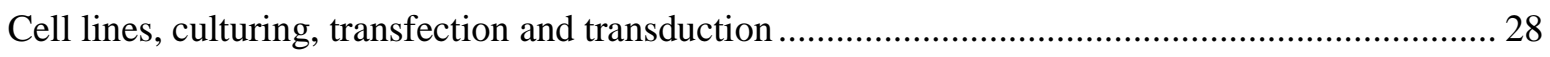

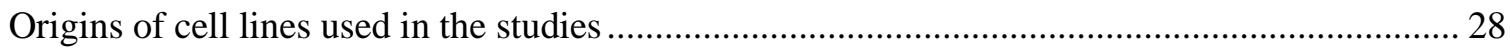

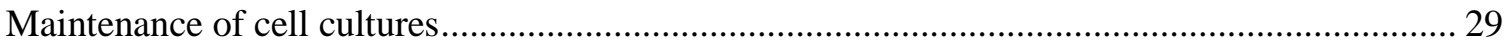

Establishment of stable expression with Sleeping Beauty transposon system.............................. 29 
Establishment of stable expression with pRRL lentiviral system. ............................................ 29

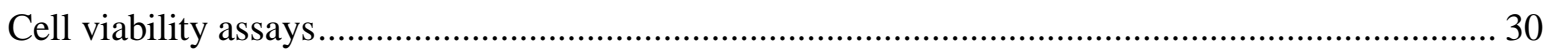

Detection of apoptosis caused by serum deprivation or PrP $\Delta$ CR expression in Zpl2-1 cells ....... 30

Analysis of drug hypersensitivity caused by $\operatorname{PrP} \Delta \mathrm{CR}$ and Shadoo............................................ 31

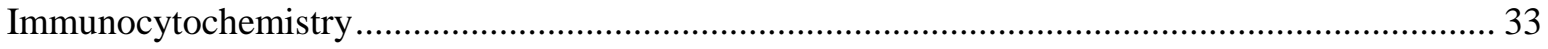

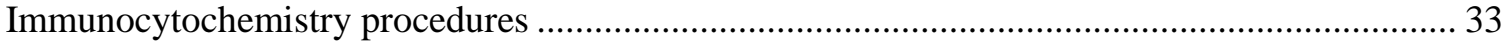

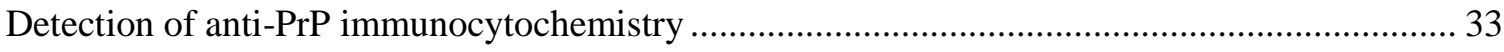

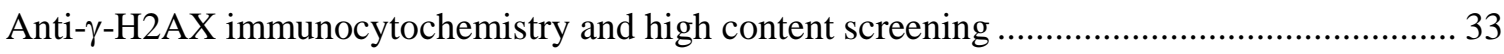

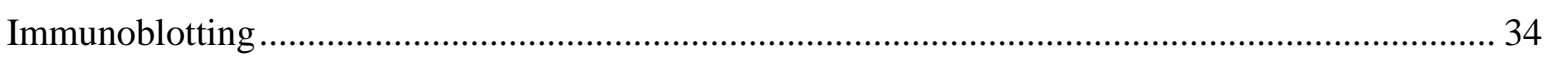

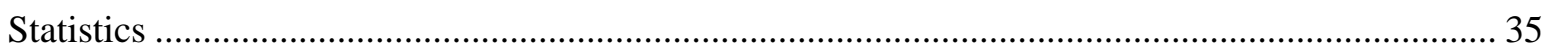

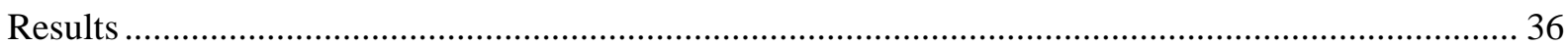

Establishment of stable transgene expression in Zpl2-1, SH-SY5Y and HEK293 cell lines............ 36

Assessing the extent of co-integration of the two expression cassettes between Sleeping Beauty

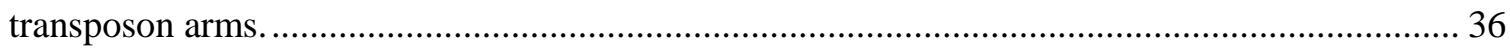

Analysis of WT and $\triangle \mathrm{CR}$ PrP expression in cells established with Sleeping Beauty transposon

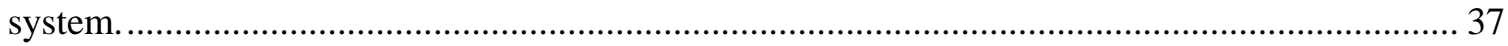

Analysis of PrP and Shadoo expression in cells transduced with lentivirus ................................... 40

Comparison of the prion and Shadoo transgene expression levels in $\mathrm{SH} / \Delta \mathrm{CR}+\mathrm{PrP}$ and

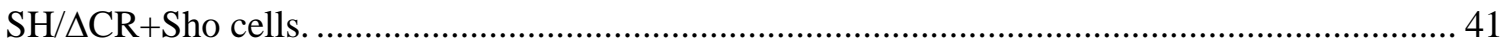

Effects of serum deprivation to WT and $\Delta \mathrm{CR}$ PrP expressing cells ................................................ 42

Shadoo does not rescue Zeocin hypersensitivity caused by PrP $\Delta$ CR in SH-SY5Y cells.................. 43

Shadoo causes Zeocin and G418 hypersensitivity in various cell lines that is diminished by WT PrP

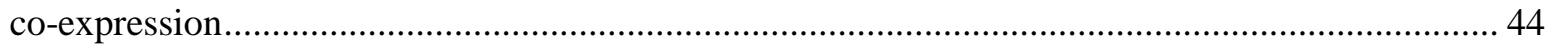

Shadoo, like PrP $\Delta$ CR modulates the initial uptake of Zeocin............................................................ 46

Searching for important regions of Shadoo protein in drug hypersensitivity effect.......................... 48

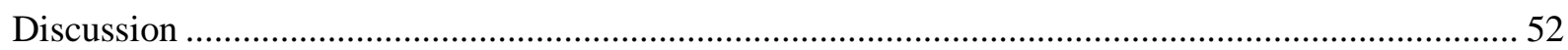

Effects of WT and $\triangle \mathrm{CR}$ PrP on serum deprivation caused cell death............................................ 52

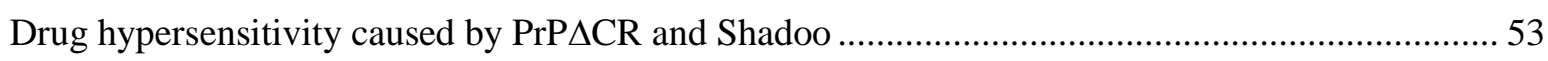

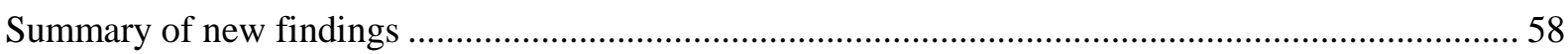

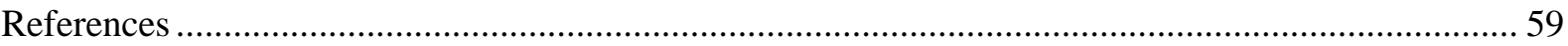

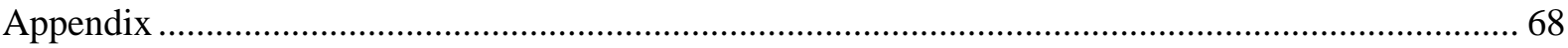




\section{Acknowledgements}

First and foremost, I would like to express my sincere gratitude to my supervisor, Ervin Welker DSc for the guidance he provided me and for teaching me the importance of controls and what it means to be a scientist. I would also like to thank him for his patience and encouragement during my $\mathrm{PhD}$ years and for providing opportunity to work in his group.

I am most grateful to Petra Bencsura, György Várady and István Vida, for without their skill and invaluable assistance this story would be much shorter.

I am thankful for Katalin Német and her group for the assistance they provided with the lentiviral work. Using lentiviruses instead of transfection saved me from going prematurely grey.

I am grateful to Nóra Kucsma and Elfrieda Fodor for offering advice and helping hand when I was in need.

I would like to give my special thanks to Ervin Welker, Ágnes Telbisz, Szilvia Pravda and Eszter Tóth for the patient and critical reading they provided, their help was invaluable in turning this into the thesis you now hold.

And last but not least, would like to thank my past and present colleagues, fellow students, family and friends whose support helped to overcome the hardships of Life and Science.

Contributions to the experiments done by my colleagues are noted in the materials and methods section and in specific captions. 


\section{Abbreviations in alphabetical order}

$A \beta: \beta$-amyloid

AD: Alzheimer disease

APP: amyloid precursor protein

CC: Charged cluster

CGN: cerebellar granular neuron

CJD: Creutzfeldt-Jacob disease

CNS: central nervous system

$\mathrm{CR}$ : central region

Dpl: doppel protein

GFP: green fluorescent protein

GPI-anchor: glycosylphosphatidylinositol-anchor

GSS: Gerstmann-Sträussler-Scheinker syndrome

HD: hydrophobic domain

IRES: internal ribosome entry site

KO: knock-out

LTP: long-term potentiation

NSC: neuronal stem cell

OR: octarepeat region

PIPLC: Phosphatidylinositol-dependent phospholipase-C

PNGaseF: Peptide-N-glycosidase F

PrP: prion protein

$\operatorname{PrP}^{\mathrm{C}}$ : cellular isoform of $\operatorname{PrP}$

$\mathrm{PrP}^{\mathrm{Sc}}$ : abnormal, scrapie isoform of PrP

PTD: protein transduction domain

ROS: reactive oxygen species

SB: sleeping beauty

Sho: Shadoo protein

SRP: signal recognition particle

TSE: transmissible spongiform encephalopathy

WT: wild type 


\section{Introduction}

\section{Transmissible spongiform encephalopathies}

Transmissible spongiform encephalopathies (TSEs) are a group of rare neurodegenerative diseases that affect several mammalian species, including humans (Table 1). These diseases are characterized by the spongiform degeneration of the brain tissue (Figure 1A), loss of neurons which cause cognitive and motor dysfunctions, depending on which regions of the nervous system are affected. Astrogliosis and sometimes amyloid plaque formation can also be detected in the TSE brain. These diseases are currently untreatable and progressive, always resulting in the death of the affected host.

\begin{tabular}{|c|c|}
\hline HOST & DISEASE \\
\hline HUMAN & $\begin{array}{l}\text { Kuru, } \\
\text { "Classic" Creutzfeldt-Jacob Disease, } \\
\text { Gerstmann-Sträussler-Scheinker syndrome (GSS), } \\
\text { Fatal familiar insomnia (FFI), } \\
\text { Fatal sporadic insomnia (FSI), } \\
\text { variant CJD } \\
\text { atypical CJD }\end{array}$ \\
\hline OVINE & Scrapie \\
\hline BOVINE & Bovine spongiform encephalopathy ("mad-cow disease", BSE) \\
\hline ELK, DEER & Chronic wasting disease (CWD) \\
\hline FELINE & Feline spongiform encephalopathy \\
\hline MINK & Mink spongiform encephalopathy \\
\hline $\begin{array}{l}\text { GREATER } \\
\text { KUDU, } \\
\text { NYALA, } \\
\text { ORYX }\end{array}$ & Exotic ungulate encephalopathy \\
\hline
\end{tabular}

Table 1: Mammalian host species and their respective transmissible spongiform encephalopathies

Human prion diseases are very rare. The prevalence of Creutzfeldt-Jacob disease (CJD), the most common human TSE, is about 1-9/1000000. Two other familiar prion diseases, fatal familiar insomnia (FFI) and Gerstmann-Sträussler-Scheinker syndrome (GSS) are even rarer, prevalence of FFI is about 1/1000000, and is unknown in case of GSS. As comparison, Parkinson's disease affects $1 \%$ of the population over 55 years of age (1), and about $4 \%$ of the population over 65 years is affected by Alzheimer's disease (2). 
"Classic" (as opposed to "variant", see below) Creutzfeldt-Jacob disease (CJD) was the first human TSE described (Creutzfeldt, 1920 and Jacob, 1921), but the cause of the disease has been found only half a century later. CJD, like Parkinson and Alzheimer, is typically a disease of the older generations.
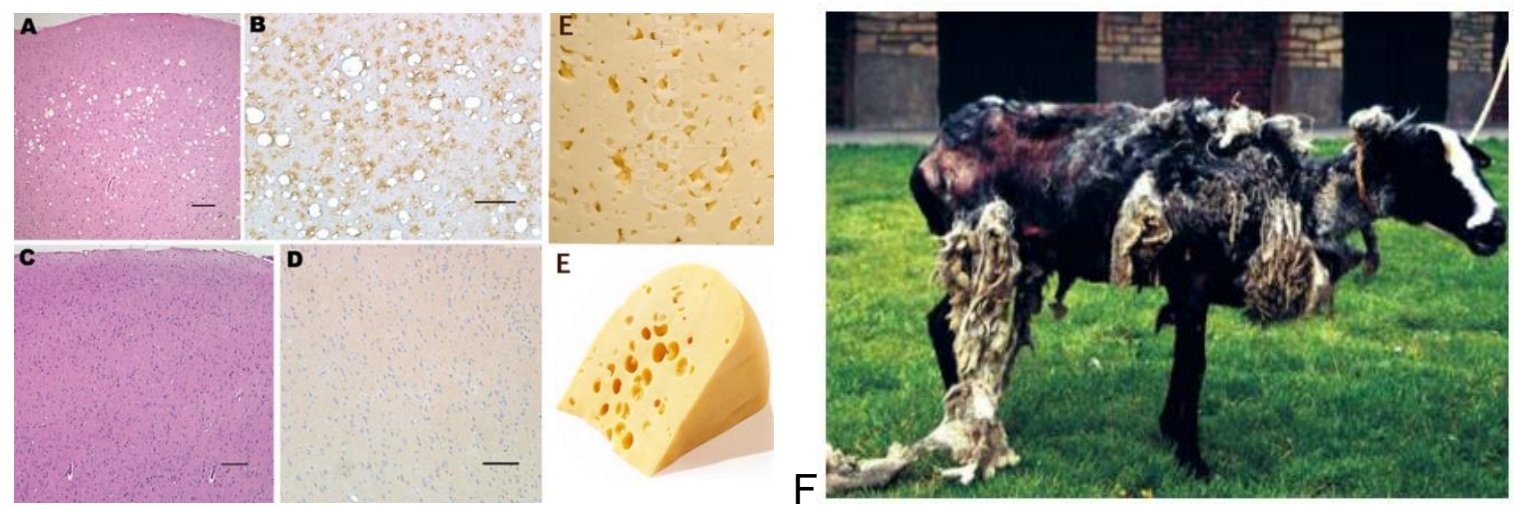

Figure 1: (A-E) Histological sections of TSE-affected $(A, B)$ or healthy $(C, D)$ brains and Swiss cheese (E). Presence of vacuolization (white spherical areas) and extracellular plaques (brown staining) are apparent. (F) Scrapie affected sheep (3)

[Source of (A-E): https://biogeekery.wordpress.com/2013/01/28/prions-pestiferous-proteins/]

"Classic" CJD has three forms: about $85 \%$ of the cases are sporadic, $10 \%$ are familiar, where the disease is associated with a gene mutation and 5\% are iatrogenic, where the disease is acquired with accidental transmission via improperly sterilized surgical tools, or transplants of dura mater or cornea fragments, or administration of pituitary hormones of cadaveric origin.

Among the human TSE-s, kuru should also be mentioned, both as a curiosity and as the disease that led to the discovery of the infectious nature of TSEs. Kuru was an endemic disease that decimated the Fore tribe in Papua New Guinea. It has been described by Charleton Gajdusek in the middle of the 20th century, who connected it to the funerary cannibalism practiced by the tribe. Despite not having found evidence of parasitic, viral or bacterial infection, he assumed the disease to be infectious. It took a decade for him and his colleagues to prove the concept in primates: the injection of brain homogenates of kuru patients into healthy monkeys caused appearance of TSE symptoms in the animals (4). 
Despite the rarity of the human TSE-s, the public health and economic issues of the ovine and bovine TSEs (Scrapie and BSE, respectively) in the past centuries highlighted the importance of understanding this family of diseases.

Scrapie is a natural disease of sheep and goats. It is known since 17-18th centuries and caused economical problem, since the disease is capable of spreading rapidly within and between flocks. The name of the disease originates from one of the most prominent symptoms: the affected animals develop a compulsive rubbing behaviour, scrape and chew their wool and skin off (Figure 1B).

Although sporadic cases of bovine spongiform encephalopathy (BSE) or "mad-cow disease" symptoms have been recorded since the 5th century B.C. (5), the disease became well-known with the significant economical and health crisis it caused two decades ago in the 1990s BSE outbreak in Great-Britain and in several other western countries $(6,7)$.

Evidences were found that affected animals were exposed to TSE infection, either scrapie or sporadic BSE, during their calfhood via ruminant-derived foodstuff. As a consequence millions of cattle had to be slaughtered and it have also led to stricter regulations of ruminant feeding. The other implication of the BSE outbreak was the appearance of "variant" CJD (vCJD) (8).

Strong evidences indicate that vCJD is linked to bovine spongiform encephalopathy (BSE) and the consumption of BSE meat was the cause of the appearance of vCJD (9). Since the first case, described in 1995, a few hundred patients have been diagnosed with the disease. There were several differences between the symptoms of CJD and vCJD. The latter affected younger people than "classic" CJD [median age of 28 (vCJD) vs. 68 (CJD) years], had relatively longer incubation time (13-14 months instead 4-5), and the first clinical symptoms were different (dementia and early neurologic signs in CJD, whereas psychiatric anomalies, behavioural problems and delayed neurologic signs in vCJD).

\section{Mechanism of TSE transmission}

The first hypothesis for the mechanism of infection was the controversial "slow virus hypothesis", suggesting that despite the missing evidence of viral infection, slow-acting viruses would cause TSEs, after a long incubation period (10). 
Several discoveries led to a new, heretical hypothesis called the prion hypothesis that suggested that TSE are caused by "prions", a new genre of disease causing agents that consist of proteinaceous infectious particles and no nucleic acids were needed for the disease propagation. The word "prion" comes from protein and infection (11).

The infectious agent is mainly composed of $\mathrm{PrP}^{\mathrm{Sc}}$, an abnormal conformational isoform of the cellular prion protein, or $\operatorname{PrP}^{\mathrm{C}}$. It also contains polysaccharides and lipids, but nucleic acids that were more than 25 nucleotide long were below the detection limit, disputing the slow virus hypothesis (12). Moreover aggregations of $\mathrm{PrP}^{\mathrm{Sc}}$ have also been detected in TSE-related amyloid plaques.

\section{Prion protein (PrP)}

\section{Expression and structure of prion protein}

Prion protein is ubiquitously expressed as a cell surface glycoprotein, showing the highest expression levels in neurons of the brain and spinal cord, although it is also expressed in other cell types of the CNS and in other tissues $(13,14)$. The protein is encoded by the prnp gene that lies in the PRN locus (human chromosome 20, mouse chromosome 2).

The expressed polypeptide is about 255 amino acids long in humans, and slightly variable in other species (254 in mice). During protein synthesis $\mathrm{N}$-terminal signal peptide of the protein is recognized by the signal recognition particle (SRP) and the nascent protein is directed to the secretory pathway where the protein folds and undergoes several modifications and at the end it is transferred onto a GPI-anchor from its C-terminal GPI-anchor signal, and the Nglycosylation occurs. Going through the secretory pathway the mature prion protein is delivered to the cell surface, where it localizes predominantly in the lipid raft compartment. The molecular weight of the mature protein without the glycan side chains is about $23 \mathrm{kDa}$.

The protein consists of two major regions, a globular C-terminal domain and a flexible $\mathrm{N}$ terminal tail (Figure 2) which evolved independently from one another (15). The C-terminal domain, despite its high sequence divergence among species, retained its basic 3D structure, containing $3 \alpha$-helices and $2 \beta$-sheets, and the protein is stabilized by a disulphide bond between the helix 2 and 3. There are two $\mathrm{N}$-glycosylation sites on the C-terminal domain: the mature PrP can be non-, mono-, and diglycosylated. The N-terminal tail of the protein is partially 
unstructured or disordered and consists of four regions, which are the following: a 6 aminoacid long extreme N-terminal charged cluster (CC1), a repeat containing motif of a 8 amino acids, called octarepeat region (OR), another charged cluster (CC2), which is followed immediately by a hydrophobic domain (HD).

\section{Role of prion protein in TSE}

The key event of TSE pathogenesis is the conversion of the host's own $\operatorname{PrP}^{\mathrm{C}}$ molecules into the pathological $\operatorname{PrP}^{\mathrm{Sc}}$ isoform where $\operatorname{PrP}^{\mathrm{Sc}}$ molecules serve as template for the conversion process $(11,14)$.

In vitro three $\operatorname{PrP}^{\mathrm{Sc}}$ binding sites have been identified on $\operatorname{PrP}^{\mathrm{C}}, 23-33$ and 98-110 amino acid segments on the N-terminal tail, and the third on the C-terminal domain (16).

Although the native C-terminal domain of $\operatorname{PrP}^{\mathrm{C}}$ consists of three alpha-helices, $\operatorname{PrP}^{\mathrm{Sc}}$ is a beta-sheet rich conformational isoform of the prion protein. Even though the high resolution 3D structure of $\operatorname{PrP}^{\mathrm{C}}$ has been determined by NMR, that of the $\mathrm{PrP}^{\mathrm{Sc}}$ is still debated (17). $\mathrm{PrP}^{\mathrm{Sc}}$ is prone to oligomerization and aggregation, insoluble in non-ionic detergents and has an increased protease resistance. A 2 hours treatment with $50 \mu \mathrm{g} / \mathrm{ml}$ Proteinase-K (PK) at $37^{\circ} \mathrm{C}$ cannot digest completely the $\operatorname{PrP}^{\mathrm{Sc}}$, a PK-resistant C-terminal core of the $\operatorname{PrP}^{\mathrm{Sc}}$ molecule remains intact unless subjected to a more vigorous proteinase treatment. This partially PKresistant core retains the ability to convert $\mathrm{PrP}^{\mathrm{C}}$ to $\mathrm{PrP}^{\mathrm{Sc}}$, thus it keeps its infectivity.

There are several experiments underlining the importance of the host's own $\operatorname{PrP}^{\mathrm{C}}$ in $\mathrm{TSE}$ progression. One of the most straightforward evidence of $\mathrm{PrP}^{\mathrm{C}}$ importance in TSE is that prnp knockout mice are resistant to TSE and the disease can't be propagated in them: after inoculation of $\mathrm{PrP}^{\mathrm{Sc}}$ these mice show neither signs of neurodegeneration nor reduced lifespan (18).

Neuron-specific ablation of PrP expression with cre-lox system in mice 8 weeks after being inoculated with $\mathrm{PrP}^{\mathrm{Sc}}$ also prevented neurodegeneration. In these mice amyloid plaques and $\mathrm{PrP}^{\mathrm{Sc}}$ were detectable in the brain tissue, but early spongiform changes were reversed and the mice didn't develop signs of neurodegeneration (19).

In a third experimental setup, nerve tissue grafts, overexpressing $\operatorname{PrP}^{\mathrm{C}}$, were implanted into brains of PrP KO mice and these mice were inoculated also with $\mathrm{PrP}^{\mathrm{Sc}}$. The $\mathrm{PrP}^{\mathrm{C}}$ expressing 
grafts propagated $\mathrm{PrP}^{\mathrm{Sc}}$ and developed lesions typical in TSE, but neighbouring $\mathrm{PrP} \mathrm{KO}$ tissues showed no signs of neurodegeneration (20).

The importance of the cell surface localization of PrP in TSE pathogenesis has also been demonstrated. Mice expressing GPI-anchorless PrP instead of wild type PrP (WT-PrP) were inoculated with $\mathrm{PrP}^{\mathrm{Sc}}$. In these mice extracellular amyloid plaque formation and $\mathrm{PrP}^{\mathrm{Sc}}$ generation was detected, and the de novo generated $\operatorname{PrP}^{\mathrm{Sc}}$ could be used to propagate the disease in other mice, but despite the presence of $\mathrm{PrP}^{\mathrm{Sc}}$ in the central nervous system (CNS) of the GPIanchorless PrP expressing mice no signs of neurodegeneration could be observed (21).

Although there is a consensus regarding the involvement of PrP in TSE pathogenesis, the mechanism of the conversion from the native cellular form into the pathogenic form that results in cell death is still debated. Since the presence of $\operatorname{PrP}^{\mathrm{Sc}}$ in a $\operatorname{PrP}^{\mathrm{C}}$-less environment doesn't cause neurodegeneration, it is reasonable to assume that the toxicity is mediated by either $\operatorname{PrP}^{\mathrm{C}}$, or an intermediary conformation of the conversion.

PrP knock-out animal models suggest that the lethal phenotype is not caused by a loss of a kind of vital function of the prion protein as neither pre- nor postnatal ablation of $\operatorname{PrP}^{\mathrm{C}}$ resulted in a lethal phenotype.

As $\operatorname{PrP}^{\mathrm{Sc}}$ and amyloid plaques are still present in mice where endogenous $\operatorname{PrP}^{\mathrm{C}}$ ablated postinoculation, without causing any neurodegeneration, the possibility that the neurodegeneration is caused merely by $\operatorname{PrP}^{\mathrm{Sc}}$ gaining a novel, toxic function can also be excluded.

According to a third hypothesis, the neurodegeneration is caused by the subversion or corruption of a normal, physiological function of the $\operatorname{PrP}^{\mathrm{C}}$ due to the conformation change, or the presence of $\mathrm{PrP}^{\mathrm{Sc}}$ somehow alters a signalization pathway affected by $\operatorname{PrP}^{\mathrm{C}}$.

\section{Physiological functions of the prion protein family members}

Even though the evolutionary conserved structure suggests an evolutionary conserved function of the protein which is probably important, knocking out the prnp gene didn't result in a lethal phenotype $(22,23)$, although PrP null mice show minor abnormalities. Studying knockout animals proposed the involvement of PrP in various physiological processes (24), notably normal olfactory behaviour and physiology (25), hippocampus-dependent spatial learning (26), and peripheral myelin maintenance (27). 
Ligands and interactions of the prion protein

As a GPI-anchor protein, PrP probably have some interacting partners in postulated signalization cascades. In fact the protein seems to be rather promiscuous, in the past three decades passed from cloning of the human prion protein (28) several partners (29) have been found to interact with PrP, and various functions were associated to several regions of the protein, but the exact physiological function of the prion protein remained elusive. The binding partners of PrP include the following examples, as reviewed in (30):

Copper: N-terminal region of the PrP has $5 \mathrm{Cu}^{2+}$-binding sites, among 4 in the $\mathrm{OR}$.

Lipids: PrP can form hydrophobic interactions with lipid vesicles independent of its GPIanchor with its $\mathrm{CC} 1, \mathrm{CC} 2$ and hydrophobic domains. $\mathrm{CC} 1$ was also reported to be acting as a transduction domain, and the HD may act as transmembrane domain under certain conditions.

Heparan sulphate: These molecules were detected in amyloid plaques found in GSS, CJD and Scrapie-brains. Surface plasmon resonance and ELISA studies demonstrated that the CC1, OR and the HD were responsible for heparan sulphate binding.

Nucleic acids: In certain experimental conditions recombinant PrP was found to be able to bind DNA and RNA in vitro. The $\mathrm{CC} 1, \mathrm{CC} 2$ and the $\mathrm{OR}$ regions of the $\mathrm{N}$-terminal domain are required for the binding. No functions have been associated to the nucleic acid binding activity of the protein, but the reports of nuclear localization of the $\mathrm{PrP}^{\mathrm{C}}$ along with two GSS associated deletion mutant PrP-s that also showed nuclear localization suggest a potential physiological or pathological role of $\operatorname{PrP}$ in the nucleus.

$\mathrm{CC} 1$ region is also critical for the endocytosis of the protein via clathrin-coated pits, it was found to be a binding site of the endocytic receptor LRP1 protein (31).

Physiologically the protein may undergo cleavages named alpha or beta cleavage. The alpha cleavage site is after the 110th amino acid residue, between CC2 and HD. Proteolytic processing in this case results in the release of an $\mathrm{N} 1$ (N-terminal) fragment, and the $\mathrm{C}$-terminal $\mathrm{C} 1$ fragment remains membrane-bound. Beta cleavage happens at residues 90-91, after the OR region, resulting in an $\mathrm{N} 2$ and $\mathrm{C} 2$ fragments (32). 
Interestingly several cytotoxic and protective functions have been associated to the $\mathrm{CC} 1$, CC2 and HD of PrP. Understanding these activities might help to understand how neurodegeneration occurs during TSE.

\section{$\underline{\text { Toxic activities of the prion protein }}$}

While the GPI-anchorless PrP expressing mouse demonstrated that prion propagation was possible without neurodegeneration, other experiments showed that neurodegeneration could also be caused without the presence of any infectious agent.

During search for the minimal essential PrP fragment required for TSE pathogenesis, Weismann and colleagues have found that the expression of certain deletion mutant PrP transgenes that lacked part of their N-terminal tail, led to progressive ataxia and degeneration in the cerebellar granular layer of prnp knockout mice (33). The deletion of the N-terminal domain of PrP became toxic when it included part or the whole of the hydrophobic domain (HD) of $\operatorname{PrP}(111-131$ st amino acids in mouse $\operatorname{PrP})$ : $\operatorname{PrP} \Delta 32-106$ was not, but $\operatorname{PrP} \Delta 32-121$ or PrP $\Delta 32-134$ were toxic (these deletion mutant PrP-s have been named "Shmerling-mutants").

Deletion of the so called "Central Region" of the protein, a region that overlaps with PrP CC2 and the HD (105-125th amino acids in mouse PrP), produced a similar phenotype to Shmerling-mutants, but the phenotype was more severe extent (34). Mice showed symptoms 2 weeks after birth and also died earlier. Also a relatively much higher expression of wild-type $\operatorname{PrP}$ is required to eliminate the effect of $\operatorname{PrP} \Delta \mathrm{CR}$ than that of Shmerling-mutants with similar expression levels. The expression of a similar construct, $\operatorname{PrP} \Delta 94-134$ in mice also caused a rapid lethality (35).

Unlike familiar TSEs, these mutations don't destabilize PrP leading to $\mathrm{PrP}^{\mathrm{Sc}}$ formation and no infectious agents could be extracted from these mice. Brain homogenates of mice expressing Shmerling-mutants didn't cause neurodegeneration in other mice.

The introduction of one or more copies of wild type PrP gene to mice expressing the deletion mutant PrP-s abrogated the neurodegeneration. To eliminate the Shmerling-mutant-induced neurotoxicity, one copy of $\operatorname{PrP}$ or $\operatorname{PrP} \Delta 32-93$ was enough (36), the later suggesting that the OR 
plays no role in the rescue effect, and the severity of $\Delta \mathrm{HD}$ (35) and $\Delta \mathrm{CR}$ PrP-induced (34) toxicities were reduced in a dose dependent manner.

Not only in animal models were Shmerling-mutants toxic, but also in primary neuron cultures, contrary to these models, when expressed in immortalized cell lines, Shmerlingmutant, $\triangle \mathrm{HD}$ or $\triangle \mathrm{CR}$ PrP-s have no such robust effect, or any at all.

Interestingly, Harris and colleagues have found that both Shmerling-mutants and $\operatorname{PrP} \Delta C R$ causes increased sensitivity to certain drugs (hygromycin, G418 and Zeocin) in several types of immortalized cell lines of neuronal and non-neuronal origins, as well as in NSCs and CGN cultures (37). Kinetic studies revealed that the mutants increase the cellular uptake of both G418 and Zeocin that could not be achieved by the modulation of $\mathrm{ABC}$ transporter activities. The presence of $\mathrm{CC} 1$ in both $\Delta 32-134$ and $\Delta 105-125$ mutant PrP-s is required for mediating the toxic signal in both animal and in the drug hypersensitivity models (38).

$\operatorname{PrP} \Delta \mathrm{CR}$ and several other $\Delta \mathrm{HD}$ mutants have also been found to cause spontaneous inward ionic currents through the plasma membranes of various cell types $(39,40)$, which activities were observed also by PrP-s harbouring familiar TSE-related point mutations. These effects, although not being directly toxic, were also abrogated by the co-expression of WT PrP.

Not only the severity of the neurotoxicity differs between the deletion mutants, but there are differences between the neuropathology of PrP $\Delta 96-134$ (myelin degeneration but intact granular layer) and PrP $\Delta 105-125$ (degeneration in cerebellar granular layer).

The signalization events in the course of neurodegeneration also differs in case of various toxic mutants. In transgenic mice it was found that $\operatorname{PrP} \Delta 32-134$ toxicity depends on BAXrelated pathways but also BAX-independent pathways are involved in $\operatorname{PrP} \Delta \mathrm{CR}$ toxicity (41).

Lastly the difference between the relative amounts of WT-PrP required for compensation of Shmerling or $\Delta \mathrm{CR}$ mutant PrP-s indicate differences between their mechanisms of action.

Another difference between the behaviour of $\Delta \mathrm{HD}$ and $\Delta \mathrm{CR}$ PrP-s is found in the glutamate toxicity model. $\operatorname{PrP} \triangle \mathrm{CR}$, expressed in CGN or neural stem cell (NSC) cultures, increase the sensitivity of the cells to glutamate (42), contrarily PrP $\Delta 113-133$, which has no such sensitizing effect when expressed in the human neuroblastoma SH-SY5Y cells (43). It must be noted that these effects were observed in different cell types. 


\section{Protective activities of the prion protein}

Several functions associated to the prion protein are related to protection against certain stressors. In murine stroke models $\operatorname{PrP}^{\mathrm{C}}$ provided neuroprotection after ischemic insult (44).

In cell culture and animal models PrP expression protected from the excitotoxicity of glutamate, kainate and NMDA. The intact N-terminal tail was required for this anti-apoptotic effect of the PrP, the deletion of amino acids 27-89 abrogated this protective activity of the PrP.

It was shown that PrP has a superoxide dismutase activity, providing protection against oxidative stress (45). Furthermore, according to certain data in literature, immortalized cells of hippocampal origin expressing prion protein were more resistant to apoptosis induced by oxidative stress (46) and also showed higher viability and lower autophagy-marker expression levels during serum deprivation (47).

Probably both oxidative stress and excitotoxicity protection is related to the copper binding activity of PrP and its role in the copper metabolism $(48,49)$. These activities require the presence of the N-terminal tail of the protein.

Wild type PrP is also able to eliminate all toxic Shmerling-mutation or $\triangle \mathrm{CR}$ PrP effects in a dose dependent manner. The presence of the N-terminal tail is also important here. In cell coculture models it has been demonstrated that the protective effect of PrP can occur in "trans" mode where the protective effect of PrP manifests in adjacent cells (50).

\section{Role of the prion protein in Alzheimer disease}

Alzheimer disease (AD) is probably the most prevalent neurodegenerative disorder. In 2015 there were about 30 million people afflicted by AD worldwide (source: http://www.who.int). Like TSE, AD is incurable, and fatal, symptoms include early memory deficits and dementia, insomnia, behavioural changes that worsen during the disease progression.

The cause of $\mathrm{AD}$ is not well understood, several risk factors and genes have been identified and some proteins were shown to have key role in the pathogenesis [amyloid precursor protein (APP), Tau, presenilins, apolipoprotein E (APOE)].

$\mathrm{AD}$ is characterized by a massive neuronal cell and synapse loss as well as the formation of extracellular senile plaques and intracellular neurofibrillary tangles containing a 
hyperphosphorylated form of the microtubule binding protein Tau. The main component of senile plaques is composed of the aggregates of $\mathrm{A} \beta 40-42$, or $\beta$-amyloid peptide, a 42 amino acid long peptide that is cleaved from APP by $\beta$ - and $\gamma$-secretases. It was suggested that A $\beta$ peptide acts primarily and triggers further downstream processes, such as tau aggregation that leads to neurodegeneration (51).

More and more results highlight the possible role of $\operatorname{PrP}^{\mathrm{C}}$ in the pathogenesis of the Alzheimer's disease (AD). There is direct interaction between $\operatorname{PrP}^{\mathrm{C}}$ and $\mathrm{A} \beta 40$ monomers (52) or a subpopulation of $\beta$-amyloid oligomers $(\mathrm{A} \beta$ ) (53) where PrP act as an $\mathrm{A} \beta$ receptor (54). Interestingly the binding sites of $\mathrm{A} \beta$ peptide overlap with the $\mathrm{CC} 1$ and $\mathrm{CC} 2$ of $\operatorname{PrP}(53)$. $\operatorname{PrP}$ has a dual role in $\mathrm{AD}$. On one hand By binding $\mathrm{A} \beta$ oligomers PrP participates in $\mathrm{A} \beta$-removal from the CNS through the blood-brain barrier (52). On the other hand PrP relays a toxic signal from $A \beta$ oligomers into the neurons, that can lead to synaptic impairment (55) or the inhibition of hippocampal LTP (53). LRP1 (56), mGlut5 receptor (57) are also involved in the toxic signalization pathway.

\section{Other members of the prion protein family}

\section{Doppel protein}

The doppelganger of the prion protein, or Doppel ( $\mathrm{Dpl})$, is encoded by the prnd gene. The prnd gene lies downstream from the prnp gene, in the same locus. Evolutionary analysis indicates that these two genes arose from a single ancestor gene by gene duplication in an ancestral tetrapoda (58).

The Doppel protein is paralog of PrP, exhibiting an average of $25 \%$ sequence identity (33). The Dpl precursor protein consists of 179 amino acids in mouse and 176 amino acids in humans. Dpl expression level is the highest in the testis and male reproductive tract, it has a role in the spermatogenesis (59) but Doppel protein or its mRNA has also been detected in the spleen, bone marrow, skeletal muscles and heart too (60).

Dpl structure resembles to the C-terminal, globular domain of the Prion protein (Figure 2): the mature protein is flanked by an $\mathrm{N}$-terminal signal peptide responsible for directing the protein to the secretory pathway and a C-terminal GPI-anchor signal. The mature protein 
consists of a short, unstructured N-terminal tail and a globular C-terminal domain that is made of three a-helices, and is stabilized by two disulphide-bonds. The C-terminal domain harbours two N-glycosylation sites too.

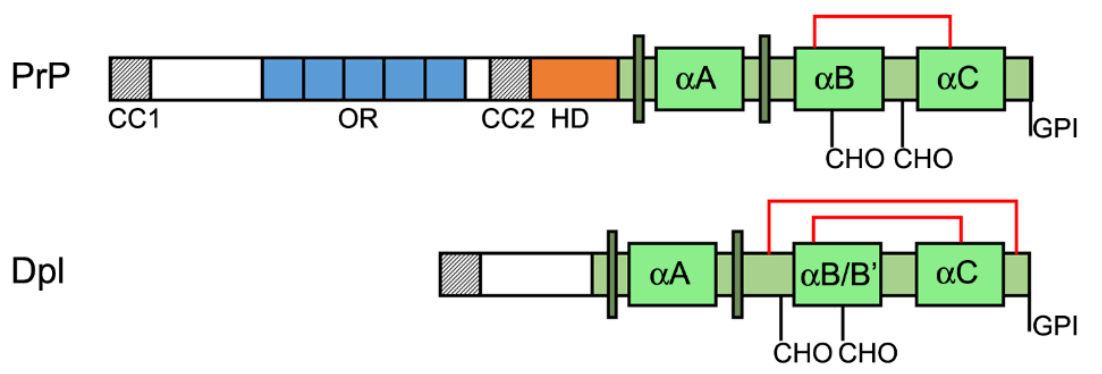

Sho

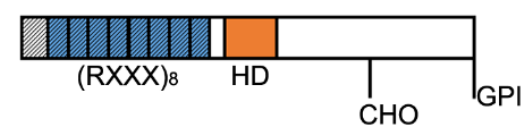

Figure 2: Domain structure of the prion protein family. $\alpha A, \alpha B$, $\alpha C$ : alpha helices. Narrow, tall, dark green boxes: $\beta$ strands. $\quad \mathrm{CHO}: \quad \mathrm{N}$ glycosylation sites. GPI: GPI-anchors. Red brackets: disulphide bonds. Striated grey boxes: charged clusters (CCl, $C C 2$ in $\operatorname{PrP}$, unnamed in

Dpl and Sho). Blue boxes in PrP: Octarepeat region (OR). Striated blue boxes in Shadoo: $(R X X X)_{8}$ region. Orange boxes: hydrophobic domains (HD). Green tones: structured region of PrP and Dpl.

Doppel normally isn't expressed in the CNS so this protein probably plays no role in TSE pathogenesis, but the absence of prnd gene in testis leads to male infertility (59). What makes this protein interesting is that it may acquire toxic activities similar to Shmerling-mutant PrP-s.

The initial prnp knockout mouse showed no major deficits or neurodegeneration but another prnp knockout strain established by another group, after normal development, showed progressive ataxia and loss of Purkinje-cells in the cerebellum from the age of 70 days (61). In this knockout mouse the imprecise attempt of knocking out the prnp gene caused the prnp promoter driving the subsequent prnd coding region, thus the establishment of an ectopic Doppel expression in the CNS (62). Later this toxic phenotype caused by the Dpl expression in the absence of PrP was confirmed in transgenic mice (63) and also in primary cerebellar granular neuron (CGN) cultures (64).

Interestingly the co-expression of wild type PrP seemed to antagonize the toxic effects of Doppel in both mice (65) and cell cultures (64): the presence of PrP eliminated the Doppel toxicity in these models. 


\section{Shadoo protein}

Shadoo of the prion protein, or Shadoo (Sho), is the latest discovered member of the prion protein family, encoded by the sprn gene, which localizes on a different chromosome (human chromosome 10, mouse chromosome 7) (66). Shadoo was first discovered in zebrafish (67), then in many fish, amphibians and mammalian species.

Sprn is expressed in the neurons of the CNS, its expression pattern seems to be complementary with that of the prnp gene (64). Similar to Doppel, Shadoo is also considered as a paralog of the prion protein. Shadoo precursor protein also contains an $\mathrm{N}$-terminal signal peptide and a C-terminal GPI-anchor signal. The protein localizes on the cell surface, although it has been demonstrated that akin to PrP, Shadoo is able to bind nucleic acids $(68,69)$ and were detected in nuclei too (69).

Shadoo is an unstructured protein, resembling to the flexible N-terminal tail of PrP. Shadoo and $\operatorname{PrP}$ have similar domain organization, even though no extended sequence similarity exists between the two proteins. Both mature Shadoo and prion proteins begin with a positively charged $\mathrm{N}$-terminal cluster, followed by repeated sequences (octarepeats in $\operatorname{PrP},(\mathrm{RXXX})_{8}$ motif in Sho (69) and they have similar hydrophobic regions.

The overlapping expression patterns of Shadoo and prion proteins and the resemblance of the two proteins explains starting examination of the Shadoo expression in TSE brains. While Sho mRNA levels were unaltered or mildly elevated (70), the Shadoo protein levels were drastically down-regulated in later stages of TSE (64), although the extent of down-regulation depended on the $\operatorname{PrP}^{\mathrm{Sc}}$ strain (70).

Several publications reported frame shifts mutations in the coding region of Sprn gene associated to TSE susceptibility in humans $(71)$ or in ovine $(72,73)$. Recently it was suggested that the PrP - Shadoo interaction may modify the PrP-folding pathway, and may affect the prion replication process (74).

Shadoo shows not only structural similarity to the N-terminal region of PrP, but also functional analogy to wild type PrP. Just like WT-PrP, Shadoo is able to eliminate the toxic phenotypes of both Doppel and the Shmerling, or $\Delta \mathrm{HD}$ mutant PrP-s in primary or immortalized cell cultures (64). Furthermore, akin to WT-PrP, Shadoo exhibits protective effect against 
glutamate-induced excitotoxicity in cell cultures emphasizing the neuroprotective feature of Sho that is also characteristic of PrP bearing an intact N-terminal part (43).

This functional analogy between the two proteins is interesting because the sequence homology between Shadoo and PrP N-terminal domain is low. Both proteins are cell surface proteins but only their hydrophobic domains show a higher degree of similarity, suggesting that these segments are important for the shared cytoprotective activities of the two proteins. These segments were also found to be important in Sho-PrP dimerization and also the deletion of Sho HD abolished the protective activities of the protein. Whether Shadoo provides any protection against the drug hypersensitivity or eliminates the ionic currents caused by $\operatorname{PrP} \Delta \mathrm{CR}$ has not been studied before our work. 


\section{Aim of this study}

As several evidences underline the hypothesis, that a toxic or protective function of the prion protein play role in TSE associated neurodegeneration, we studied the toxic and protective effects associated to the prion protein family.

Our goal was to establish a model system where such activities of the prion protein family can be studied. We investigated experimental constructs of PrPs in immortalized human and non-human mammalian cell lines that were either prnp knock-out or had low endogenous PrP expression.

We studied two models:

In the first model we investigated the role of the prion protein in the effects of serum deprivation on cells and tried to answer the following questions:

1. Does wild-type PrP confer any protection against serum deprivation induced apoptosis?

2. Does $\operatorname{PrP} \triangle \mathrm{CR}$ increase the sensitivity of the cells to serum deprivation?

3. Does PrP $\triangle \mathrm{CR}$ expression decrease the viability to cells maintained in normal condition?

In the second model system we studied the $\operatorname{PrP} \Delta \mathrm{CR}$-induced Zeocin and G418 hypersensitivity found by the Harris-group (37). We postulated that overlapping protective function of Shadoo and WT-PrP from literature may have the consequence that Shadoo can also eliminate PrP $\Delta$ CR-induced Zeocin and G418 hypersensitivity. Surprisingly we have found that Shadoo protein not only doesn't eliminate the PrP $\Delta$ CR-induced antibiotic-sensitivity, but instead induces such sensitivity.

Based on this surprising finding have characterized further this effect of the Shadoo protein. In this topic we tried to answer the following questions:

1. Can WT-PrP eliminate also the antibiotic-sensitivity caused by Shadoo protein?

2. Which regions of Shadoo protein is required for the sensitizing activity?

3. Similarly to $\operatorname{PrP} \triangle \mathrm{CR}$, does Shadoo induce hypersensitivity by increasing the initial drug uptake or by another mechanism? 


\section{Materials and methods}

\section{Reagents used in the studies}

Restriction Endonucleases, T4 DNA ligase, ATP, dNTP mixture, Pfu DNA polymerase were purchased from Thermo Scientific. Isopropyl $\beta$-D-1 thiogalactopyranoside was purchased from Thermo Scientific. High-glucose Dulbecco's Modified Eagle Medium (DMEM) and fetal bovine serum (FBS) were obtained from Life Technologies/Gibco and Penicillin/Streptomycin from Lonza. TurboFect transfection reagent were purchased from Thermo Scientific.

Zeocin and PrestoBlue reagent were obtained from Life Technologies. Geneticin (G418), puromycin and 3-(4,5-dimethylthiazol-2-yl)-2,5-diphenyltetrazolium bromide (MTT) were obtained from Sigma-Aldrich.

Bradford-reagent was purchased from Bio-Rad. Polyvinylidene fluoride (PVDF) transfer membrane and chemiluminescent substrate (Immobilon ECL substrate) were from Millipore.

Peptide-N-glycosidase F (PNGaseF) was purchased from New England Biolabs. Phosphatidylinositol-dependent phospholipase-C (PI-PLC) was purchased from Thermo Scientific (LifeTechnologies).

All other reagents and chemicals were purchased from Sigma-Aldrich.

\section{Antibodies used in immunocytochemistry (ICC) and immunoblotting (WB)}

Primary antibodies and dilutions:

SAF32 anti-PrP mouse IgG (Cayman Chemical, 189720), in 1:200 (ICC) or 1:5000 (WB).

Purified anti H2AX.phospho antibody (Biolegend, 613402), in 1:250 (ICC).

Anti-Shadoo rabbit polyclonal antibody (Abgent, AP4754b), in 1:200 (WB).

Anti- $\beta$-actin chicken IgG (Sigma, GW23014), in 1:2000 (WB).

Primary antibodies were diluted in IF solution (ICC) or TBST (WB), supplemented with $7 \mathrm{mM}$ (ICC) or $2 \mathrm{mM}$ (WB) $\mathrm{NaN}$ and were stored at $4^{\circ} \mathrm{C}$ after usage.

Secondary antibodies and dilutions:

ICC: Goat anti-mouse IgG (H+L), Alexa Fluor 594 or Alexa Fluor 647 conjugated (Life Technologies, A11005 and A21235) were used in 1:250 in IF.

WB: Horseradish peroxidase (HRP)-conjugated anti-mouse, anti-rabbit and anti-chicken IgG were from Jackson ImmunoResearch (715-035-151), Pierce Biotechnology (31460) and Sigma- 
Aldrich (A9046), in 1:20000, 1:200000 and 1:200000 in blocking solution (WB) respectively. Secondary antibody dilutions were never reused.

\section{Plasmid constructs and DNA cloning}

DNA sequences used in the cloning processes

The cDNA of mouse Shadoo protein (mSho) (Uniprot entry Q8BWU1) in a pSPORT1 plasmid was obtained from MRC Geneservice, the cDNA of mouse PrP (mPrP) (Uniprot entry P04925) from the Caughey lab (75).

Plasmid vectors of the Sleeping Beauty Transposon based gene delivery system (SB CAGx100 (76), pSB-CAG-Puro (77)) and the pRRL lentiviral vectors (pRRL-EF1-mCherry, pRRL-EF1EGFP (78)) were kind gifts of Dr. Zsuzsa Izsvák and Dr. Zoltán Ivics and of Dr. Katalin Német, respectively.

DNA fragments were isolated from agarose gel using Macherey-Nagel NucleoSpin kit and plasmids were purified with QiaGen Miniprep kits.

DNA oligonucleotides were bought from Microsynth AG (http://microsynth.ch). For the sequences of the oligonucleotides used for PCR and linker ligation see Appendix Table 2.

All plasmids were constructed with standard molecular biology techniques, briefly as follows. The correct sequences for the expression cassettes in all plasmids generated in this study were confirmed by Sanger sequencing (Microsynth AG).

All other reagents and chemicals were purchased from Sigma-Aldrich.

\section{DNA linker hybridization}

Short DNA fragments were inserted into plasmid vectors in the form of short DNA linkers. DNA linkers were hybridized from their respective oligo-pairs in PCR in the following hybridization mixture:

$2 \mu \mathrm{l}$ restriction enzyme buffer

$9 \mu \mathrm{l}$ forward oligo $(1 \mathrm{mM})$

$9 \mu \mathrm{l}$ reverse oligo $(1 \mathrm{mM})$ 
The hybridization mixture was heated to $95^{\circ} \mathrm{C}$ in PCR machine for 5 minutes then cooled to $25{ }^{\circ} \mathrm{C}$ with a $-0.7{ }^{\circ} \mathrm{C} /$ minute cooling speed. Hybridized DNA linkers were either used immediately in ligation or were stored at $-20^{\circ} \mathrm{C}$.

\section{Preparation of Shadoo and PrP constructs}

The deletion of the central region (amino acid residues 105-125) of mPrP in the pcDNA3 vector and the introduction of a silent mutation for removing the XhoI restriction site of the mSho cDNA in the pSPORT1 vector were carried out using QuikChange site directed mutagenesis protocol (Stratagene) with the following oligos: Delta105-125for and Delta105-125rev, XhoImutator 5 and XhoImutator3, respectively. The removal of XhoI restriction site from $\mathrm{mSho}$ cDNA was carried out by Krisztián Kovács. Subsequently, XhoI-mutated mSho cDNA was PCR-amplified, using mShoBamHI5 and XhoISho3 primers and cloned to the pcDNA3 vector between BamHI and XhoI restriction sites.

The deletion of the Shadoo HD (aa 62-71) was carried out with QuikChange site directed

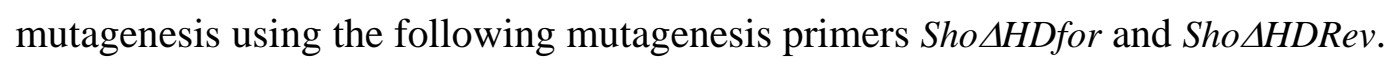

The replacement of Shadoo HD with PrP HD in Shadoo was carried out, briefly as follows. The DNA linker coding the MPrP HD (amino acids 113-133) was ligated between the PCR products coding the N- (amino acids 1-61) and C-terminal (amino acids 78-147) fragments of the Shadoo protein and the ligation was followed by the PCR amplification of the full DNA sequence encoding the chimeric protein Sho(1-61)-PrP(113-133)-Sho(78-147). The cloning of the chimeric protein [will be referred as Sho(PrPHD)] was carried out by Petra Bencsura.

The Sho $\Delta 25-61\left[\Delta(\mathrm{RXXX})_{8}\right]$ and the ShoQXXX8 constructs were prepared by Péter Kulcsár (69).

\section{Preparation of Sleeping Beauty plasmid constructs}

The cDNA of the Enhanced Green Fluorescent Protein (EGFP) with a Kozak-sequence was cloned into the polycloning site of the pcDNA3 eukaryotic expression vector, between BamHI and NotI restriction sites. The whole expression cassette containing the CMV-IE promoter and EGFP followed by a BGH PolyA signal was amplified from the vector by PCR with the following primers: ApoICMV5 and ApoIBGH3. PCR fragments were purified and digested by 
ApoI enzyme, and were cloned into the EcoRI site of a Sleeping Beauty plasmid containing a puromycin resistance gene driven by a CAG promoter (pSB-CAG-Puro). The resulted plasmid is named $\mathrm{pSB} / \mathrm{GFP}$.

The cDNA-s of wild type $\mathrm{mPrP}$ and $\mathrm{mPrP} \Delta \mathrm{CR}$ were PCR-amplified with the primers PrPNheI5 and PrPBamHI3 from the pcDNA3 vectors encoding the respective constructs. After purification, the amplified DNA fragments were digested with NheI and BamHI enzymes and inserted downstream of the CAG promoter into the pSB/GFP vectors, between the restriction sites of NheI and BglII, which also removed the cDNA of the Puromycin resistance gene. The resulted plasmids were named $\mathrm{pSB} / \mathrm{PrP}$ and $\mathrm{pSB} / \Delta \mathrm{CR}$. Figure $3 \mathrm{~A}$ shows the prepared $\mathrm{pSB}$ plasmid construct topologies.

\section{Preparation of lentiviral plasmid constructs}

A DNA linker (linker2-3048) containing the unique sites of AscI and BsiWI restriction endonucleases were cloned into the pRRL-EF1-mCherry or pRRL-EF1-EGFP lentiviral vectors between BsrGI and SalI sites. The modified pRRL vectors are called LV/mCh and LV/GFP. Expression cassettes containing the $\mathrm{mPrP}, \mathrm{mSho}$ or Sho $\Delta \mathrm{HD}$ coding sequences after CMV-IE promoters were amplified by PCR from the pcDNA3 vectors encoding the respective constructs with the following PCR primers: $V$ - $C M V-P r P f w$ and $V$-CMV-PrP rev (for PrP), $V-C M V-P r P$ $f w$ and $V$-CMV-PA rev (for Sho) and V-dHD-fwd and V-dHD-rev (for Sho $\Delta H D$ ). In case of PrP and Sho expression cassettes the PCR products were digested and inserted between AscI and BsiWI sites of the modified pRRL-EF1-mCherry or pRRL-EF1-EGFP vectors and were called $\mathrm{LV} / \mathrm{PrP}(\mathrm{R}), \mathrm{LV} / \mathrm{Sho}(\mathrm{R})$ and $\mathrm{LV} / \mathrm{PrP}(\mathrm{G})$. PCR product containing Sho $\Delta \mathrm{HD}$ coding sequence was inserted between the NdeI and SapI sites of the LV/Sho(R) vector, replacing wild type Shadoo cDNA.

The DNA fragments harbouring the $\Delta\left(\mathrm{RXXX}_{8}\right.$ and QXXX8 mutations in Shadoo cDNA were cut from the respective plasmids by NdeI and Eco81I restriction enzymes and ligated between the same restriction sites in the LV/Sho(R) plasmid, replacing wild type Shadoo cDNA with the deletion mutant constructs. 
The DNA fragment encoding Sho(PrPHD) construct was digested and inserted between NdeI and ApaI restriction sites in the LV/Sho(R) plasmid, replacing wild type Shadoo cDNA.

The lentivirus plasmids containing the $\Delta(\mathrm{RXXX})_{8},(\mathrm{QXXX})_{8}, \Delta \mathrm{HD}$ Sho and Sho(PrPHD) constructs are called $\mathrm{LV} / \mathrm{Sho}^{\triangle \mathrm{RX}}(\mathrm{R}), \mathrm{LV} / \mathrm{Sho}^{\mathrm{RQ}}(\mathrm{R}), \mathrm{LV} / \mathrm{Sho}^{\Delta \mathrm{HD}}(\mathrm{R})$, and $\mathrm{LV} / \mathrm{Sho}^{\mathrm{PrPHD}}(\mathrm{R})$ respectively. The pRRL vector constructs were designed by Petra Bencsura and Antal Nyeste, and the vectors were cloned by Petra Bencsura. Figure 3B shows the prepared pRRL plasmid construct topologies.

A

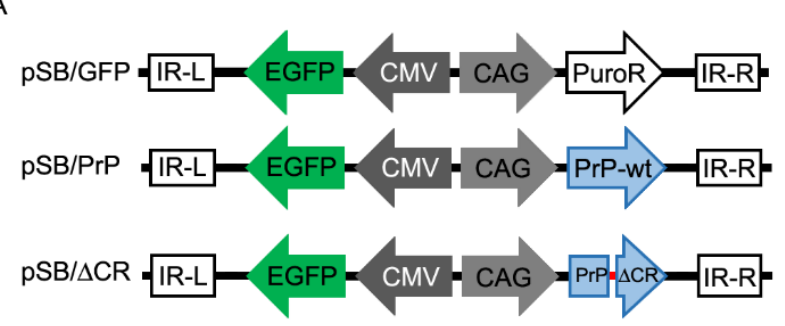

B

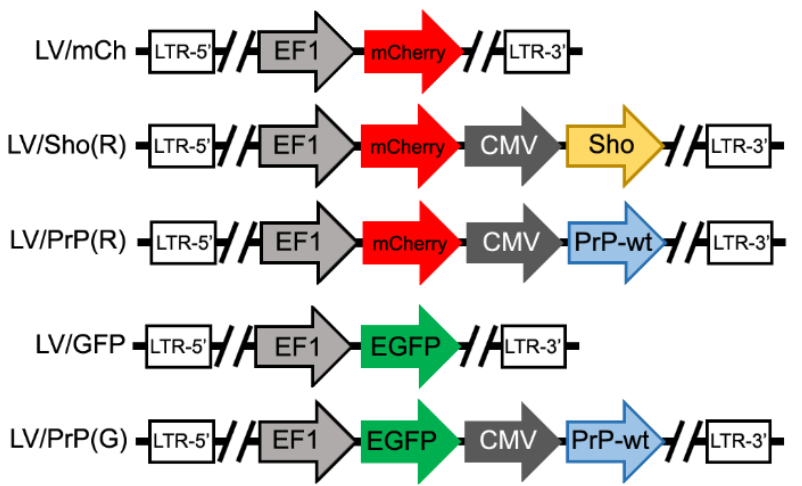

Figure 3: Topologies of the plasmid constructs used in these studies. (A) Sleeping beauty plasmids used for integration of the expression cassettes. (B) pRRL plasmids used for lentivirus generation. IR-L, IR-R: left and right inverse repeats of $S B$. LTR-5', LTR-3': 5' and 3' long terminal repeats. CMV: $C M V$ intermediate early promoter. CAG: $C M V$ early enhancer/chicken beta actin promoter. EF1: elongation factor-1 promoter. EGFP: enhanced green fluorescent protein. PuroR: puromycin resistance gene. PrP-wt: wild type mouse prion protein. PrPACR: mouse prion protein missing the central region (aa. 105-125th). Sho: mouse Shadoo protein. Topologies of $L V / S_{h} o^{\Delta R X}(R)$, $L V / S h o^{R Q}(R), \quad L V / S h o^{P r P H D}(R), \quad$ and $L V / S h o^{\triangle H D}(R)$ plasmid vectors are identical

to $L V / S h o(R)$ and are not represented on the figure.

Cloning of the recombinant Sho-PrP (rSho-PrP) fusion polypeptide

The fusion polypeptide rSho-PrP was made by cloning a DNA fragment coding the mSho fragment 81-116th amino acids (TGSGWRRTSG PGELGLEDDE NGAMGGNGTD RGVYSYS) corresponding to the Abgent Sho antibody epitope, into a fragment coding for $\operatorname{PrP}(23-230)$ in a pET41 expression vector, between positions corresponding to the 93rd and 94th amino acids of PrP. The mSho fragment was made by three DNA linkers (Sho-epil, -2, 3) with overlapping overhangs with phosphorylated 5' ends and was ligated into the unique 
Acc65I restriction enzyme site of the pET41-mPrP(23-230) plasmid vector. The cloning of $\underline{\text { rSho-PrP coding plasmid was carried out by Petra Bencsura. }}$

\section{Expression, purification and refolding of the recombinant Sho-PrP fusion protein}

Plasmid pET41a encoding the rSho-PrP fusion polypeptide encompassing both PrP and Sho epitopes was transformed into competent E. coli BL21 (DE3) pLysS and after induction by isopropyl- $\beta$-D-1-thiogalactopyranoside it was expressed at $37{ }^{\circ} \mathrm{C}$ in inclusion bodies. Cells were harvested 8 hours after induction. Proteins were purified as follows: inclusion bodies were dissolved in buffer A [6 M guanidinium chloride (GdmCl), $100 \mathrm{mM} \mathrm{Na}_{2} \mathrm{HPO}_{4} 400 \mathrm{mM} \mathrm{NaCl}$, $5 \mathrm{mM}$ imidazole and $5 \mathrm{mM} \beta$-Mercaptoethanol, $\mathrm{pH} \mathrm{8.0]} \mathrm{and} \mathrm{stirred} \mathrm{overnight} \mathrm{at} 4{ }^{\circ} \mathrm{C}$. After centrifugation, the soluble protein fraction was transferred to a nickel-nitriolotriacetic acid (NTA) agarose column. Before the oxidative refolding step, the column was washed with buffer B (10 mM Tris-HCl, $100 \mathrm{mM} \mathrm{Na} 2 \mathrm{HPO}_{4}, \mathrm{pH}$ 8.0) containing at first $6 \mathrm{M} \mathrm{GdmCl}$, then $1 \mathrm{M}$ GdmCl. Oxidative refolding was performed in buffer B containing $1 \mathrm{M} \mathrm{GdmCl}, 10 \mathrm{mM}$ glutathione (reduced), $5 \mathrm{mM}$ glutathione (oxidized). To remove the non-specifically bound protein impurities, the column was washed with buffer B containing $50 \mathrm{mM}$ imidazole. Elution was carried out with $50 \mathrm{mM}$ sodium acetate, $\mathrm{pH} 4.1$. Proteins obtained were stored at $-80{ }^{\circ} \mathrm{C}$ in separate vials until use. A thawed vial was never refrozen. Protein concentration was determined by Bradford protein assay (see below). Expression and purification of the rSho-PrP fusion protein was carried out by István Vida and was the fusion protein was tested by Antal Nyeste with western blotting.

\section{Cell lines, culturing, transfection and transduction}

Origins of cell lines used in the studies

Zpl2-1 mouse hypothalamic cell line was a kind gift of Y.S. Kim (79).

SH-SY5Y human neuroblastoma cell line was from ATCC (ATCC CRL-2266 ${ }^{\mathrm{TM}}$ )

HEK293 human embryonic kidney cell line from Gibco (11631-017). 


\section{Maintenance of cell cultures}

Each type of cell was cultured in high-glucose Dulbecco's Modified Eagle Medium (DMEM) complemented with $10 \%$ heat inactivated fetal bovine serum (FBS) and 100 units/ml Penicillin and $100 \mu \mathrm{g} / \mathrm{ml}$ Streptomycin, at $37{ }^{\circ} \mathrm{C}$ in a humidified atmosphere with $5 \% \mathrm{CO}_{2}$. Cells were passed at 90-95\% confluence at 1:10 splitting ratios (SH-SY5Y and HEK293) or 1:20 splitting ratio $(\mathrm{Zpl} 2-1)$.

Vials of cells were frozen in $-80^{\circ} \mathrm{C}$ overnight then stored in liquid nitrogen. Freezing DMEM contained 10\% DMSO, 55\% FBS and 40 units $/ \mathrm{ml}$ Penicillin and $40 \mu \mathrm{g} / \mathrm{ml}$ Streptomycin.

All types of cells were regularly tested for mycoplasma contamination. SH-SY5Y lines were maintained till 20th passage number then new vials were thawed.

Establishment of stable expression with Sleeping Beauty transposon system.

The Sleeping Beauty synthetic Tcl-like DNA transposon is a Class II or DNA transposon. DNA transposons are excised from the DNA and reinserted into the host, thus their mechanism of propagation is cut and paste. Sleeping Beauty was reconstructed in 1997 and became one of the transposon-based tools that can be used for gene delivery in vertebrate model system $(80,81)$. The Sleeping Beauty (SB) gene delivery system consists of two plasmid vectors, one plasmid (SBx100) encoding the transposase, and the other (pSB) contains the terminal inverse repeat (IR) sequences with the to-be-inserted DNA sequence between the repeats.

For transfection purposes $1 * 10^{5} \mathrm{Zpl2-1}$ or SH-SY5Y cells were seeded on multiple wells of 6well plates. The transfection was carried out at 50-70\% confluence, using a mixture of $3 \mu \mathrm{g}$ of one of the pSB constructs encoding either only GFP (SB/GFP), or GFP and WT-PrP (SB/PrP) or GFP and $\operatorname{PrP} \Delta \mathrm{CR}(\mathrm{SB} / \Delta \mathrm{CR})$ and $1 \mu \mathrm{g}$ of SBx100 plasmid, encoding a functional Sleeping Beauty Transposase, with TurboFect transfection reagent, in accordance with the manufacturer's manual.

Establishment of stable expression with pRRL lentiviral system.

For lentiviral constructs pRRL, a third generation transfer vector was used (82). 
In case of lentiviral transductions, the lentiviruses were generated and the virus titers were determined in the Hungarian National Blood Transfusion Service's lentiviral facility. The transduction of SH-SY5Y and HEK293 cells were carried out briefly as follows.

$3 * 10^{4}$ cells were seeded on 24 well plates. 24 hours after seeding medium was removed and replaced by fresh medium containing polybrene $(60 \mu \mathrm{g} / \mathrm{ml})$ and lentivirus for 24 hours. Transductions were carried out at multiplicities of infections (MOI) 1 to 5. After the removal of the transduction medium cells were cultured in normal growth medium and were kept in quarantine for 3 passages.

Conditions with the highest MOI were maintained for experiments, where cells remained viable and showed no morphological changes or decreased duplication rates. Transductions of SHSY5Y cells were carried out by Mónika Bácskai and Áron Szepesi. Transduction of HEK293 cells was carried out by Antal Nyeste.

Fluorescence-activated cell sorting (FACS) was used to separate cells with stable transgene expression in the transfected or transduced cell populations based on the expression of the fluorescent marker. In case of transfection with the Sleeping Beauty constructs, the EGFP positive cells were sorted at 3 and 14 days post-transfection. In the case of transduced cells, mCherry positive, or mCherry and EGFP double positive cells were sorted 7-10 days posttransduction.

EGFP and mCherry positivity were examined at every passage and experiments were carried out on cultures in which at least $90 \%$ of the cells expressed the required fluorescent markers. In parallel with the execution of the experiments, the expression levels of the transgenes were determined by immunoblotting technique. Cell sorting was carried out by György Várady.

\section{Cell viability assays}

Detection of apoptosis caused by serum deprivation or PrPACR expression in Zpl2-1 cells Spontaneous toxicity conferred by $\operatorname{PrP} \Delta \mathrm{CR}$, as well as the effect of serum deprivation on the various transgene-expressing cells, were assayed using Cy5 conjugated annexin- $\mathrm{V}$ and 7aminoactinomycin D (7-AAD). 
Zpl2-1, Zpl/GFP, Zpl/PrP and Zpl/ACR cells were seeded on 24 well plates at $3 * 10^{4}$ cells/well density. 24 hours after seeding, cells were washed twice with FBS-free high-glucose DMEM to remove dead/unattached cells and any residual FBS from the well before the incubation in FBS-free DMEM (completed with 100 units/ml Penicillin and $100 \mu \mathrm{g} / \mathrm{ml}$ Streptomycin), for either 48 or 72 hours. Each condition was tested in triplicates and the experiment was carried out three times.

After serum deprivation, cells were processed for flow cytometry analysis. The medium removed from the cells was placed into FACS tubes, then the cells were trypsinized and transferred into the tubes containing their corresponding media. This way many of the cells that were dead and floating were included in the measurement. Cells were washed twice with PBS, and were resuspended in $1 \mathrm{x}$ annexin binding buffer at $10^{6}$ cells $/ \mathrm{ml}$ concentration (10x Binding buffer: 0.1 M HEPES (pH 7.4), $1.4 \mathrm{M} \mathrm{NaCl}, 25 \mathrm{mM} \mathrm{CaCl}_{2}$ ) containing Cy5-conjugated annexin-V (BD Pharmigen; 559934. used in 1:100 dilution) and 7-aminoactinomycin-D (7AAD, Sigma-Aldrich; A9400-1MG, used in $0.5 \mu \mathrm{g} / \mu \mathrm{l}$ concentration).

30000 cells were counted from each sample and three groups of single-cells were identified: annexin and 7-AAD double negative i.e. living cells, annexin-positive and 7-AAD negative early apoptotic cells, and 7-AAD positive dead cells. For statistical analysis the percentage of viable cell populations (double negative) were determined and compared after 0, 2 or 3 days of serum deprivation.

\section{Analysis of drug hypersensitivity caused by PrPACR and Shadoo}

Cells stably transfected or transduced were seeded onto 96 well flat bottom plates at $3 * 10^{4}$ cells/well density (SH-SY5Y cells) or $1 * 10^{4}$ cells/well density (HEK293 cells). 24 hours after seeding, the medium was changed to fresh medium containing serial dilutions of various drugs: Zeocin or G418 treatments were administered for 48 hours, and puromycin treatment for 24 hours. The measurement of PrP $\Delta$ CR-induced Zeocin hypersensitivity (Figure 10A, B) was carried out using 3-(4,5-dimethylthiazol-2-yl)-2,5-diphenyl tetrazolium bromide (MTT), all other cell viability assays were carried out using PrestoBlue reagent according to the 
manufacturers protocol, briefly as follows. Cell viability assays on SH-SY5Y cells with Presto Blue reagent were carried out by Petra Bencsura and Antal Nyeste as indicated in captions.

MTT assay (83) is a colorimetric assay. The tetrazolium-ring of the MTT molecules is cleaved by the dehydrogenase enzymes of the mitochondria, reducing the MTT into a formazan dye that forms insoluble crystals in the cells. Since it requires mitochondrial function, it measures only the living cells. The signal generated correlates with mitochondrial activity and the number of living cells.

After drug treatment, the medium was changed to PBS containing $0.5 \mu \mathrm{g} / \mathrm{ml}$ MTT and plates were placed back into the cell culture incubator. After 4 hours of incubation, MTT solution was carefully removed and the converted formazan crystals were solubilized in acidic isopropanol (isopropanol:1 N HCl, 9:1) and the absorbance of the solution was measured at $560 \mathrm{~nm}$.

PrestoBlue (PB) assay is based on the intracellular reduction of resazurin to resorufin by the mitochondrial enzymes, which can be detected with colorimetry or fluorimetry. PB assay has several advantages over the classic MTT assay (84): Resazurin is stable, and unlike MTT, is not toxic to the cells, so it allows continuous monitoring of the same cells. In addition, PB assay is much faster than the MTT assay, and its sensitivity is higher.

After the drug treatment the medium was changed to PBS containing 5\% PrestoBlue and cells were placed back for 60 minutes into the $\mathrm{CO}_{2}$ incubator before measuring fluorescence with a Perkin Elmer Enspire Multimode Plate Reader (excitation: 555 nm, emission: 585 nm).

Analysis of cell proliferation was carried out using 96-well plates and PrestoBlue assay. About 4 hours after seeding, when cell attachment was confirmed by microscopy analysis, the fluorescence in 4 wells of each cell type was measured in order to be used as initial values. After every 24 hours for 8 days 4-4 wells of each cell were measured and the measured fluorescence values were normalized to the initial values to estimate the change in the number of cells. We were unable to calculate EC50 values from our curves, instead, based on previous articles of this field in the literature, we chose the viability values of a Zeocin and a G418 concentrations from the middle of the dilution series for comparison and statistical analysis. 


\section{Immunocytochemistry}

\section{Immunocytochemistry procedures}

Cells were seeded on Labtek-II 8-well slides $\left(5 * 10^{4}\right.$ cell/well density) or on 96 well plates at $1.5^{*} 10^{4}$ cells/well density for phosphorylated Histone $2 \mathrm{AX}(\gamma-\mathrm{H} 2 \mathrm{AX})$ detection. 24 hours after seeding cells were fixed with $4 \%$ paraformaldehyde (PFA) in PBS for 10 minutes at room temperature (RT), washed 3 times in immunofluorescence washing (IF) solution ( $0,2 \%$ bovine serum albumin, 0,1\% Triton-X 100 in PBS) followed by blocking and permeabilization (5\% bovine serum albumin, $0.5 \%$ Triton-X 100 in IF solution) for 10 minutes at RT.

Cells were washed again 3 times in IF solution before applying the primary antibody (SAF32 anti-PrP mouse IgG for PrP staining, and purified anti H2AX.phospho antibody for $\gamma$-H2AX staining) for 1 hour at RT.

The cells were then washed once by IF solution, and the secondary antibody was applied for 30 minutes at RT. From the application of secondary antibodies, slides and plates were kept in dark. Cells were washed 3 more times for 10 minutes then for overnight. Nuclei were stained with DAPI for 10 minutes at RT ( $1 \mu \mathrm{M}$ DAPI in PBS) before microscope analysis.

\section{Detection of anti-PrP immunocytochemistry}

The cells were observed using an Olympus FV500-IX Confocal Laser Scanning Microscope, with a PLAPO 60x (1.4 N.A.) oil immersion objective (Olympus). DAPI, EGFP, mCherry and Alexa Fluor 647 fluorophores were excited at 405, 488, 543 and 633 nm, respectively. Emission detection ranges were 430-460 $\mathrm{nm}$ (DAPI), 505-525 nm (EGFP), 560+ $\mathrm{nm}$ (mCherry) and 660+ nm (Alexa Fluor 647), respectively. Confocal images were recorded with Olympus Fluoview 5.0 software. Image acquisition settings (laser intensity, PMT settings, and confocal aperture size for each channel) were kept unchanged during confocal microscopy sessions. Images were captured in sequential scanning mode and using 1024x1024 pixel resolution.

\section{Anti- $\gamma-H 2 A X$ immunocytochemistry and high content screening}

Detection of Histone 2AX phosphorylation: SH-SY5Y cells expressing either Sho, PrP $\triangle \mathrm{CR}$ or their respective controls, mCherry or EGFP, were seeded on 96 well plates at $1.5^{*} 10^{4}$ cells/well density. 24 hours after seeding the cells were subjected to $0,20,100 \mu \mathrm{g} / \mathrm{ml}$ Zeocin, or $50 \mu \mathrm{M}$ 
Etoposide in normal culture medium for $60 \mathrm{~min}$ at a $37^{\circ} \mathrm{C}$, then washed once with PBS and immunostained as described above.

Image acquisition was performed with a ImageXpress ${ }^{\circledR}$ Micro XLS high-content screening system (Molecular Devices) using Nikon 10x Plan Fluor objective (NA=0.3). Blue and far-red fluorescence signals of DAPI and $\gamma$-H2AX for nuclei were detected using emission filters of $447 / 60 \mathrm{~nm}$ and 692/40 $\mathrm{nm}$, respectively, with 377/50 and 635/18 nm excitation filters, and 4-6 fields of view were imaged per well. For analysis the cells were segmented on the basis of DAPI staining, and the percentage of $\gamma-\mathrm{H} 2 \mathrm{AX}$ positive nuclei was determined using the MetaXpress software. At least 4000 cells were analysed per conditions.

Image acquisition was carried out by Zoltán Hegyi.

Image analysis - Microscopy images were analysed using the Image J 1.48v software with BioFormats plugin. During image processing the lookup tables were always linear and covered the full range of the data.

\section{Immunoblotting}

Cells seeded on $100 \mathrm{~mm}$ cell culture dishes were harvested at 70-90\% confluence after being washed once with PBS by scraping in $1 \mathrm{ml}$ PBS. Cells were pelleted by centrifugation (3', 200xg) and re-suspended in ice cold lysis buffer (50 mM HEPES, pH 7.5, 0.2 mM EDTA, 10 $\mathrm{mM} \mathrm{NaF}, 250 \mathrm{mM} \mathrm{NaCl}, 0.5 \% \mathrm{NP}-40$, freshly supplemented with $1 \%$ Proteinase inhibitor cocktail, 1\% Calpain inhibitor, 1 mM DTT).

The total protein concentration was measured by using Bradford protein assay.

Where needed, PNGaseF treatment was carried out on samples of 50-100 $\mu \mathrm{g}$ total protein, according to the manufacturer's protocol. Samples of 1-50 $\mu \mathrm{g}$ total protein, depending on the necessities of the experiment, were run on $15 \%$ denaturing SDS-PAGE and were blotted onto activated PVDF membrane, using a wet blotting system from Bio-Rad.

The membrane was incubated for at least 1 hour in blocking buffer (Tris buffered saline supplemented with 1\% Tween-20 (TBST) containing 5\% non-fat milk powder), and primary antibodies were applied overnight, at $4{ }^{\circ} \mathrm{C}$. Next day, after washing the membrane in TBST 3 times for 10-10 minutes, HRP-conjugated secondary antibodies were applied to the membrane 
for 60 minutes, followed by 3 times of washing in TBST and one time in distilled water. The proteins were visualized by adding chemiluminescent substrate for 1 minutes.

Phosphatidylinositol-dependent phospholipase-C (PI-PLC) treatment

Cells were seeded on 24 well plates. After reaching confluence, the PI-PLC treatment was carried out according to the manufacturer's protocol. Briefly: cells were washed twice in PBS and the plate with cells having only PBS or PBS with PI-PLC (1 unit/ml PI-PLC) was rocked gently for 30 minutes at $4{ }^{\circ} \mathrm{C}$. The supernatants were removed from the cells, centrifuged ( 5 ', $20000 \mathrm{xg}$ ) to remove cells and debris and processed for SDS-PAGE [noted as "medium (M)" samples on figures]. The PI-PLC treated and untreated cells were harvested from the plates by scraping and were processed for SDS-PAGE [noted as "cell lysate (Cl)" samples on figures].

\section{Statistics}

Cell viability assays were done with 5 parallel samples for every condition. The number of surviving cells in case of each drug concentration was normalized to the number of cells receiving no drug treatments. For statistical analysis one concentration was chosen from each drug-treatment: $6.25 \mu \mathrm{g} / \mathrm{ml}$ for Zeocin, $250 \mu \mathrm{g} / \mathrm{ml}$ for G418 and $1.6 \mu \mathrm{g} / \mathrm{ml}$ for puromycin in case of SH-SY5Y cells and $50 \mu \mathrm{g} / \mathrm{ml}$ for Zeocin, $250 \mu \mathrm{g} / \mathrm{ml}$ for G418 in case of HEK293 cells. Statistical analysis (Normality tests, Student's t-tests, One-way ANOVAs with two-tailed Dunnett's or Tukey's HSD post-hoc tests) was carried out on data from at least 3 independent experiments using SPSS Statistics v20 software. On plots, mean \pm standard deviation (SD) values are shown. $\mathrm{p}$ values: $* 0.01<\mathrm{p}<0.05, * * 0.001<\mathrm{p}<0.01, * * * \mathrm{p}<0.001$. 


\section{Results}

\section{Establishment of stable transgene expression in Zpl2-1, SH-SY5Y and HEK293 cell lines}

In order to establish stable expression of Shadoo, WT-PrP or PrP $\Delta$ CR in various cell lines, we prepared a bicistronic system in Sleeping Beauty transposon based gene delivery system (SB) (85), and when additional transgene expression was required we chose a lentiviral approach (82), where an independent fluorescent protein, EGFP, or mCherry, expression was tightly coupled to the expression of our genes of interest.

Our criteria for the expression system were:

1) Easy detection of transgene expression. Immunocytochemistry is the most straightforward way of detecting a protein expression in situ, but we also wanted an easy and quick way, which can be used during cell culturing, to monitor the transgene expression. To achieve this we used fluorescent proteins as reporters, instead of antibiotic selection. We used fluorescent microscopy for regular monitoring of cells during maintenance of the cultures. The presence of the fluorescent reporters was used also to select the cells with stable transgene integration by using fluorescence-activated cell sorting (FACS).

2) Usage of untagged Shadoo and PrP constructs. Fluorescent or epitope tagging of a protein may affect adversely the protein localization or function (i.e. loss of protein function), thus we established the expression of untagged proteins.

3) Avoiding the positional effect of the transgene integration. We have worked with non-cloned cells where the randomized sites of the integrations eliminated the potential risk of positional effects.

Assessing the extent of co-integration of the two expression cassettes between Sleeping Beauty transposon arms.

At first, we tested the SB transposon system and found that the collective integration of the two expression cassettes between the transposon arms produced more than 95\% coupling (Figure 4). Zpl2-1 cells were transfected with SH/GFP plasmids in the presence or absence of SBx100 transposase. After puromycin selection $(6.25 \mu \mathrm{g} / \mathrm{ml}$ puromycin, for 13 days $)$ the percentage of GFP positive cells in the surviving, puromycin resistant population were tested with flow cytometry (Figure 4). Transposition of the two transgene resulted a more than 95\% 
coupling of the two transgenes (Figure 4B, D), whereas random integration of SB/GFP plasmid into the genome resulted only about a $40 \%$ co-integration of expression cassettes coding GFP and puromycin resistance genes (Figure 4C, D).

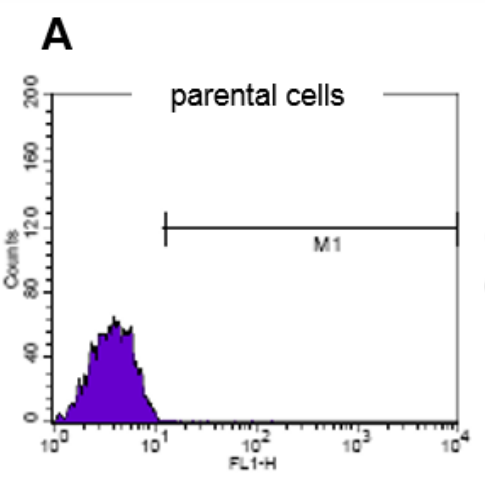

B
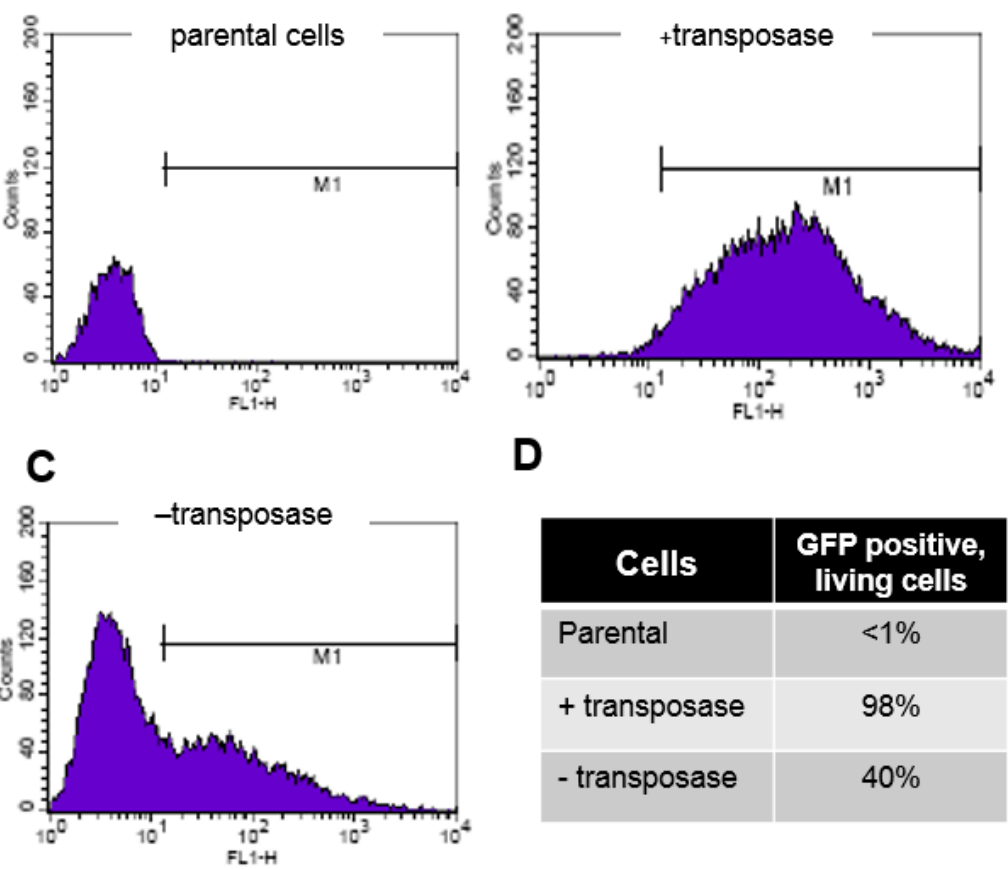

D

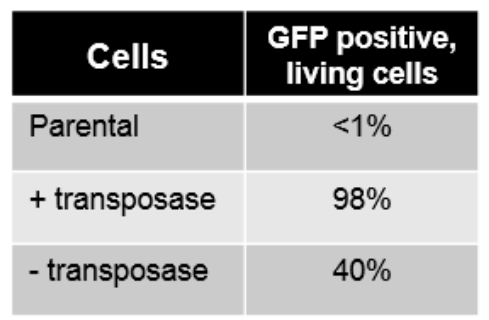

Figure 4: The integration of the two expression cassettes between the transposon arms to be inserted by the Sleeping Beauty transposase is coupled. (A) Histogram of GFP positivity in untransfected, parental Zpl2-1 cells (B) Histogram of GFP positivity in Zpl2-1 cells transfected with SH/GFP and SBx100 after 13 days of puromycin treatment $(C)$ Histogram of GFP positivity in Zpl2-1 cells transfected with only SH/GFP after 13 days of puromycin treatment. (A-C) M1 markers were used to identify GFP positive cells.

(D) Percentages of puromycin resistant, GFP positive cells under M1 markers on A-C histograms.

Analysis of WT and $\triangle C R$ PrP expression in cells established with Sleeping Beauty transposon system.

Using SB system, we established stable expressions of PrP $\triangle \mathrm{CR}$, PrP-WT and EGFP in Zpl21 immortalized hippocampal Prnp-knockout cells (79), and in SH-SY5Y human neuroblastoma cells of very low endogenous PrP level $(43,86)$.

Transgene expression was analysed by immunocytochemistry and immunoblotting in both Zp12-1 (Figure 5) and SH-SY5Y (Figure 6) cells. The endogenous PrP expression was below the detection limit in SH-SY5Y by both immunocytochemistry and western blot technics (Figure 5B, 6B; lanes 1, 2). In both cell types prion proteins localize predominantly on the cell surface and their expressions are coupled with the reporter EGFP (Fig 5A and 6A). Both WT 
and $\triangle \mathrm{CR}$ PrP were glycosylated in both Zpl2-1 and SH-SY5Y cells and both non-glycosylated and glycosylated forms of the proteins were present (Figures 5B and 6B). The slight mobility shift caused by the deletion of the 21 amino acids of the central region (CR) can be detected in both $Z p l / \Delta C R$ (Figure 5B lane 3 vs. 4) and $S H / \Delta C R$ (Figure 6B lane 7 vs. 8) cells.
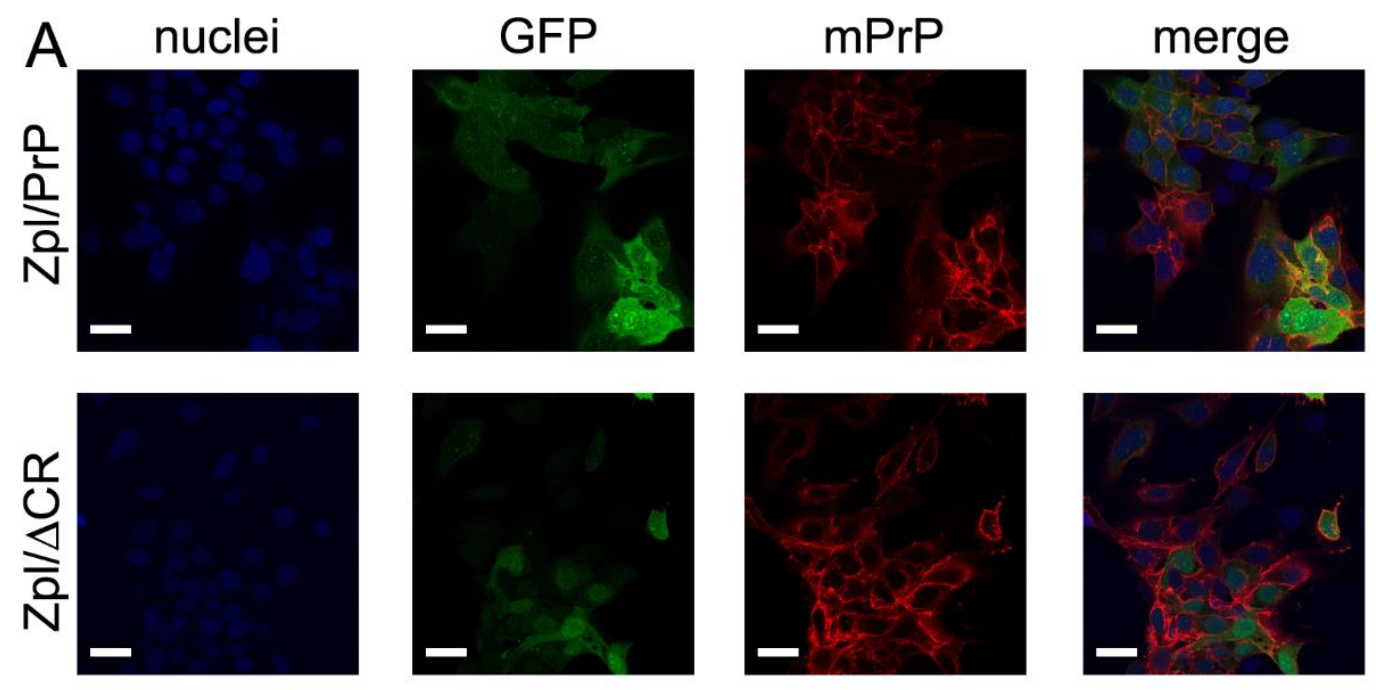

B

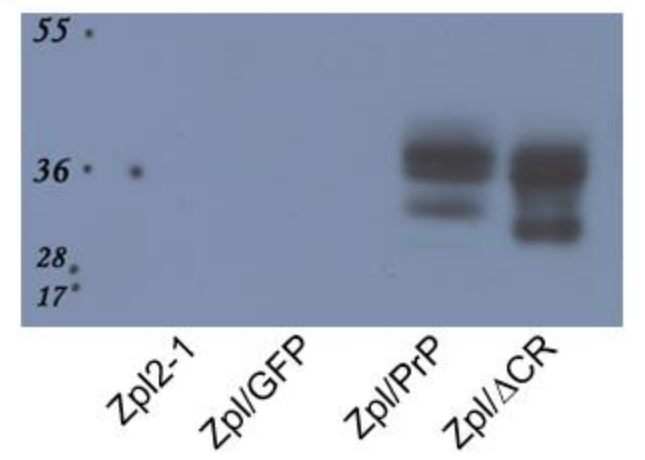

Figure 5: Analysis of PrP-WT and PrP $\Delta C R$ overexpression and localization in stably transfected Zpl2-1 cells. (A) Immunocytochemistry analysis of $\operatorname{Pr} P$ overexpression and localization. Laser scanning confocal microscopy images, Nuclei (blue) and PrP-s (red) are stained by DAPI and SAF32 anti-PrP antibody, respectively. GFP is shown in green. Scale bar, $30 \mu m$. (B) Western blot analysis of PrP expression in Zpl cell lysates.

The correct plasma membrane localization and the presence of the GPI-anchor of prion protein constructs were analysed by western blotting of cell lysates made from PI-PLC treated and non-treated SH-SY5Y cells (Figure 6C). In the PI-PLC treated cell lysates (upper panel, lanes 3 and 5) PrP signal was lower compared to the untreated samples (lanes 4 and 6), whereas the respective loading controls (upper actin panel) showed no such differences. Corroborating this, PrP appeared in the supernatant treated with PI-PLC (lower panel, lanes 4, 6). Note, that 
while $\beta$-actin showed cell contamination in all supernatant samples (lower actin panel), $\operatorname{PrP}$ coming from the cell contamination remained below detection limit in case of PI-PLC untreated samples. It can be concluded that both WT PrP (Figure 6C lanes 3, 4) and $\Delta \mathrm{CR} \operatorname{PrP}($ lanes 5, 6) are attached to the cell surface by GPI-anchor.

A
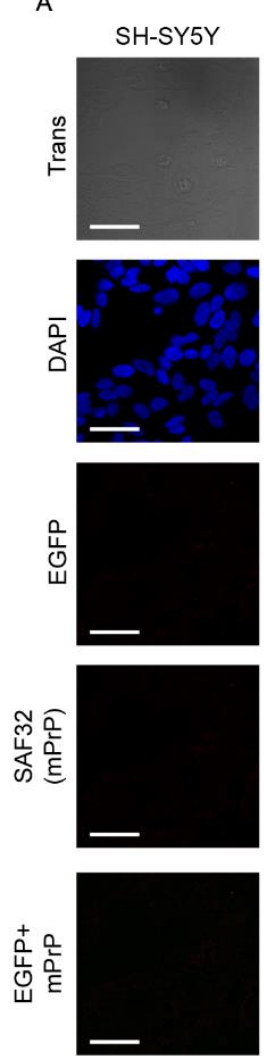

SH/GFP
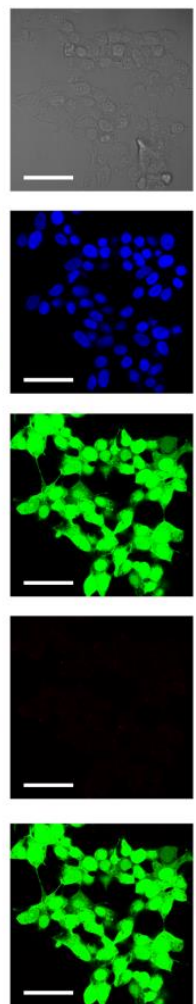

SH/PrP
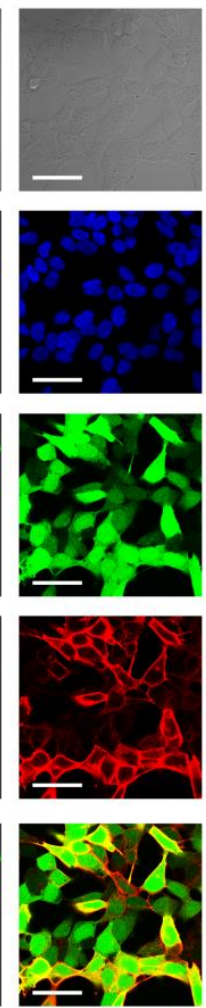

$\mathrm{SH} / \Delta \mathrm{CR}$
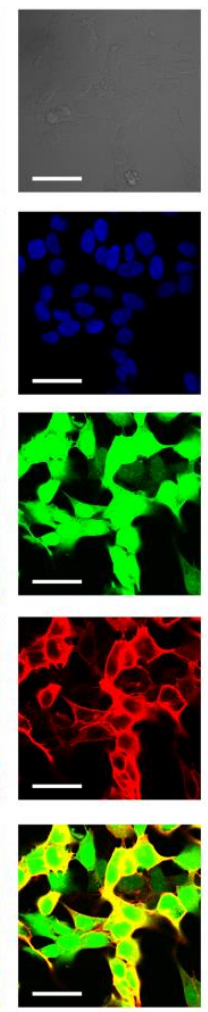

B

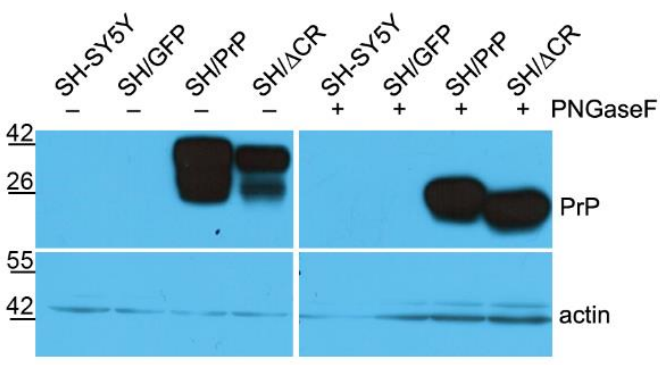

C

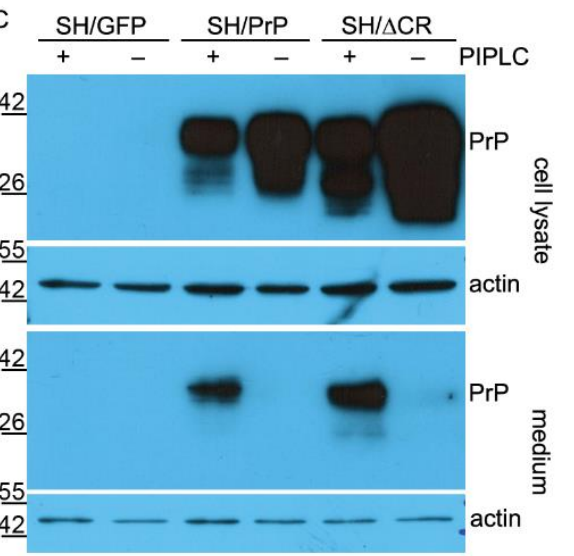

Figure 6: Analysis of the glycosylation, localization and expression levels of prion proteins in SH/PrP and SH/DCR cells. (A) Immunocytochemistry analysis of PrP overexpression and localization. Laser scanning confocal microscopy images. Nuclei (blue) and PrP-s (red) are stained by DAPI and SAF32 anti-PrP antibody, respectively. Scale bar, $40 \mu \mathrm{m}$. (B) Western blot analysis of PrP expression and glycosylation in SH-SY5Y cell lysates. Extracts from various cells as indicated above the lanes, were untreated (-) or treated (+) with PNGaseF and visualized using SAF32 anti-prion antibody. $\beta$-actin was used as loading control (lower panel). (C) Western blot analysis of PrP cell surface localization. Extracts (cell lysate) and medium (medium) from various cells as indicated above the lanes, untreated (-) or treated (+) with PIPLC (upper panel). $\beta$-actin was used as loading control (lower panel) in case of cell lysates, and to detect cell contamination in supernatant medium samples. 
Analysis of $\operatorname{PrP}$ and Shadoo expression in cells transduced with lentivirus

Introduction of Shadoo or WT PrP transgenes into PrP $\Delta$ CR expressing cells were carried out with lentiviral transduction, also the same approach was used for the establishment of SH/Sho and respective control cells. With no appropriate anti-Sho antibody for immunocytochemistry, the confirmation of correct localization and overexpression of Shadoo was carried out by immunoblotting. We found no morphological change (data not shown) or adverse effect on cell proliferation of $\mathrm{SH} / \Delta \mathrm{CR}$ cells (Figure 7A) caused by the transduction of cells and stable expression of WT PrP or Shadoo.

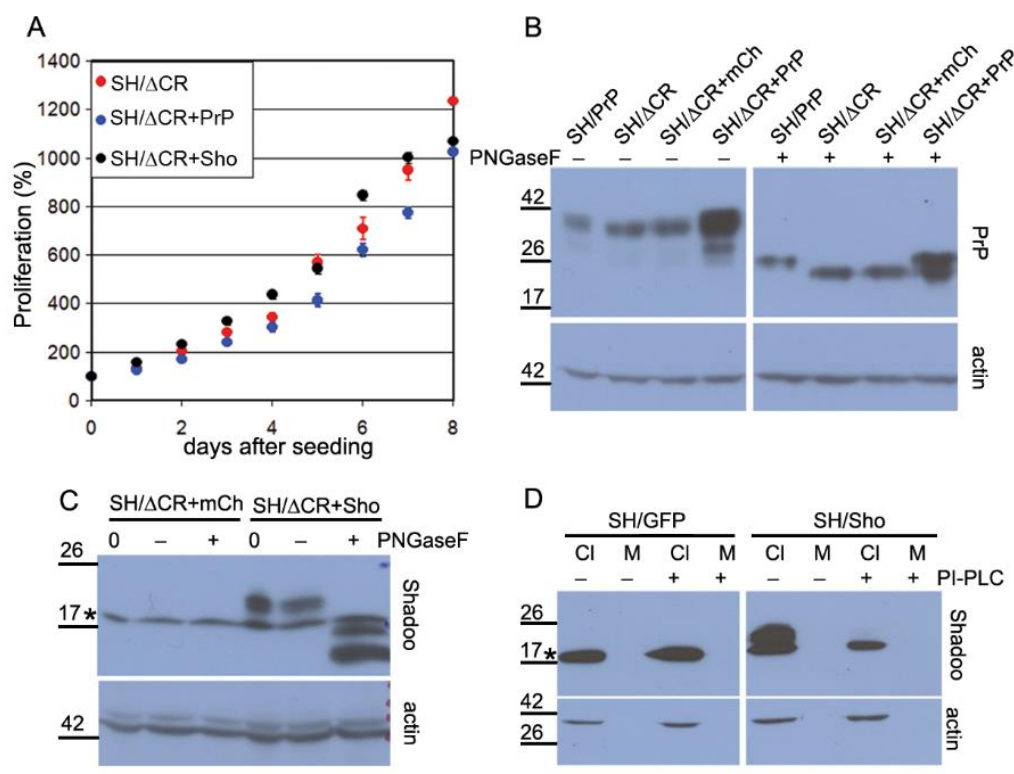

Figure 7: Analysis of the overexpression, glycosylation, localization and relative protein levels of prion and Shadoo transgenes in $\mathbf{S H}$ SY5Y cells. (A) Proliferation assay of the indicated cell lines using PrestoBlue reagent. Representative plot. $100 \%$ is the fluorescence value at day zero after attachment for each type of cell. (B) Western blot analysis of $W T$ and $\triangle C R \operatorname{PrP}$ expression and glycosylation in SH-SY5Y cell lysates. (C) Western blot analysis of Sho expression and glycosylation in

SH-SY5Y cell lysates. $(B, C)$ Lysates from various cells as indicated above the lanes were untreated (-) or treated with PNGaseF (+) or without incubation (O). (D) Western blot analysis of Shadoo cell surface localization. Cl: Cell lysates, M: supernatant medium from SH/GFP (left panel) and SH/Sho (right panel) cells, incubated with (+) or without (-) PI-PLC. An intracellular protein, $\beta$-actin was used as loading control for cell lysates, and as detection of cell contamination in medium samples. $(B, D)$ Left and right panels are from the same X-ray film, corresponding to the left and right parts of the same membrane. $(C, D) *$ marks a nonspecific band. As loading control $\beta$-actin was used. (A) Proliferation assay was carried out by Petra Bencsura.

The glycosylation of the Shadoo protein was determined using western blot after PNGaseF treatment of cell lysates. We found that Sho expressed in SH-SY5Y cells, like WT and $\Delta \mathrm{CR}$ PrP, showed complex glycosylation (Fig. 7B, C). PrP $\triangle \mathrm{CR}$ expression levels in $S H / \Delta C R$, 
$S H / \triangle C R+m C h, S H / \triangle C R+\operatorname{PrP}$ cells are comparable (Fig. 7B, lanes 6-8) after PNGaseF treatment, the $\mathrm{C} 1$ fragment (87) of Shadoo is more readily detectable (Fig. 7C, lane 6). Endogenous Shadoo expression is below the detection limit (Figure 7C, lanes 1-3).

The cell surface localization and GPI-attachment of the Shadoo protein was verified by western blotting lysates of cells treated or not treated with PI-PLC (Figure 7D). The amount of Shadoo decreases below detection limit in the cell samples of PI-PLC treated cells (Figure 7D, lanes 5 vs. 7, upper panel), while the amount of an intracellular protein, $\beta$-actin, remains unchanged (Figure 7D, lanes 5 vs. 7, lower panel). Shadoo remains below the detection limit in the medium samples. As Shadoo is a natively unfolded protein, it may be prone to proteolytic digestion in the medium, hence the lack of signal in the PI-PLC treated medium sample.

SH/Sho, HEK/Sho cells and derivatives were established by subsequent lentiviral transductions. Shadoo and WT PrP expression were analysed by using western blot in both SHSY5Y (Figure 11A, B) and HEK293 (Appendix Figure 17) cells.

Shadoo expression levels in SH/Sho and HEK/Sho were slightly lower than in their derivatives, SH and HEK/Sho+GFP and SH and HEK/Sho+PrP. In HEK293 cells endogenous WT PrP was detectable but the level of overexpressed PrP was significantly higher.

The cells generated with either SB or LV are listed in Appendix Table 3, and the topologies of the plasmid constructs are shown on Figure 3.

Comparison of the prion and Shadoo transgene expression levels in SH/ACR+PrP and SH/ACR+Sho cells.

Since the antagonizing effects of the PrP $\Delta$ CR, Shadoo and WT PrP depend on their relative concentration we compared the expression levels of these transgenes in the $S H / \triangle C R+P r P$ and $\mathrm{SH} / \Delta \mathrm{CR}+\mathrm{Sho}$ cell lines.

Serial dilutions of PNGaseF-treated cell lysates were analysed on western blot (Figure 8A). $\operatorname{PrP} \Delta \mathrm{CR}$ and WT PrP expression level was comparable in $S H / \Delta C R+\operatorname{PrP}$ cells, and $\operatorname{PrP} \Delta \mathrm{CR}$ expression was higher in $S H / \triangle C R+S h o$ cell than in $S H / \triangle C R+\operatorname{PrP}$ cell. On the other hand, $\operatorname{PrP} \Delta \mathrm{CR}$ expression levels were comparable in $S H / \Delta C R+\operatorname{Pr} P$ and the parental $S H / \Delta C R$ cells (Fig 7B, lanes 6-8). 
Since direct comparison of the expression levels of two untagged proteins in a total cell lysate is impossible, the comparison of $\operatorname{PrP} \triangle \mathrm{CR}$ and Shadoo was carried out by a bacterially expressed polypeptide (rSho-PrP) that contained epitopes of both anti-PrP and anti-Shadoo antibodies (Figure 8B). Serial dilution of PNGaseF-treated total cell lysate of $S H / \Delta C R+S h o$ was blotted, along with a serial dilution of rSho-PrP on the same gel (Figure 8C).

Bands representing the Shadoo and PrP $\Delta$ CR proteins expressed in $S H / \Delta C R+S h o$ (left side of the blot photo) were compared to bands representing the rSho-PrP polypeptide (on the right side of the blot photo). The estimated expression levels of PrP $\triangle \mathrm{CR}$ and Shadoo in $S H / \Delta C R+S h o$ cells are similar.

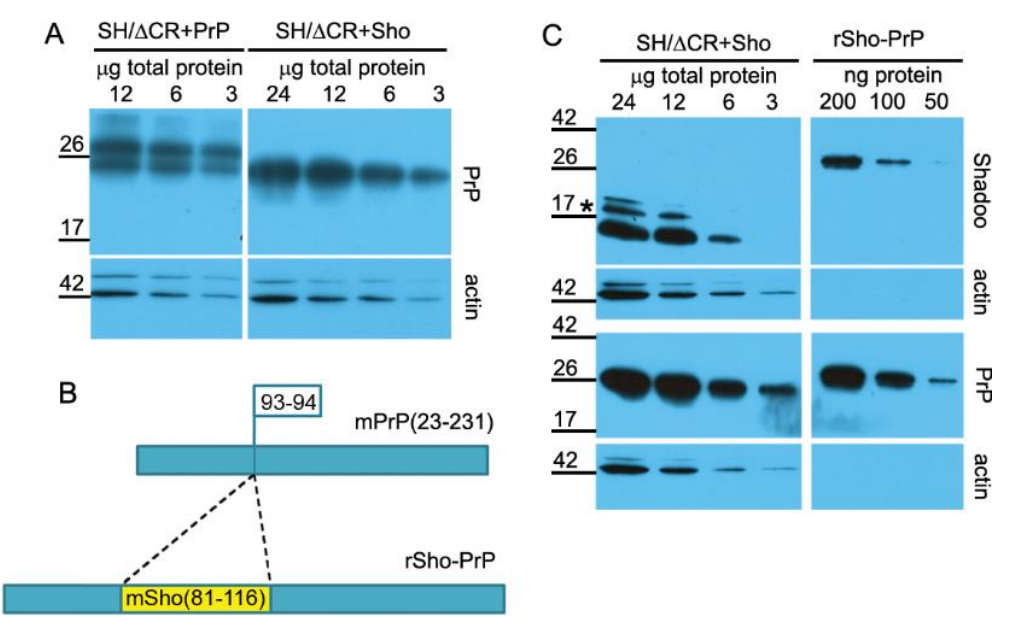

Figure 8: Comparison of prion protein and Shadoo expression levels in SH-SY5Y cells. (A) Comparison of overexpressed prion protein levels in serial dilutions of the indicated cell lysates using western blot analysis. Total protein of cell lysates loaded are indicated above the panels. (B) Schematic design of rSho-PrP recombinant polypeptide. $(C)$ Comparison of $\operatorname{PrP} \triangle C R$ and Shadoo expression

levels of SH/ACR+Sho cells using western blot analysis. Total protein of cell lysates or purified $r$ Sho-PrP recombinant polypeptide loaded onto the gels are indicated above the panels. * marks a nonspecific band. $(A, C)$ Left and right panels are from the same $X$-ray film, corresponding to the left and right parts of the same membrane. As loading control $\beta$-actin was used.

\section{Effects of serum deprivation to WT and $\Delta \mathrm{CR}$ PrP expressing cells}

Based on previously published data $(46,47,88)$ we investigated if the presence of WT or $\Delta \mathrm{CR}$ PrP changes the extent of apoptosis caused by serum deprivation in an immortalized cell line of hippocampal origin (Zpl2-1) (79), and the human neuroblastoma cell line SH-SY5Y.

We investigated apoptosis in these cell lines by FACS analysis by labeling early apoptotic cells by annexin- $\mathrm{V}$ and dead cells by 7-AAD staining and we were unable to detect any significant protection conferred by WT PrP expression in serum deprived Zp12-1 cells (Fig. 9). 
Expression of $\operatorname{PrP} \triangle \mathrm{CR}$ in Zpl2-1 cells did not increase number of apoptotic cells as tested by annexin staining in FACS (Figure 9, 0 day columns) and we could not detect any significant increase in cell death of SH-SY5Y cells as tested by Trypan blue staining (data not shown), despite spontaneous toxicity of HD deletion mutants of PrP have been reported in CGN (64) or SH-SY5Y (43) in sometimes devastating extent. We found no shocking decrease in the viability of any of the tested $\mathrm{Zpl}$ cells, but interestingly the viability loss of the $\mathrm{Zpl} / \Delta C R$ cells after 3 days of serum deprivation turned out to be significant (Figure 9, yellow bars of 0 and 3 days). Whether this difference has any biological relevance is to be answered.

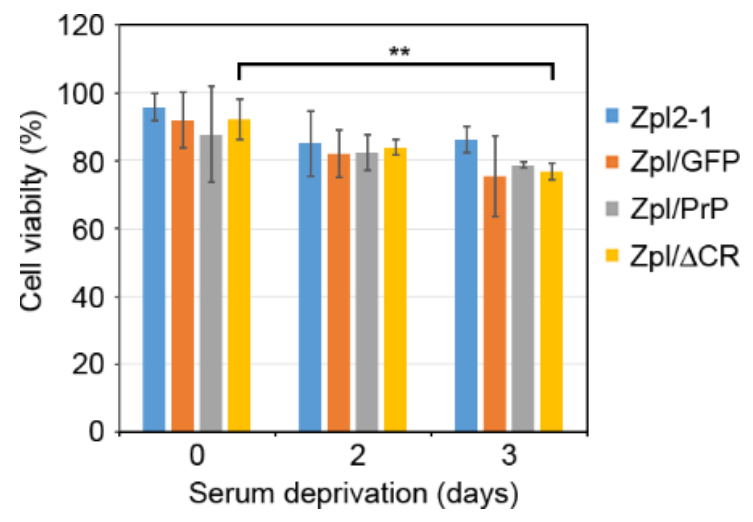

Figure 9: Viability assays on Zpl2-1 cells expressing wild type or mutant PrP constructs. The percentage of living cell populations (annexin$V$ and 7-AAD negative) were determined using flow cytometry and compared after 0, 2 or 3 days of serum deprivation in 3 independent experiments. $100 \%$ is the sum of respective living (double negative), early apoptotic (annexin-V positive; 7$A A D$ negative) and dead (7-AAD positive) populations for each cell lines and conditions. Bars represent mean $\pm S . D$. **: $p<0.01$.

\section{Shadoo does not rescue Zeocin hypersensitivity caused by PrP $\Delta$ CR in SH-SY5Y cells}

$\operatorname{PrP} \triangle \mathrm{CR}$ is reported to cause hypersensitivity to Zeocin- and G418-related antibiotics in HEK, CHO, mouse NSCs and other cell lines, which is eliminated by PrP-WT co-expression $(37,38,50,89)$.

We also detected increased Zeocin sensitivity in SH-SY5Y cells expressing of PrP $\triangle \mathrm{CR}$ but not in cells expressing WT PrP or GFP (Fig. 10A, B). To assess whether the co-expression of Shadoo would eliminate this phenotype caused by $\operatorname{PrP} \Delta \mathrm{CR}$ we introduced Shadoo into $\mathrm{SH} / \Delta \mathrm{CR}$ with lentivirus. Shadoo co-expression didn't antagonize with the Zeocin hypersensitivity, where it was diminished by the co-expression of WT PrP (Figure 10C, D). As positive control WT PrP, for negative control only mCherry was introduced to the SH/ $\Delta$ CR cells. 
Shadoo causes Zeocin and G418 hypersensitivity in various cell lines that is diminished by WT PrP co-expression

Contrary to our expectations, Shadoo overexpression in SH-SY5Y cells caused hypersensitivity to both Zeocin and G418 (Figure 11) but not to puromycin (Figure 12), like $\operatorname{PrP} \Delta \mathrm{CR}$ overexpression. Furthermore co-expression of WT PrP eliminated both the Shadooinduced Zeocin and G418 hypersensitivities (Figure 11).

Figure 10: Overexpression of PrPACR causes Zeocin hypersensitivity in SH-SY5Y cells that is eliminated by WT PrP co-expression. (A, B) PrP $\triangle C R$ makes SH-SY5Y cells hypersensitive
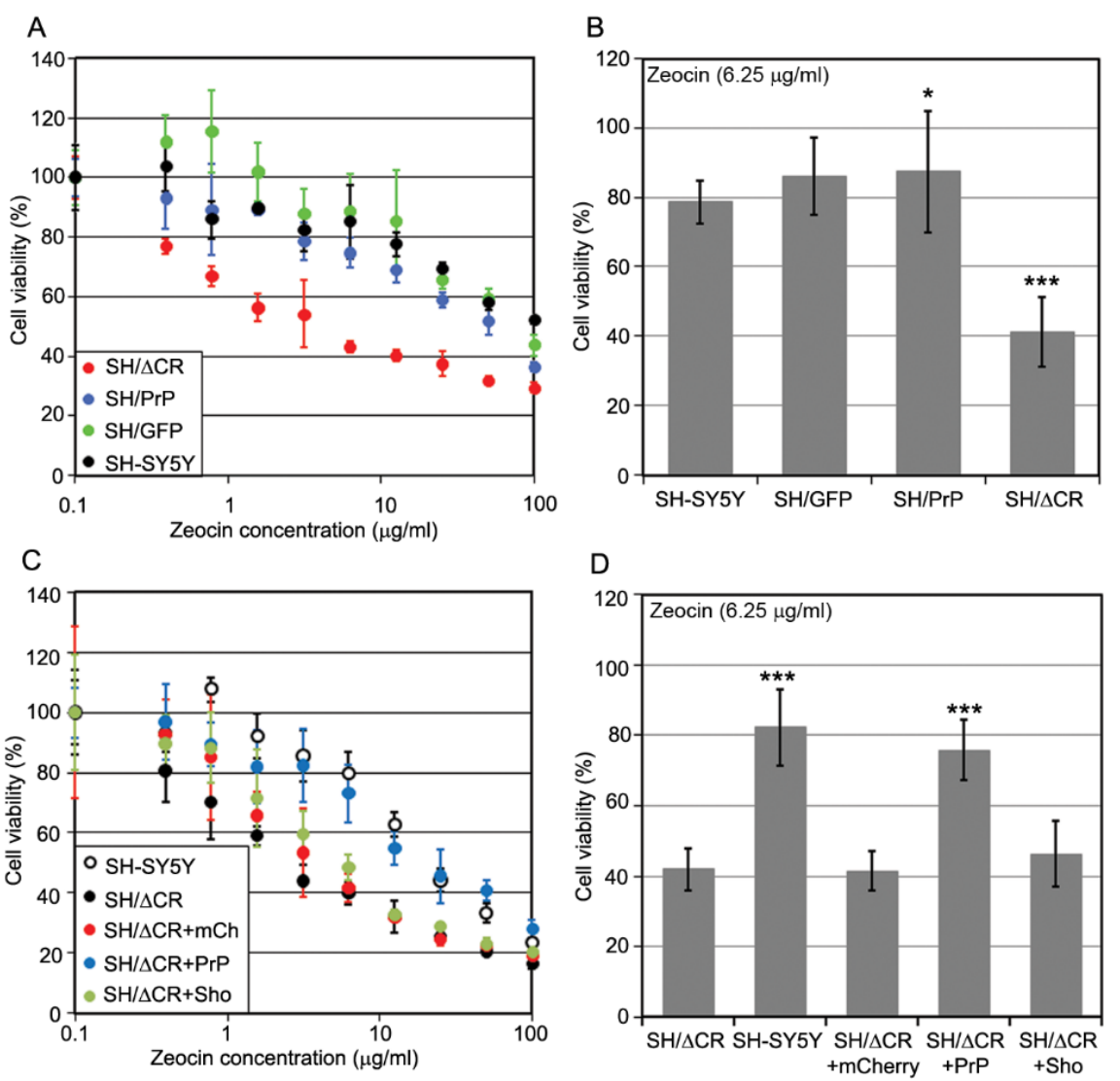

to Zeocin. Cytotoxicity assays by MTT reagent. (A) Panel shows a representative experiment. Zeocin was applied from 0 to 100 $\mu \mathrm{g} / \mathrm{ml}$ on various cells, as indicated, for 48 hours. Values are means \pm S.D. of parallels in the individual experiment. (B) Panel shows the average of 4 independent experiments measured at $6.25 \mu \mathrm{g} / \mathrm{ml}$ Zeocin concentration. $(C, D)$ Co-expression of $\mathrm{PrP}$ WT but not Sho diminishes $\operatorname{PrP} \triangle C R$ caused Zeocin hypersensitivity. Cytotoxicity assay by PrestoBlue reagent. (C) Representative experiment carried out at Zeocin concentrations between 0-100 $\mu \mathrm{g} / \mathrm{ml}$ Zeocin on various cells as indicated, for 48 hours. Values are means \pm S.D. of replicas. (D) Bars show the means \pm S.D. of cell viabilities measured at $6.25 \mu \mathrm{g} / \mathrm{ml}$ Zeocin concentration in $n=3$ independent experiments. $(A-D) .100 \%$ is the absorbance $(A, B)$ or fluorescence $(C, D)$ values of untreated cells of each cell type. $(B, D)$ Samples were compared to the first column of each diagram (B: SH-SY5Y, D: SH/ $\triangle C R$ ), * $p=0.04$, *** $p<0.001$. 
We compared Zeocin and G418 hypersensitivity in different cell types - SH-SY5HY and HEK cells and we got similar results.

According to Western blot analysis $S H / S h o+G F P$ or $S H / S h o+\operatorname{PrP}$ cells have slightly higher Shadoo expression than the parental SH/Sho cells (Figure 11A) and WT PrP can be detected only in $S H / S h o+\operatorname{PrP}$ cells (Figure 11B) verifying that the presence of WT PrP and not the lack of Shadoo expression is responsible for the elimination of G418 and Zeocin hypersensitivity in SH/Sho $+\operatorname{PrP}$ cells.

Figure 11: Overexpression of Shadoo causes Zeocin and G418 hypersensitivity in SH-SY5Y cells could be eliminated by WT PrP co-expression.

$(A, B)$ Western blot analysis of Shadoo expression (A) and $\operatorname{Pr} P$ expression $(B)$ in $P N G a s e F$ treated extracts from SH cells. * marks a nonspecific band. $\beta$-actin was used as loading control. $(C, D)$ Cytotoxicity assays by Presto blue after 48 hours of Zeocin treatment. (C) Concentration dependence of Zeocin cytotoxicity is shown in a representative experiment in SH-SY5Y cell types as indicated. (D) Differences in the viability of compared cell types was characterized at a selected concentration of Zeocin. Columns show the means \pm S.D in 4 independent experiments. $(E, \quad F)$ Cytotoxicity assays by Presto Blue after 48 hours of G418 treatment. (E) Concentration dependence of G418 cytotoxicity is shown in a representative experiment in cell types as indicated $(F)$ Differences in the viability of compared cell types was characterized at a selected concentration of G418. Columns show the means \pm S.D. in 3 independent experiments. $(C-F)$ Viability is given as percentage of non-treated controls. * $p<0.05, * * p<0.01, * * * p<0.001$.

$(C, E)$ Cytotoxicity assays on $\mathrm{SH}-\mathrm{SY} 5 \mathrm{Y}$ cells were carried out by Petra Bencsura.
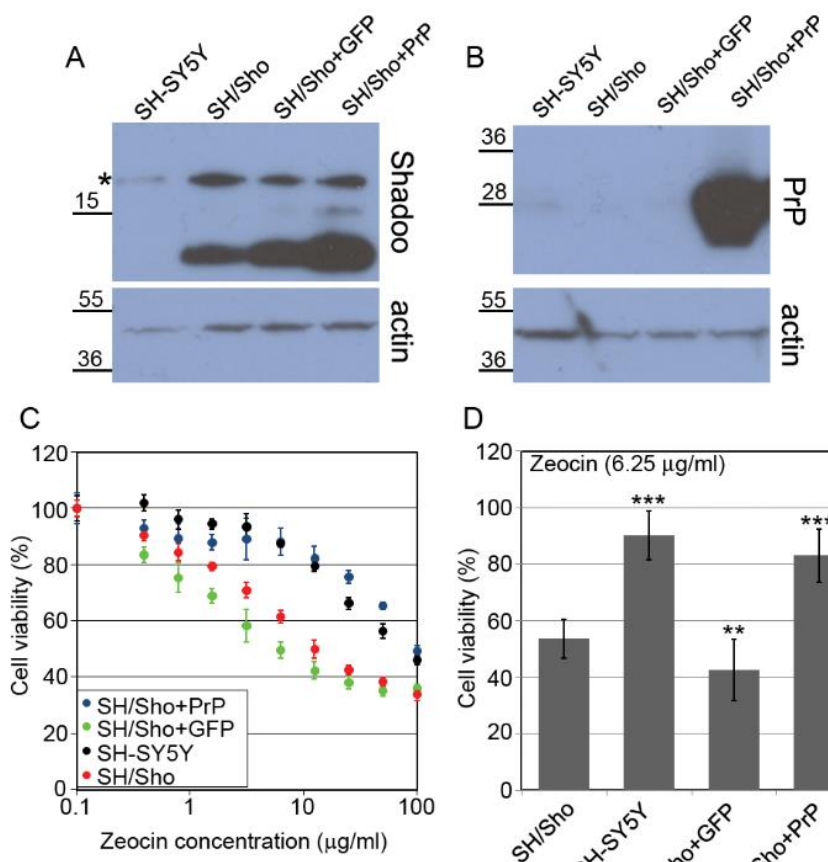

D
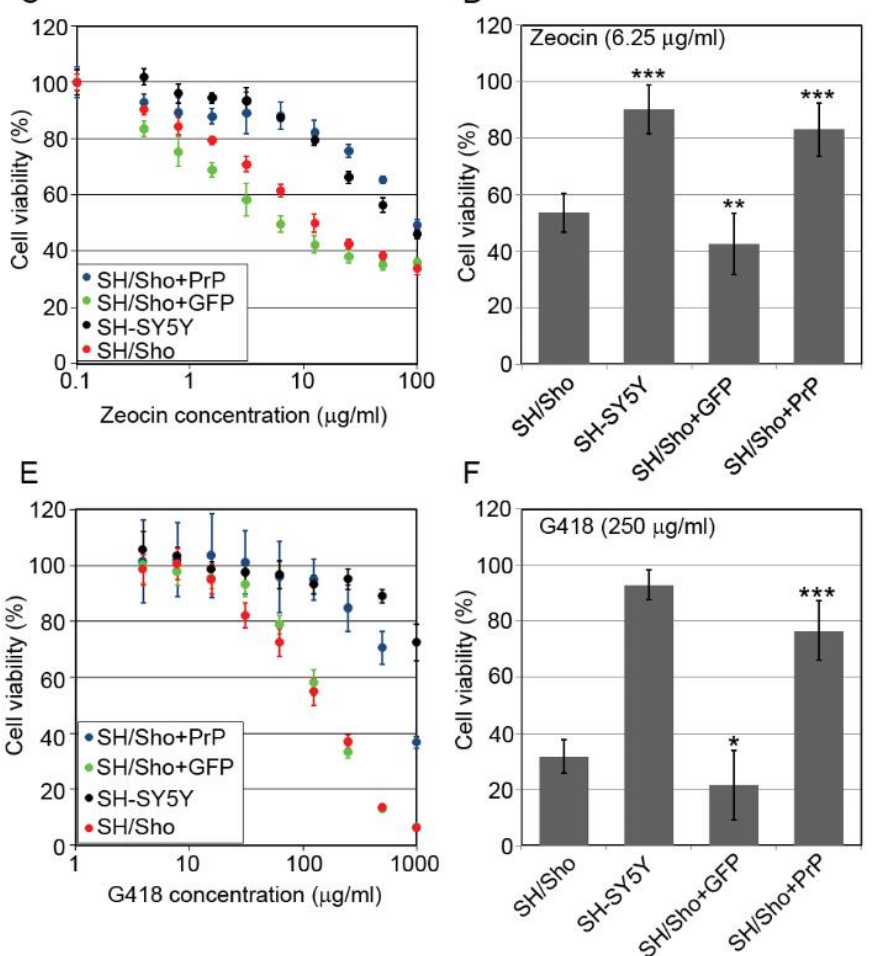
These phenomena were also observed in HEK293 cells. HEK/Sho cells, which overexpress Shadoo protein (Appendix Fig. 17A) were more sensitive to Zeocin (Appendix Fig. 17C, D) or G418 (Appendix Fig. 17 E, F) than HEK/mCh cells and the hypersensitivity to both drugs could be eliminated by the co-expression of wild type PrP (Appendix Fig. 17). It should be mentioned that low endogenous WT-PrP level of HEK293 cells were not able to overcome the sensitizing effect of Shadoo.
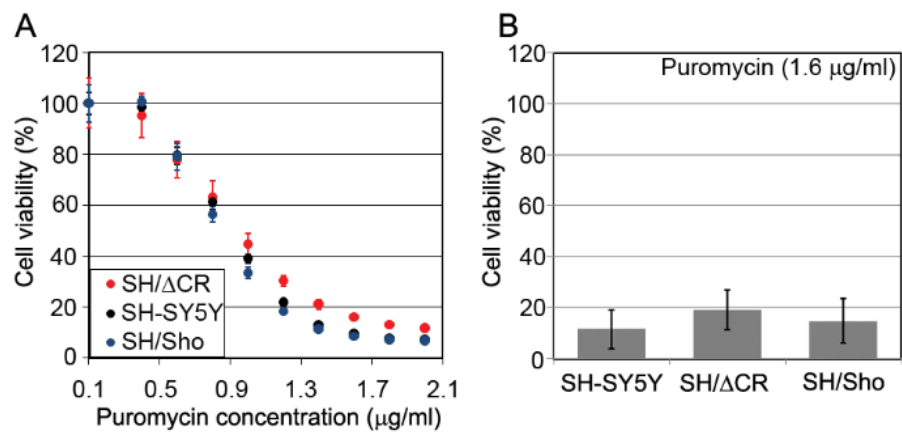

Cytotoxicity assays were carried out by Petra Bencsura.
Figure 12: Neither SH/Sho, nor SH/ACR cells are hypersensitive to puromycin. (A) Representative experiment carried out at puromycin concentrations between $0-2 \mu \mathrm{g} / \mathrm{ml}$ on various cells as indicated. $(24$ hours treatment) (B) Bars show the means \pm S.D. of cell viabilities measured at $1.6 \mu \mathrm{g} / \mathrm{ml}$ puromycin concentration in $n=6$ independent experiments.

To assess the dependency of drug hypersensitivity upon Shadoo expression levels, three subpopulations of SH/Sho cells were generated with low, medium or high Shadoo levels by sorting cells for the related GFP fluorescence (Figure 13A).

The G418 hypersensitivities of the SH/Sho subpopulation correlated to their relative Shadoo expression (Figure 13B, C)

\section{Shadoo, like PrP $\Delta$ CR modulates the initial uptake of Zeocin}

It was shown that PrP $\Delta C R$ increases the initial uptake of drugs (37). In our experiments we investigated whether Shadoo is similar to $\operatorname{PrP} \Delta \mathrm{CR}$ in this respect or not. Zeocin causes double strand breaks in DNA, triggering the recruitment and phosphorylation of Histone 2AX at the break points that can be detected by immunocytochemistry $(37,90)$.

Using High Content Screening (HCS) microscopy we compared the $\gamma$-H2AX positivity in the nuclei of SH/ $\triangle \mathrm{CR}$ and $\mathrm{SH} / \mathrm{Sho}$ cells to their respective controls (SH/GFP and SH/mCherry) after 60 minutes of Zeocin treatment $(0,20$ or $100 \mu \mathrm{g} / \mathrm{ml})$. As a positive control of $\gamma$-H2AX staining 
we used etoposide, a cytotoxic drug that causes double strand breaks by inhibition of DNA religation by topoisomerase II (91).

A

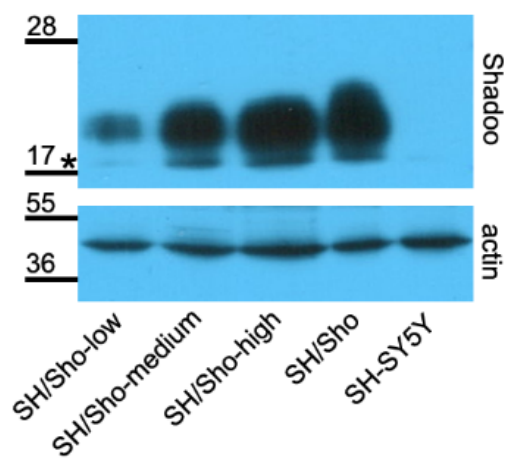

B

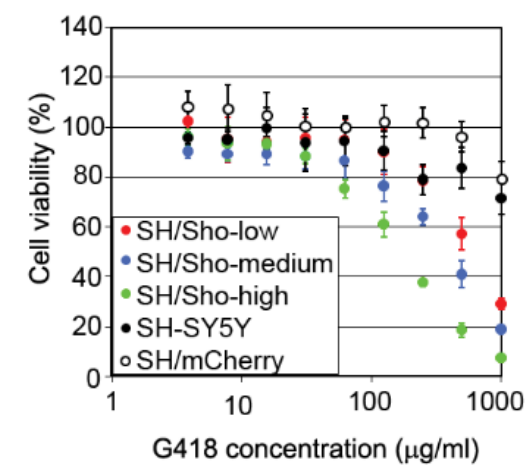

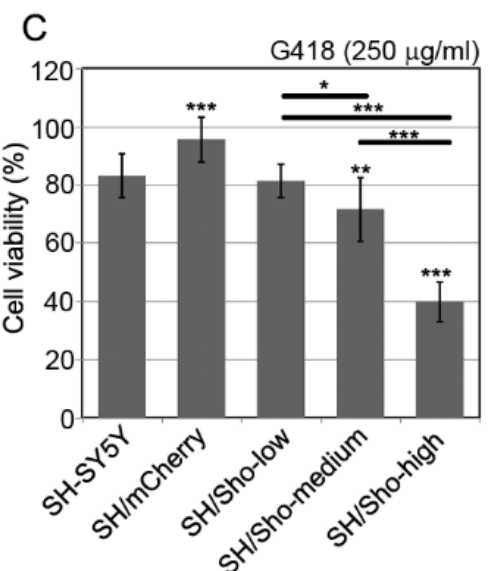

Figure 13: Shadoo induces G418 hypersensitivity in a dose dependent manner (A) Western blot comparison of relative Shadoo protein levels in SH/Sho cell lines sorted by FACS for related GFP levels. Western blot analysis of extracts from SH/Sho-low, SH/Sho-medium, SH/Sho-high as well as the parental SH/Sho and SH-SY5Y cells. * marks a nonspecific band. $\beta$-actin was used as loading control. (B) Cytotoxicity of G418. Representative experiment carried out at G418 concentrations from 0 to $1000 \mu \mathrm{g} / \mathrm{ml}$ on cells with different Shadoo levels. Values are means $\pm S$.D. of corresponding replicas within the experiment. (C) Bars show the

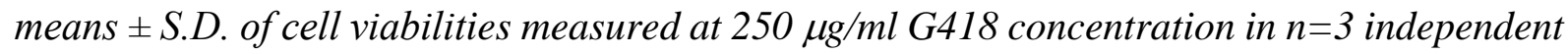
experiments. For testing significance, values were compared to the control, SH-SY5Y cell line and bars connected with brackets were also compared using Tukey's HSD post-hoc test. * $p<0.05, * * p<0.01, * * * p<0.001(B, C) 100 \%$ is the fluorescence values of untreated cells for each cell type. $(B, C)$ Cytotoxicity assays were carried out by Petra Bencsura.

We observed an increased number of $\gamma-\mathrm{H} 2 \mathrm{AX}$ positive nuclei in $\mathrm{SH} / \Delta \mathrm{CR}$ cells compared to SH/GFP cells (Fig. 14A) consistently with earlier reports (37). Similarly, a substantial increase could be seen in the number of $\gamma-\mathrm{H} 2 \mathrm{AX}$ positive nuclei in SH/Sho cells (Fig. 14B), however, this effect was less pronounced in ( 20\% vs. $\sim 50 \% \gamma-\mathrm{H} 2 \mathrm{AX}$ positive nuclei in $\mathrm{SH} / \Delta \mathrm{CR})$. 

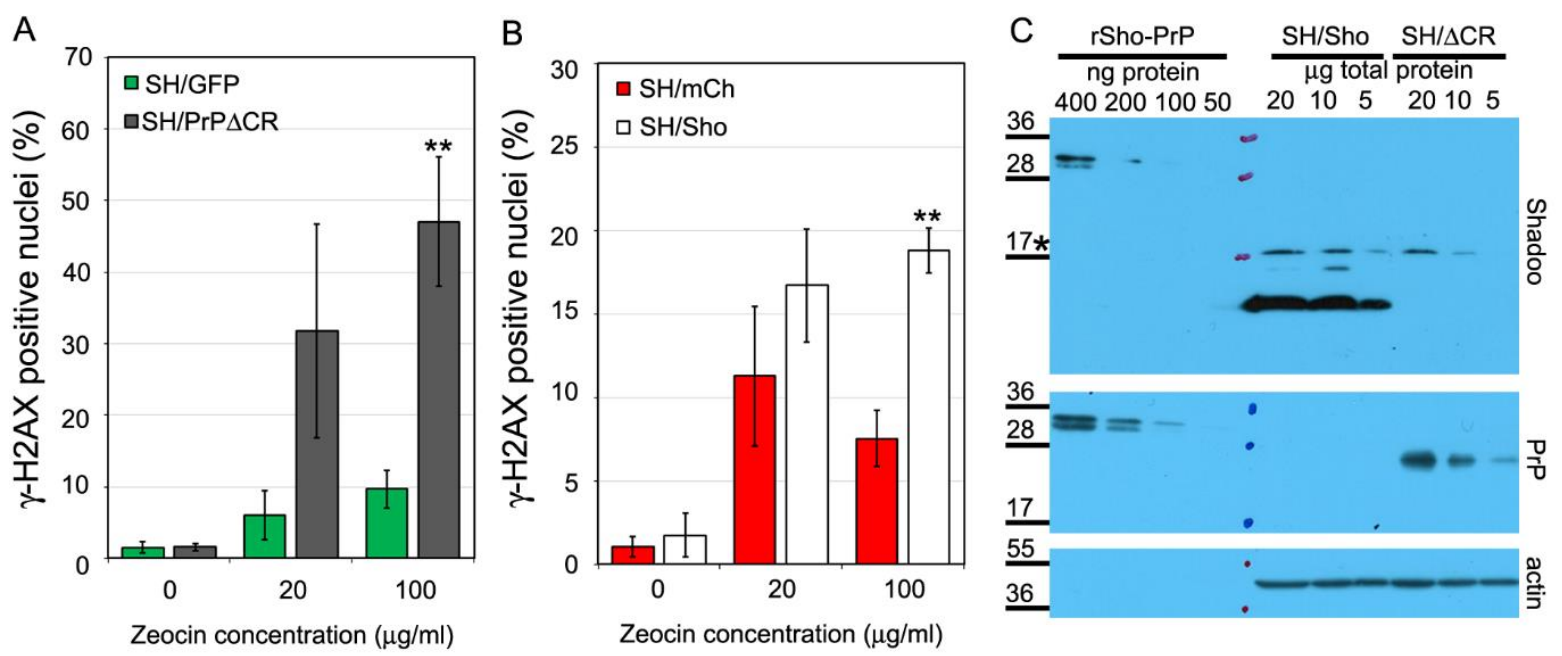

Figure 14: Detection of Histone 2AX-phosphorylation caused by Zeocin treatment. . $(A, B)$ $\gamma-H 2 A X$ positive nuclei was measured relative to total nuclei counted in (A) SH/GFP and $S H / \triangle C R$ or $(B)$ in SH/mCherry and SH/Sho cells, in untreated and Zeocin treated samples (20 or $100 \mu \mathrm{g} / \mathrm{ml}$ for 60 minutes) in $n=3$ independent experiments. $\gamma$-H2AX positivity of cells that received the same treatment was compared with independent samples Student's t-tests. **: $p<0.01$. (C) Comparison of Shadoo and PrP $\Delta C R$ expression in SH/Sho and SH/ACR cells using the rSho-PrP polypeptide. Western blot analysis of serial dilutions made from PNGaseF treated samples of total cell lysates of SH/Sho and SH/ACR and from rSho-PrP polypeptide. * marks a nonspecific band. $\beta$-actin was used as loading control. HCS analysis was carried out by Zoltán Hegyi and Antal Nyeste.

As both Shadoo and $\operatorname{PrP} \Delta \mathrm{CR}$ induce drug hypersensitivities in a dose dependent manner the difference in sensitivities might be caused by a relative low Shadoo expression, thus we compared the levels of Shadoo and PrP $\Delta$ CR in their respective cell lines, using the rSho-PrP fusion peptide and found that Shadoo expression in SH/Sho cells were even higher compared to that of PrP $\Delta \mathrm{CR}$ in SH/ $\triangle \mathrm{CR}$ cells (Fig. 14C). These results suggest that both Shadoo and PrP $\triangle C R$ increase the uptake of Zeocin, although Shadoo might be less effective in this respect.

\section{Searching for important regions of Shadoo protein in drug hypersensitivity effect.}

The $\mathrm{CC} 1$ domain is essential for both toxic and protective activities of the prion protein (38, 92). In order to examine whether the similar, positively charged N-terminal domain of the Shadoo protein [(RXXX $)_{8}$ motif, (69)] is involved in the drug sensitizing activity of the protein, we established SH-SY5Y cells stably expressing either Shadoo mutant lacking the amino acid 
residues from 25 to 61 th $\left[\mathrm{Sho} \Delta(\mathrm{RXXX})_{8}\right]$ or another Shadoo construct where the $(\mathrm{RXXX})_{8}$ arginines were changed to glutamines [Sho $\left.(\mathrm{QXXX})_{8}\right]$.

We found that both Shadoo constructs are correctly localized on the cell surface, attached to the plasma membrane with GPI-anchors (Figure 15A) and that they are N-glycosylated (Figure $15 \mathrm{~B})$. The mobility shift caused by the deletion of the $(\mathrm{RXXX})_{8}$ motif is also detectable after deglycosylation (Figure 15B lanes 2 vs. 3). According to lanes 3, 7 and 11, their expression levels of the $(\mathrm{RXXX})_{8}$ mutant Shadoo constructs were higher than that of the wild type Shadoo.

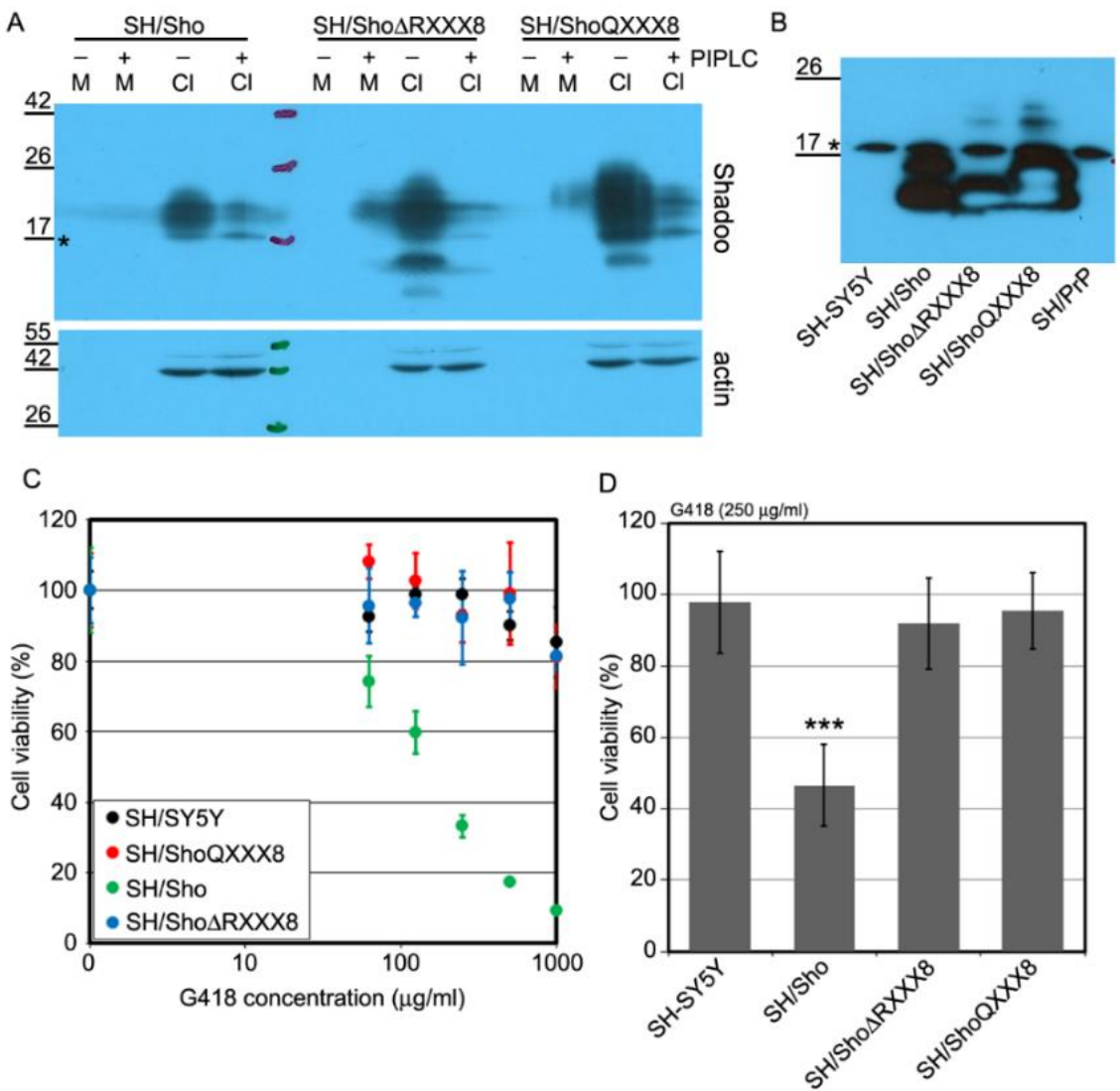

Figure 15. The presence of the $(R X X X)_{8}$ domain is necessary for the drug sensitizing activity of the Shadoo protein. (A) Western blot analysis to investigate the cell surface localization of $(R X X X)_{8}$ domain mutant Sho construct. Cl: Cell lysates, $\mathrm{M}$ : medium from $W T, \Delta(R X X X)_{8}$ and $(Q X X X)_{8}$ Sho expressing cells, incubated with $(+)$ or without (-) PI-PLC (upper panel). An intracellular protein, $\beta$ actin was used as loading control for cell lysates, and as indicator of cellular contamination of medium samples (lower panel). (B) Sho expression in different cell lysates after PNGaseF treatment. * marks a nonspecific band in both panels. (C, D) Cytotoxicity assays by Presto blue after 48 hours of G418 treatment. 100\% is the fluorescence values of untreated controls of each cell line. $(C)$ Concentration dependence of G418 cytotoxicity is shown in a representative experiment in cell types as indicated (D) Differences in the viability of compared cell types was characterized at a selected concentration of G418. Columns show the means \pm S.D. in 3 independent experiments. Samples were compared to $\mathrm{SH}-\mathrm{SY} 5 Y$ cells, *** $p<0.001$.

$(C, D)$ Cytotoxicity assays were carried out by Petra Bencsura and Antal Nyeste. 
After 48 hours treatment with G418 SH-SY5Y cells expressing either (RXXX)8 mutant Sho constructs showed no elevated sensitivity to the drug, compared to the parental SH-SY5Y cells, while cells expressing wild type Shadoo were significantly more sensitive (Figure 15C, D).

The importance of the Hydrophobic Domain (HD) was studied also by the expression of a Shadoo construct lacking HD motif (62-77th amino acids; Sho $\Delta$ HD) in SH-SY5Y (SH/Sho $\Delta$ HD), and by another Shadoo construct in which HD (amino acids 62-77) was replaced by the PrP HD motif (amino acids 113-133) [Sho(PrPHD)]. We found both proteins were correctly localized at the cell surface by a GPI-anchor (Figure 16A, C) and both were complex $\mathrm{N}$-glycosylated (Figure 16B, D), although, Sho $\Delta$ HD expression was significantly lower than that of the WT Shadoo (Fig. 16A lanes 1 vs. 3).

We detected increased sensitivity to G418 in cells expressing Sho $\Delta \mathrm{HD}$ (similar to SH/Sho) despite its low expression, but the replacement of Sho HD to PrP HD suppressed greatly the sensitizing effect (Figure 16 C, D). Slight hypersensitivities could be observed only at the two highest concentration of G418.

Our results therefore suggested that the arginines in the $\mathrm{N}$-terminal $(\mathrm{RXXX})_{8}$ motif are necessary for the drug sensitizing activity of the Shadoo protein but the presence of the Hydrophobic Domain (HD) is not required. 

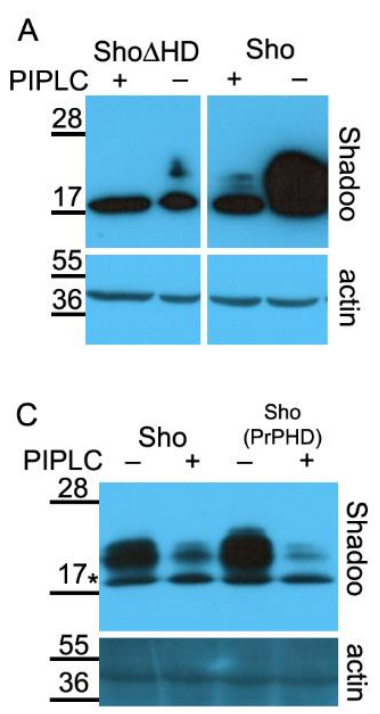

E

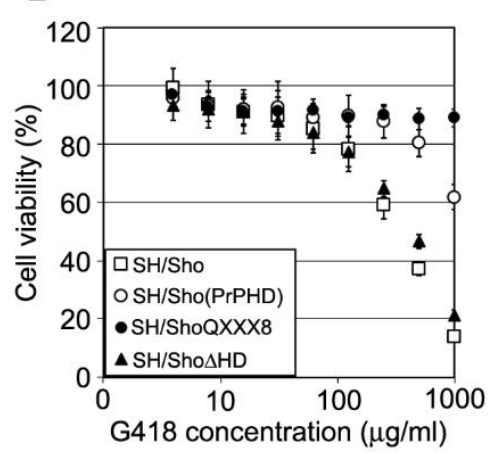

B

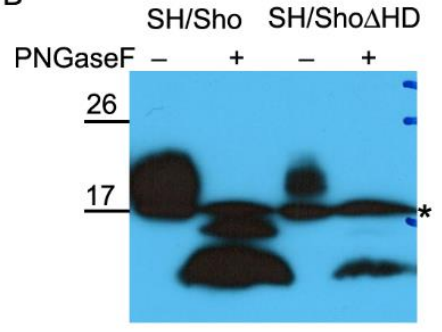

D

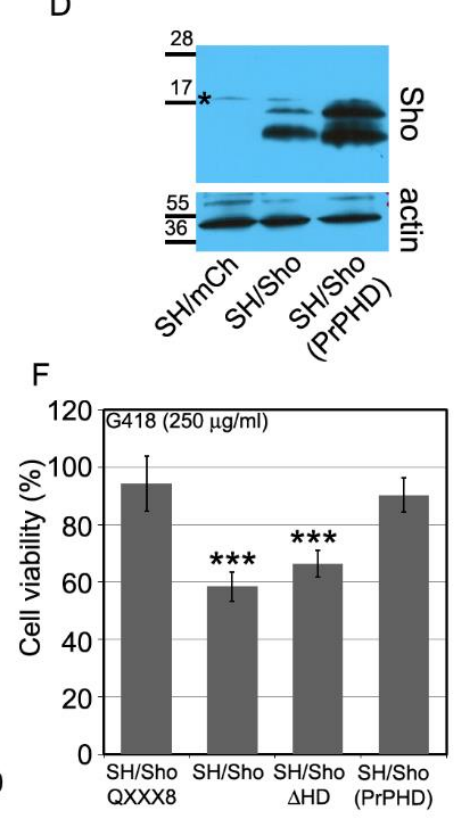

Figure 16. The hydrophobic domain (HD) of the Shadoo protein isn't necessary for the drug sensitizing activity but modulates the effect. A: Western blot analysis of Sho $\triangle H D$ cell surface localization. Cell lysates from $W T$ and $\triangle H D$ Sho expressing $\mathrm{SH}-\mathrm{SY} 5 \mathrm{Y}$ cells, were incubated with (+) or without (-) PI-PLC (upper panel). An intracellular protein, $\beta$-actin was used as loading control for cell lysates (lower panel). Left and right panels are from the same $X$ ray film, corresponding to the left and right parts of the same membrane. (B) Western blot analysis Shadoo glycosylation in WT or $\triangle H D$ Sho expressing $\mathrm{SH}$ SY5Y cell lysates treated (+) or not treated (-) with PNGaseF. (C) Western blot analysis of Sho(PrPHD) construct cell surface localization. Cell lysates from WT and Sho(PrPHD) expressing SH-SY5Y cells,

incubated with (+) or without (-) PI-PLC (upper panel). An intracellular protein, $\beta$-actin was used as loading control for cell lysates (lower panel). (D) Western blot analysis Shadoo glycosylation in WT Sho or Sho(PrPHD) expressing SH-SY5Y cell lysates treated with PNGaseF. (A-D) * marks a nonspecific band. $(C, D)$ Cytotoxicity assays by Presto blue after 48 hours of G418 treatment. 100\% is the fluorescence values of untreated controls of each cell line. $(C)$ Concentration dependence of $G 418$ cytotoxicity is shown in a representative experiment in cell types as indicated (D) Differences in the viability of compared cell types were characterized at a selected concentration of G418. Columns show the means \pm S.D. in 3 independent experiments. Samples were compared to SH/ShoQXXX8 cells, *** $p<0.001$.

$(E, F)$ Cytotoxicity assays on $S H / S h o(Q X X X) 8$ and $S h o(P r P H D)$ were carried out by Petra Bencsura and Antal Nyeste. 


\section{Discussion}

Almost a century passed since the discovery of the Creutzfeldt-Jacob Disease, but fundamental questions, such as how does the $\operatorname{PrP}^{\mathrm{C}}-\operatorname{PrP}^{\mathrm{Sc}}$ conversion contribute to the neurodegeneration in various forms of transmissible spongiform encephalopathies remained unanswered.

Several pieces of evidence (18-21) support a hypothesis suggesting that the TSE-associated neurodegeneration is caused neither by the loss of a vital function of the $\operatorname{PrP}^{\mathrm{C}}$ nor by $\operatorname{PrP}^{\mathrm{Sc}}$ merely gaining a novel, toxic function, but probably by the subversion or corruption of a nontoxic function of the prion protein that leads to neurotoxic phenotype. Therefore investigating the numerous functions of the WT PrP and its mutants - especially those activities that participate in toxic or protective processes - might help to elucidate the role of this protein in the mechanism of neurodegeneration in TSE.

In this work we established cell culture models that enabled us to investigate the protective and toxic characteristics associated with prion protein expression.

\section{Effects of WT and $\triangle C R$ PrP on serum deprivation caused cell death}

There are several reports about the $\operatorname{PrP}^{\mathrm{C}}$ cytoprotective activity, that prevents the oxidative stress or serum deprivation caused death of neurons and other cells $(46,47,88,93,94)$. It is also known that in TSE an increased oxidative stress occurs (95). All this suggests an impaired or altered protective function of the prion protein that possibly lead to neurodegeneration.

Contrary to the published data about the cytoprotective activity of $\operatorname{PrP}^{\mathrm{C}}$, we could not detect protection against serum deprivation conferred by the wild type prion protein when the protein was expressed in immortalized hippocampal-originated cell line.

Although different cell types used in different studies may explain the observed differences our results are in line with a report where no robust cytoprotective effect of PrP was found in a similar cell culture model (96).

While in our model WT PrP offered no protection, we found that the presence of PrP $\Delta C R$ increased the sensitivity of the cells to serum deprivation. Although this sensitizing effect was 
statistically significant and reproducible, it wasn't too robust (about $15 \%$ decrease from day 0 to day 3$)$.

The exact role of the $\mathrm{PrP}$ in the serum deprivation sensitivity of $\mathrm{Zpl}$ cells and effect of the examined deletion mutation in the protein is still not clear and further investigation is needed.

\section{Drug hypersensitivity caused by $\operatorname{PrP} \Delta \mathrm{CR}$ and Shadoo}

Shadoo and PrPACR cause drug hypersensitivity by a similar mechanisms of action.

Expression of prion protein variants lacking the central region or hydrophobic domains have been associated with harmful phenotypes in animal or cell culture models in the absence of wild type PrP. Even though the expression of these mutants causes severe toxicity in $\operatorname{PrP}$ null transgenic mice $(33-35)$ and in CGN cultures $(64,97)$, they show reduced effect $(43,98)$, or no effect $(42,96)$ when expressed in immortalized cell lines. The most obvious phenotype associated with the Shmerling or $\Delta \mathrm{CR}$ mutations in PrP-s in cell models is the drug hypersensitivity and the occurrence of spontaneous inward cationic currents $(37,39)$. Strong evidence supports that the same functional changes of $\operatorname{PrP} \Delta \mathrm{CR}$ is behind these two phenotypes detected in different models (40).

Shadoo is generally regarded as an analogue of the N-terminal domain of the WT PrP, showing similar cytoprotective features $(43,64)$ in models for exploration of the toxic and protective functions of the PrP.

In the drug hypersensitivity model, however, we have found that Shadoo, instead of elimination of the $\operatorname{PrP} \triangle \mathrm{CR}$ induced phenotype also increased drug hypersensitivity in a dose dependent manner which could be eliminated by co-expression of WT PrP in the cells similarly to the $\operatorname{PrP} \triangle \mathrm{CR}$ induced alterations.

The drug sensitizing effects of Shadoo and $\operatorname{PrP} \Delta \mathrm{CR}$ proteins share further features, such as increased initial drug uptake or the similar drug selectivity of these proteins (Zeocin or G418, but not to puromycin). Furthermore, in our preliminary patch clamping experiments, Shadoo expression induced inward ionic currents similarly to PrP $\Delta \mathrm{CR}$ (data not shown).

These similarities suggest overlapping mechanisms of action behind the analogous functions of the Shadoo and $\operatorname{PrP} \Delta \mathrm{CR}$, which is surprising, as the two proteins are sequentially different: 
the only region that shows sequential homology between the Shadoo and $\operatorname{PrP} \Delta \mathrm{CR}$ (hydrophobic domain) is missing from the latter one.

It must be also noted that Zeocin uptake was less efficient in Shadoo expressing cells, even though Sho expression level was higher than that of PrP $\Delta$ CR in the parallel SH/ $\Delta C R$ cells suggesting that the drug sensitizing functions of Shadoo and $\operatorname{PrP} \Delta \mathrm{CR}$ are related but not identical.

Similar differences were found between the effects of Shmerling mutant (PrP $\Delta 32-121$ and $\operatorname{PrP} \Delta 32-134)$ and $\Delta \mathrm{CR}$ PrP-s in multiple models. Shmerling and $\Delta \mathrm{CR}$ mutants of the PrP exhibit related neurotoxic phenotypes in mice, but both the severity and the relative amount of coexpressed $\operatorname{PrP}^{\mathrm{C}}$ is different that is required to eliminate the toxicity. Furthermore Massignan and colleagues demonstrated that this difference between the various PrP mutants also exists in the drug sensitizing paradigm: PrP $\Delta$ CR causes more severe drug hypersensitivity than Shmerling mutant PrP-s at similar expression levels (37).

\section{Importance of the $(R X X X)_{8}$ motif in the drug sensitizing function of Shadoo}

The $(\mathrm{RXXX})_{8}$ domain of the Shadoo is similar to the N-terminal charged cluster $(\mathrm{CC} 1)$ of the $\mathrm{PrP}$ in respect of bearing several positively charged residues, although in the $(\mathrm{RXXX})_{8}$ domain the positive charges are not as stacked as in the $\mathrm{CC} 1$, but more spread out along the $\mathrm{N}$ terminus of the protein.

$\mathrm{CC} 1$ is conserved from bird to mammals and was demonstrated to be essential for both protective and toxic phenotypes caused by the protein $(38,92)$, its deletion didn't render the protein toxic, but disrupted both protective and toxic activities of the WT or $\Delta \mathrm{CR} \operatorname{PrP}$.

The role of $(\mathrm{RXXX})_{8}$ in the protective functions of the Shadoo protein hasn't been explored, but this domain was found to be highly conserved among species and also being required of the nuclear accumulation of the Shadoo protein (69).

Although in our experiments Shadoo mutants lacking the $(\mathrm{RXXX})_{8}$ motif or when arginines of this domain replaced with glutamines had correct cell surface localization and glycosylation (as inferred by western blotting of PIPLC or PNGaseF treated samples), we found that cells 
expressing these constructs exhibited no drug hypersensitivity, supporting the importance of the positively charged $(\mathrm{RXXX})_{8}$ domain in the drug sensitizing function of the Shadoo.

The PrP CC1 was described to be able to bind glycosaminoglycans (GAGs) and also act as a protein transduction domain (PTD) $(40,99)$. Based on their previous findings of drug hypersensitivity and spontaneous ionic currents, and the PTD activity of the CC1 domain, the Harris-group proposed a model where $\operatorname{PrP} \Delta \mathrm{CR}$ is able to form transmembrane pores, through which such elevated uptake of drugs and spontaneous inward cationic currents may occur (40, 99).

There is no data in the literature about any GAG-binding or PTD-like activities of the $(\mathrm{RXXX})_{8}$ domain. Since its function is currently unknown, further studies required to reveal a potential role in the pore forming mechanism.

\section{Importance of the hydrophobic domain of Shadoo in drug sensitization}

In previous studies it was demonstrated that the presence of the HD is required for various protective effects of the Shadoo, such as protection against toxicity of $\operatorname{PrP} \Delta 32-121$, or Doppel in CGN cultures (64) or against glutamate toxicity (43). This domain also acts as an interface of PrP binding $(43,100)$, and shows the highest sequential similarity to the analogous region of PrP.

Our finding that the absence of the HD didn't eliminate the sensitizing effect of the Shadoo protein, suggests that the Shadoo HD doesn't play any essential role in the drug sensitizing function of the protein however its replacement with the prion protein HD greatly reduced this sensitizing effect. It raises the question, what is the difference between the behaviour of the two HD-s?

PrP only exhibits ion channel forming activities, when the HD is removed from the protein, which suggests an inhibitory function of the PrP HD to this activity.

As the decreased drug hypersensitivity in Sho(PrPHD) expressing cells cannot be explained by the impaired localization or posttranslational modification of the Sho(PrPHD), one can hypothesise that the differing drug sensitizing functions of WT Shadoo and Sho(PrPHD) expressing cells originate only in a difference between the HD-s of Shadoo and PrP. For 
example, Shadoo HD may be an imperfect, "loss-of- function" PrP HD analogue that is not able to completely inhibit or keep the drug sensitizing/ionic current forming activities of the protein under control.

Sho HD has no role in the inhibition of the drug sensitizing function of Shadoo, but if this domain has any other role related to this phenomenon is yet to be examined.

\section{Consequences of Shadoo-induced drug hypersensitivity}

Our finding that Shadoo (similarly to $\operatorname{PrP} \Delta \mathrm{CR}$ ) induces drug hypersensitivity is surprising and raises further questions. Among them the most interesting ones is how these phenotypes caused by Shadoo or PrP $\Delta$ CR relate to the other toxic activities of the prion family members, and to the neurodegeneration occurring in TSE and AD?

$\underline{\text { Relation with other PrP } \Delta \mathrm{CR} \text { associated toxic phenotypes }}$

In the drug hypersensitivity model, Shadoo behaves similar to $\operatorname{PrP} \Delta \mathrm{CR}$. Instead of suppressing the deleterious effect of the toxic PrP mutant as Sho does in other models akin to WT PrP, it also causes drug hypersensitivity. This difference suggests that this activity of $\operatorname{PrP} \triangle \mathrm{CR}$ is not related to other toxic phenotypes caused by it in transgenic PrP-null animal or CGN cultures.

\section{$\underline{\text { Relation with neurodegeneration occurring in TSE-S }}$}

A handful PrP variants harbouring certain familial GSS or CJD-related point mutations in the $\mathrm{CC} 2$ or HD exhibit both of the drug sensitizing and ionic current generating activities (39, 40). One of them is P101L, the mouse variant of the most common GSS-causing mutation of human PrP (P102L PrP) (101). Transgenic mice expressing P101L PrP on $\mathrm{PrP}^{+/+}$background (with about 8:1 P101L:WT PrP ratio) develop spontaneous neurological dysfunctions and spongiform degeneration of brain tissue reminiscent of TSE. Extracellular amyloid plaques are present in the brains of these mice, but PK-resistant PrP is not detectable (102). Note that similar phenotype was described in human GSS caused by P102L mutation, where clinical signs of neurodegeneration was present without any detectable PK-resistant $\mathrm{PrP}^{\mathrm{Sc}}$ (103).

Interestingly, the expression of $\mathrm{P} 101 \mathrm{~L} \operatorname{PrP}$ on $\mathrm{PrP}^{0 / 0}$ background exhibited spontaneous clinical signs earlier in mice (102), suggesting a suppressing role of $\operatorname{PrP}^{\mathrm{C}}$ in the GSS animal 
model, thus supporting a hypothesis that the function of the mutant PrP that manifests in increased drug sensitivity and inward cationic currents is probably behind some of the symptoms of GSS caused by certain mutations in PrP.

While endogenous Shadoo protein level is dramatically decreased in some TSE-brains, the brain of P101L PrP expressing mice shows minimal decrease in Shadoo protein level (70), suggesting that unlike in other forms of TSE-s, Shadoo is present and thus has a chance to become involved in the P102L-caused GSS pathogenesis but whether it has any relevance in neurodegeneration occurring in that disease is yet to be found out.

\section{$\underline{\text { Relation to prnp null phenotypes in mice }}$}

There is one more important aspect of the drug sensitizing/ionic current forming activity of Shadoo. If these activities of Shadoo and $\operatorname{PrP} \Delta \mathrm{CR}$ are really related to one other and to some forms of GSS pathogenesis, then Shadoo expressing prnp-knockout mice should also exhibit some overt phenotypes. Contrarily to this, PrP null mice are viable and without such phenotype (104) but they show minor abnormalities $(25,26)$. It must be noted that endogenous Shadoo expression level is thought to be much lower than that of $\operatorname{PrP}$, which might also contribute to the absence of a clear phenotype.

Whether such abnormalities are related to the Shadoo expression on PrP null background has been examined only in case of the axonal demyelination, where it was found that the phenotype was not related to Shadoo (87). Whether the untested phenotypes are related to Shadoo expression or not, could be tested by crossing Shadoo-overexpressing mice (70) to a prnp-knockout background.

Last, but not least, one must consider that it is very unlikely that Shadoo would have remained as such conserved protein as it is with a potentially toxic and uncontrolled function like the drug sensitizing/ionic current forming activity. Because of this it would be highly illuminating to understand its purpose under physiological condition and to understand the mechanisms that participate in the regulation of this function. 


\section{Summary of new findings}

\section{Serum deprivation model}

1. We detected no protection provided by WT PrP against the apoptosis caused by serum deprivation.

2. While PrP $\Delta$ CR expression wasn't lethal or toxic in Zpl2-1 cells, it made the cells slightly more sensitive to serum deprivation than control cells were.

\section{Drug hypersensitivity model}

1. We found that Shadoo induces hypersensitivity to Zeocin and G418 but not to puromycin in cells overexpressing the protein.

2. Our results suggest that the mechanisms behind Shadoo and $\operatorname{PrP} \Delta \mathrm{CR}$-induced drug hypersensitivities are closely related.

2.1. Shadoo and $\operatorname{PrP} \Delta \mathrm{CR}$ sensitizes cells to identical antibiotics (Zeocin and G418 but not puromycin) in a dose dependent manner.

2.2. Wild type PrP interferes with the G418 and Zeocin hypersensitivity caused by both Shadoo and PrP $\Delta$ CR in SH-SY5Y and HEK293 cell cultures.

2.3. Shadoo increases the initial drug uptake of the cell akin to $\operatorname{PrP} \Delta \mathrm{CR}$ but with a lower efficiency.

3. We identified a region of the mature Shadoo protein, the $(\mathrm{RXXX})_{8}$ domain whose presence is essential for the drug-sensitizing activity of the Shadoo protein. 


\section{References}

1. Blesa, J., Phani, S., Jackson-Lewis, V., and Przedborski, S. (2012) Classic and new animal models of Parkinson's disease. J. Biomed. Biotechnol. 2012, 845618

2. 2015 Alzheimer's disease facts and figures. (2015) Alzheimers. Dement. 11, 332-84

3. Liberski, P. P., Brown, D. R., Sikorska, B., Caughey, B., and Brown, P. (2008) Cell death and autophagy in prion diseases (transmissible spongiform encephalopathies). Folia Neuropathol. 46, 1-25

4. Gajdusek, D. C., Gibbs, C. J., and Alpers, M. (1967) Transmission and passage of experimenal "kuru" to chimpanzees. Science. 155, 212-4

5. McAlister, V. (2005) Sacred disease of our times: failure of the infectious disease model of spongiform encephalopathy. Clin. Investig. Med. Médecine Clin. Exp. 28 , $101-4$

6. Wilesmith, J. W., Wells, G. A., Cranwell, M. P., and Ryan, J. B. (1988) Bovine spongiform encephalopathy: epidemiological studies. Vet. Rec. 123, 638-44

7. Aguzzi, A., Heikenwalder, M., and Polymenidou, M. (2007) Insights into prion strains and neurotoxicity. Nat. Rev. Mol. Cell Biol. 8, 552-61

8. Bateman, D., Hilton, D., Love, S., Zeidler, M., Beck, J., and Collinge, J. (1995) Sporadic Creutzfeldt-Jakob disease in a 18-year-old in the UK. Lancet (London, England). 346, 1155-6

9. Belay, E. D., and Schonberger, L. B. (2002) Variant Creutzfeldt-Jakob disease and bovine spongiform encephalopathy. Clin. Lab. Med. 22, 849-62, v-vi

10. "Slow virus" in Kuru? (1966) Br. Med. J. 1, 996-7

11. Prusiner, S. B. (1998) Prions. Proc. Natl. Acad. Sci. U. S. A. 95, 13363-13383

12. Safar, J. G., Kellings, K., Serban, A., Groth, D., Cleaver, J. E., Prusiner, S. B., and Riesner, D. (2005) Search for a prion-specific nucleic acid. J. Virol. 79, 10796-806

13. Ford, M. J., Burton, L. J., Morris, R. J., and Hall, S. M. (2002) Selective expression of prion protein in peripheral tissues of the adult mouse. Neuroscience. 113, 177-92

14. Aguzzi, A., and Polymenidou, M. (2004) Mammalian prion biology: one century of evolving concepts. Cell. 116, 313-27

15. Rivera-Milla, E., Oidtmann, B., Panagiotidis, C. H., Baier, M., Sklaviadis, T., Hoffmann, R., Zhou, Y., Solis, G. P., Stuermer, C. A. O., and Málaga-Trillo, E. (2006) Disparate evolution of prion protein domains and the distinct origin of Doppel- and prion-related loci revealed by fish-to-mammal comparisons. FASEB J. 20, 317-9 
16. Solforosi, L., Bellon, A., Schaller, M., Cruite, J. T., Abalos, G. C., and Williamson, R. A. (2007) Toward molecular dissection of PrPC-PrPSc interactions. J. Biol. Chem. 282, $7465-71$

17. Requena, J. R., and Wille, H. The structure of the infectious prion protein: experimental data and molecular models. Prion. 8, 60-6

18. Büeler, H., Aguzzi, a, Sailer, a, Greiner, R. a, Autenried, P., Aguet, M., and Weissmann, C. (1993) Mice devoid of PrP are resistant to scrapie. Cell. 73, 1339-47

19. Mallucci, G., Dickinson, A., Linehan, J., Klöhn, P.-C., Brandner, S., and Collinge, J. (2003) Depleting neuronal PrP in prion infection prevents disease and reverses spongiosis. Science. 302, 871-4

20. Brandner, S., Isenmann, S., Raeber, A., Fischer, M., Sailer, A., Kobayashi, Y., Marino, S., Weissmann, C., and Aguzzi, A. (1996) Normal host prion protein necessary for scrapie-induced neurotoxicity. Nature. 379, 339-343

21. McNally, K. L., Ward, A. E., and Priola, S. A. (2009) Cells expressing anchorless prion protein are resistant to scrapie infection. J. Virol. 83, 4469-75

22. Richt, J. a, Kasinathan, P., Hamir, A. N., Castilla, J., Sathiyaseelan, T., Vargas, F., Sathiyaseelan, J., Wu, H., Matsushita, H., Koster, J., Kato, S., Ishida, I., Soto, C., Robl, J. M., and Kuroiwa, Y. (2007) Production of cattle lacking prion protein. Nat. Biotechnol. 25, 132-8

23. Büeler, H., Fischer, M., Lang, Y., Bluethmann, H., Lipp, H. P., DeArmond, S. J., Prusiner, S. B., Aguet, M., and Weissmann, C. (1992) Normal development and behaviour of mice lacking the neuronal cell-surface PrP protein. Nature. 356, 577-582

24. Aguzzi, A., Baumann, F., and Bremer, J. (2008) The prion's elusive reason for being. Annu. Rev. Neurosci. 31, 439-77

25. Le Pichon, C. E., Valley, M. T., Polymenidou, M., Chesler, A. T., Sagdullaev, B. T., Aguzzi, A., and Firestein, S. (2009) Olfactory behavior and physiology are disrupted in prion protein knockout mice. Nat. Neurosci. 12, 60-9

26. Criado, J. R., Sánchez-Alavez, M., Conti, B., Giacchino, J. L., Wills, D. N., Henriksen, S. J., Race, R., Manson, J. C., Chesebro, B., and Oldstone, M. B. a (2005) Mice devoid of prion protein have cognitive deficits that are rescued by reconstitution of $\operatorname{PrP}$ in neurons. Neurobiol. Dis. 19, 255-65

27. Bremer, J., Baumann, F., Tiberi, C., Wessig, C., Fischer, H., Schwarz, P., Steele, A. D., Toyka, K. V, Nave, K.-A., Weis, J., and Aguzzi, A. (2010) Axonal prion protein is required for peripheral myelin maintenance. Nat. Neurosci. 13, 310-8

28. Kretzschmar, H., Stowring, L. E., Westaway, D., Stubblebine, W. H., Prusiner, S. B., and Dearmond, S. J. (1986) Molecular cloning of a human prion protein cDNA. DNA. 5, 315-24 
29. Watts, J. C., Huo, H., Bai, Y., Ehsani, S., Jeon, A. H. W., Won, A. H., Shi, T., Daude, N., Lau, A., Young, R., Xu, L., Carlson, G. a, Williams, D., Westaway, D., and Schmitt-Ulms, G. (2009) Interactome analyses identify ties of PrP and its mammalian paralogs to oligomannosidic $\mathrm{N}$-glycans and endoplasmic reticulum-derived chaperones. PLoS Pathog. 5, e1000608

30. Béland, M., and Roucou, X. (2012) The prion protein unstructured N-terminal region is a broad-spectrum molecular sensor with diverse and contrasting potential functions. $J$. Neurochem. 120, 853-858

31. Taylor, D. R., and Hooper, N. M. (2007) The low-density lipoprotein receptor-related protein 1 (LRP1) mediates the endocytosis of the cellular prion protein. Biochem. $J$. 402, 17-23

32. Chen, S. G., Teplow, D. B., Parchi, P., Teller, J. K., Gambetti, P., and Autilio-

Gambetti, L. (1995) Truncated forms of the human prion protein in normal brain and in prion diseases. J. Biol. Chem. 270, 19173-80

33. Flechsig, E., Hegyi, I., Leimeroth, R., Zuniga, A., Rossi, D., Cozzio, A., Schwarz, P., Rülicke, T., Götz, J., Aguzzi, A., and Weissmann, C. (2003) Expression of truncated PrP targeted to Purkinje cells of PrP knockout mice causes Purkinje cell death and ataxia. EMBO J. 22, 3095-101

34. Li, A., Christensen, H. M., Stewart, L. R., Roth, K. A., Chiesa, R., and Harris, D. A. (2007) Neonatal lethality in transgenic mice expressing prion protein with a deletion of residues 105-125. EMBO J. 26, 548-58

35. Baumann, F., Tolnay, M., Brabeck, C., Pahnke, J., Kloz, U., Niemann, H. H., Heikenwalder, M., Rülicke, T., Bürkle, A., and Aguzzi, A. (2007) Lethal recessive myelin toxicity of prion protein lacking its central domain. EMBO J. 26, 538-47

36. Shmerling, D., Hegyi, I., Fischer, M., Blättler, T., Brandner, S., Götz, J., Rülicke, T., Flechsig, E., Cozzio, A., von Mering, C., Hangartner, C., Aguzzi, A., and Weissmann, C. (1998) Expression of amino-terminally truncated PrP in the mouse leading to ataxia and specific cerebellar lesions. Cell. 93, 203-14

37. Massignan, T., Stewart, R. S., Biasini, E., Solomon, I. H., Bonetto, V., Chiesa, R., and Harris, D. A. (2010) A novel, drug-based, cellular assay for the activity of neurotoxic mutants of the prion protein. J. Biol. Chem. 285, 7752-65

38. Westergard, L., Turnbaugh, J. A., and Harris, D. A. (2012) A Nine Amino Acid Domain is Essential for Mutant Prion Protein Toxicity. J. Neurosci. 31, 617-638

39. Solomon, I. H., Huettner, J. E., and Harris, D. A. (2010) Neurotoxic mutants of the prion protein induce spontaneous ionic currents in cultured cells. J. Biol. Chem. 285, 26719-26

40. Solomon, I. H., Biasini, E., and Harris, D. A. (2012) Ion channels induced by the prion protein. Prion. 6, 40-45 
41. Li, A., Barmada, S. J., Roth, K. a, and Harris, D. A. (2007) N-terminally deleted forms of the prion protein activate both Bax-dependent and Bax-independent neurotoxic pathways. J. Neurosci. 27, 852-9

42. Biasini, E., Unterberger, U., Solomon, I. H., Massignan, T., Senatore, A., Bian, H., Voigtlaender, T., Bowman, F. P., Bonetto, V., Chiesa, R., Luebke, J., Toselli, P., and Harris, D. A. (2013) A mutant prion protein sensitizes neurons to glutamate-induced excitotoxicity. J. Neurosci. 33, 2408-18

43. Sakthivelu, V., Seidel, R. P., Winklhofer, K. F., and Tatzelt, J. (2011) Conserved stress-protective activity between prion protein and Shadoo. J. Biol. Chem. 286, 89018

44. Weise, J., Sandau, R., Schwarting, S., Crome, O., Wrede, A., Schulz-Schaeffer, W., Zerr, I., and Bähr, M. (2006) Deletion of cellular prion protein results in reduced Akt activation, enhanced postischemic caspase-3 activation, and exacerbation of ischemic brain injury. Stroke. 37, 1296-300

45. Brown, D. R., Wong, B. S., Hafiz, F., Clive, C., Haswell, S. J., and Jones, I. M. (1999) Normal prion protein has an activity like that of superoxide dismutase. Biochem. J. 344(Pt 1), 1-5

46. Kim, B.-H., Lee, H.-G., Choi, J.-K., Kim, J.-I., Choi, E.-K., Carp, R. I., and Kim, Y.-S. (2004) The cellular prion protein (PrPC) prevents apoptotic neuronal cell death and mitochondrial dysfunction induced by serum deprivation. Brain Res. Mol. Brain Res. 124, 40-50

47. Oh, J.-M., Shin, H.-Y., Park, S.-J., Kim, B.-H., Choi, J.-K., Choi, E.-K., Carp, R. I., and Kim, Y.-S. (2008) The involvement of cellular prion protein in the autophagy pathway in neuronal cells. Mol. Cell. Neurosci. 39, 238-47

48. Brown, D. R., Qin, K., Herms, J. W., Madlung, A., Manson, J., Strome, R., Fraser, P. E., Kruck, T., von Bohlen, A., Schulz-Schaeffer, W., Giese, A., Westaway, D., and Kretzschmar, H. (1997) The cellular prion protein binds copper in vivo. Nature. 390, 684-7

49. Brown, D. R., Clive, C., and Haswell, S. J. (2001) Antioxidant activity related to copper binding of native prion protein. J. Neurochem. 76, 69-76

50. Biasini, E., Turnbaugh, J. A., Massignan, T., Veglianese, P., Forloni, G., Bonetto, V., Chiesa, R., and Harris, D. A. (2012) The toxicity of a mutant prion protein is cellautonomous, and can be suppressed by wild-type prion protein on adjacent cells. PLoS One. 10.1371/journal.pone.0033472

51. Espinoza-Fonseca, L. M. (2004) Base docking model of the homomeric alpha7 nicotinic receptor-beta-amyloid(1-42) complex. Biochem. Biophys. Res. Commun. 320, $587-91$ 
52. Pflanzner, T., Petsch, B., André-Dohmen, B., Müller-Schiffmann, A., Tschickardt, S., Weggen, S., Stitz, L., Korth, C., and Pietrzik, C. U. (2012) Cellular prion protein participates in amyloid- $\beta$ transcytosis across the blood-brain barrier. J. Cereb. Blood Flow Metab. 32, 628-32

53. Laurén, J., Gimbel, D. A., Nygaard, H. B., Gilbert, J. W., and Strittmatter, S. M. (2009) Cellular prion protein mediates impairment of synaptic plasticity by amyloid-beta oligomers. Nature. 457, 1128-32

54. Jarosz-Griffiths, H. H., Noble, E., Rushworth, J. V., and Hooper, N. M. (2015) Amyloid- $\beta$ receptors: the good, the bad and the prion protein. J. Biol. Chem. 10.1074/jbc.R115.702704

55. Peters, C., Espinoza, M. P., Gallegos, S., Opazo, C., and Aguayo, L. G. (2014) Alzheimer's $A \beta$ interacts with cellular prion protein inducing neuronal membrane damage and synaptotoxicity. Neurobiol. Aging. 10.1016/j.neurobiolaging.2014.11.019

56. Rushworth, J. V., Griffiths, H. H., Watt, N. T., and Hooper, N. M. (2013) Prion protein-mediated toxicity of amyloid- $\beta$ oligomers requires lipid rafts and the transmembrane LRP1. J. Biol. Chem. 288, 8935-51

57. Um, J. W., Kaufman, A. C., Kostylev, M., Heiss, J. K., Stagi, M., Takahashi, H., Kerrisk, M. E., Vortmeyer, A., Wisniewski, T., Koleske, A. J., Gunther, E. C., Nygaard, H. B., and Strittmatter, S. M. (2013) Metabotropic glutamate receptor 5 is a coreceptor for Alzheimer a $\beta$ oligomer bound to cellular prion protein. Neuron. 79, 887-902

58. Mastrangelo, P., and Westaway, D. (2001) The prion gene complex encoding $\operatorname{PrP}(\mathrm{C})$ and Doppel: insights from mutational analysis. Gene. 275, 1-18

59. Behrens, A., Genoud, N., Naumann, H., Rülicke, T., Janett, F., Heppner, F. L., Ledermann, B., and Aguzzi, A. (2002) Absence of the prion protein homologue Doppel causes male sterility. EMBO J. 21, 3652-8

60. Li, Y. R., Li, Q., Yang, J. M., Zhou, X. M., Yin, X. M., and Zhao, D. M. (2008) Expression patterns of Doppel gene in golden hamster: quantification using real-time RT-PCR. Mol. Cell. Probes. 22, 255-8

61. Sakaguchi, S., Katamine, S., Nishida, N., Moriuchi, R., Shigematsu, K., Sugimoto, T., Nakatani, A., Kataoka, Y., Houtani, T., Shirabe, S., Okada, H., Hasegawa, S., Miyamoto, T., and Noda, T. (1996) Loss of cerebellar Purkinje cells in aged mice homozygous for a disrupted PrP gene. Nature. 380, 528-31

62. Moore, R. C., Lee, I. Y., Silverman, G. L., Harrison, P. M., Strome, R., Heinrich, C., Karunaratne, a, Pasternak, S. H., Chishti, M. a, Liang, Y., Mastrangelo, P., Wang, K., Smit, a F., Katamine, S., Carlson, G. a, Cohen, F. E., Prusiner, S. B., Melton, D. W., Tremblay, P., Hood, L. E., and Westaway, D. (1999) Ataxia in prion protein (PrP)deficient mice is associated with upregulation of the novel PrP-like protein doppel. $J$. Mol. Biol. 292, 797-817 
63. Moore, R. C., Mastrangelo, P., Bouzamondo, E., Heinrich, C., Legname, G., Prusiner, S. B., Hood, L., Westaway, D., DeArmond, S. J., and Tremblay, P. (2001) Doppelinduced cerebellar degeneration in transgenic mice. Proc. Natl. Acad. Sci. U. S. A. 98, 15288-93

64. Watts, J. C., Drisaldi, B., Ng, V., Yang, J., Strome, B., Horne, P., Sy, M.-S., Yoong, L., Young, R., Mastrangelo, P., Bergeron, C., Fraser, P. E., Carlson, G. a, Mount, H. T. J., Schmitt-Ulms, G., and Westaway, D. (2007) The CNS glycoprotein Shadoo has $\operatorname{PrP}(\mathrm{C})$-like protective properties and displays reduced levels in prion infections. EMBO J. 26, 4038-50

65. Yamaguchi, N., Sakaguchi, S., Shigematsu, K., Okimura, N., and Katamine, S. (2004) Doppel-induced Purkinje cell death is stoichiometrically abrogated by prion protein. Biochem. Biophys. Res. Commun. 319, 1247-52

66. Premzl, M., Sangiorgio, L., Strumbo, B., Marshall Graves, J. A., Simonic, T., and Gready, J. E. (2003) Shadoo, a new protein highly conserved from fish to mammals and with similarity to prion protein. Gene. 314, 89-102

67. Premzl, M., Gready, J. E., Jermiin, L. S., Simonic, T., and Marshall Graves, J. a (2004) Evolution of vertebrate genes related to prion and Shadoo proteins--clues from comparative genomic analysis. Mol. Biol. Evol. 21, 2210-31

68. Corley, S. M., and Gready, J. E. (2008) Identification of the RGG box motif in Shadoo: RNA-binding and signaling roles? Bioinform. Biol. Insights. 2, 383-400

69. Tóth, E., Kulcsár, P. I., Fodor, E., Ayaydin, F., Kalmár, L., Borsy, A. É., László, L., and Welker, E. (2013) The highly conserved, N-terminal (RXXX)8 motif of mouse Shadoo mediates nuclear accumulation. Biochim. Biophys. Acta. 1833, 1199-211

70. Watts, J. C., Stöhr, J., Bhardwaj, S., Wille, H., Oehler, A., Dearmond, S. J., Giles, K., and Prusiner, S. B. (2011) Protease-resistant prions selectively decrease Shadoo protein. PLoS Pathog. 7, e1002382

71. Beck, J. a, Campbell, T. a, Adamson, G., Poulter, M., Uphill, J. B., Molou, E., Collinge, J., and Mead, S. (2008) Association of a null allele of SPRN with variant Creutzfeldt-Jakob disease. J. Med. Genet. 45, 813-7

72. Lampo, E., Duchateau, L., B. Schepens, Van Poucke, M., Saelens, X., Erkens, T., Van Zeveren, A., and Peelman, L. J. (2010) Identification of polymorphisms in the ovine Shadow of prion protein (SPRN) gene and assessment of their effect on promoter activity and susceptibility for classical scrapie. Anim. Genet. 41, 169-178

73. Piestrzyńska-Kajtoch, A., Gurgul, A., Polak, M. P., Smołucha, G., Zmudziński, J. F., and Rejduch, B. (2012) Characterization of PRNP and SPRN coding regions from atypical scrapie cases diagnosed in Poland. Mol. Biol. Rep. 39, 2575-83 
74. Ciric, D., Richard, C.-A., Moudjou, M., Chapuis, J., Sibille, P., Daude, N., Westaway, D., Adrover Estelrich, M., Béringue, V., Martin, D., and Rezaei, H. (2015) Interaction between Shadoo and PrP affects the PrP folding pathway. J. Virol. 10.1128/JVI.0342914

75. Atarashi, R., Sim, V. L., Nishida, N., Caughey, B., and Katamine, S. (2006) Prion strain-dependent differences in conversion of mutant prion proteins in cell culture. $J$. Virol. 80, 7854-62

76. Mátés, L., Chuah, M. K. L., Belay, E., Jerchow, B., Manoj, N., Acosta-Sanchez, A., Grzela, D. P., Schmitt, A., Becker, K., Matrai, J., Ma, L., Samara-Kuko, E., Gysemans, C., Pryputniewicz, D., Miskey, C., Fletcher, B., VandenDriessche, T., Ivics, Z., and Izsvák, Z. (2009) Molecular evolution of a novel hyperactive Sleeping Beauty transposase enables robust stable gene transfer in vertebrates. Nat. Genet. 41, 753-61

77. Kolacsek, O., Erdei, Z., and Apati, A. (2014) Excision efficiency is not strongly coupled to transgenic rate: cell type dependent transposition efficiency of Sleeping Beauty and piggyBac DNA transposons. ... Gene Ther. Part .... 25, 1-38

78. Tátrai, P., Sági, B., Szigeti, A., Szepesi, A., Szabó, I., Bősze, S., Kristóf, Z., Markó, K., Szakács, G., Urbán, I., Mező, G., Uher, F., and Német, K. (2013) A novel cyclic RGDcontaining peptide polymer improves serum-free adhesion of adipose tissue-derived mesenchymal stem cells to bone implant surfaces. J. Mater. Sci. Mater. Med. 24, 47988

79. Kim, B.-H., Kim, J.-I., Choi, E.-K., Carp, R. I., and Kim, Y.-S. (2005) A neuronal cell line that does not express either prion or doppel proteins. Neuroreport. 16, 425-429

80. Ivics, Z., Hackett, P., Plasterk, R., and Izsvák, Z. (1997) Molecular Reconstruction of Sleeping Beauty, a Tc1-like Transposon from Fish, and Its Transposition in Human Cells. Cell. 91, 501-10

81. Miskey, C., Izsvák, Z., Kawakami, K., and Ivics, Z. (2005) DNA transposons in vertebrate functional genomics. Cell. Mol. Life Sci. 62, 629-41

82. Barde, I., Salmon, P., and Trono, D. (2010) Production and titration of lentiviral vectors. Curr. Protoc. Neurosci. Chapter 4, Unit 4.21

83. Mosmann, T. (1983) Rapid colorimetric assay for cellular growth and survival: application to proliferation and cytotoxicity assays. J. Immunol. Methods. 65, 55-63

84. Boncler, M., Rózalski, M., Krajewska, U., Podswdek, A., and Watala, C. (2014) Comparison of PrestoBlue and MTT assays of cellular viability in the assessment of anti-proliferative effects of plant extracts on human endothelial cells. J. Pharmacol. Toxicol. Methods. 69, 9-16

85. Izsvák, Z., and Ivics, Z. (2004) Sleeping beauty transposition: biology and applications for molecular therapy. Mol. Ther. 9, 147-56 
86. Rambold, A. S., Müller, V., Ron, U., Ben-Tal, N., Winklhofer, K. F., and Tatzelt, J. (2008) Stress-protective signalling of prion protein is corrupted by scrapie prions. EMBO J. 27, 1974-84

87. Daude, N., Wohlgemuth, S., Brown, R., Pitstick, R., Gapeshina, H., Yang, J., Carlson, G. A., and Westaway, D. (2012) Knockout of the prion protein (PrP)-like Sprn gene does not produce embryonic lethality in combination with $\operatorname{PrP}(\mathrm{C})$-deficiency. Proc. Natl. Acad. Sci. U. S. A. 109, 9035-40

88. Kuwahara, C., Takeuchi, a M., Nishimura, T., Haraguchi, K., Kubosaki, a, Matsumoto, Y., Saeki, K., Matsumoto, Y., Yokoyama, T., Itohara, S., and Onodera, T. (1999) Prions prevent neuronal cell-line death. Nature. 400, 225-226

89. Solomon, I. H., Khatri, N., Biasini, E., Massignan, T., Huettner, J. E., and Harris, D. A. (2011) An N-terminal polybasic domain and cell surface localization are required for mutant prion protein toxicity. J. Biol. Chem. 286, 14724-36

90. Celeste, A., Fernandez-Capetillo, O., Kruhlak, M. J., Pilch, D. R., Staudt, D. W., Lee, A., Bonner, R. F., Bonner, W. M., and Nussenzweig, A. (2003) Histone H2AX phosphorylation is dispensable for the initial recognition of DNA breaks. Nat. Cell Biol. 5, 675-9

91. van Maanen, J. M., Retèl, J., de Vries, J., and Pinedo, H. M. (1988) Mechanism of action of antitumor drug etoposide: a review. J. Natl. Cancer Inst. 80, 1526-33

92. Turnbaugh, J. a, Westergard, L., Unterberger, U., Biasini, E., and Harris, D. A. (2011) The N-terminal, polybasic region is critical for prion protein neuroprotective activity. PLoS One. 6, e25675

93. White, A. R., Collins, S. J., Maher, F., Jobling, M. F., Stewart, L. R., Thyer, J. M., Beyreuther, K., Masters, C. L., and Cappai, R. (1999) Prion protein-deficient neurons reveal lower glutathione reductase activity and increased susceptibility to hydrogen peroxide toxicity. Am. J. Pathol. 155, 1723-1730

94. Roucou, X., Gains, M., and LeBlanc, A. C. (2004) Neuroprotective functions of prion protein. J. Neurosci. Res. 75, 153-61

95. Kim, J. I., Choi, S. I., Kim, N. H., Jin, J. K., Choi, E. K., Carp, R. I., and Kim, Y.-S. (2001) Oxidative stress and neurodegeneration in prion diseases. Ann. N. Y. Acad. Sci. 928, 182-186

96. Christensen, H. M., and Harris, D. A. (2008) Prion protein lacks robust cytoprotective activity in cultured cells. Mol. Neurodegener. 3, 11

97. Drisaldi, B., Coomaraswamy, J., Mastrangelo, P., Strome, B., Yang, J., Watts, J. C., Chishti, M. A., Marvi, M., Windl, O., Ahrens, R., Major, F., Sy, M.-S., Kretzschmar, H., Fraser, P. E., Mount, H. T. J., and Westaway, D. (2004) Genetic mapping of activity determinants within cellular prion proteins: N-terminal modules in PrPC offset pro-apoptotic activity of the Doppel helix B/B' region. J. Biol. Chem. 279, 55443-54 
98. Resenberger, U. K., Harmeier, A., Woerner, A. C., Goodman, J. L., Müller, V., Krishnan, R., Vabulas, R. M., Kretzschmar, H., Lindquist, S., Hartl, F. U., Multhaup, G., Winklhofer, K. F., and Tatzelt, J. (2011) The cellular prion protein mediates neurotoxic signalling of $\beta$-sheet-rich conformers independent of prion replication. EMBO J. 30, 2057-70

99. Chu, N. K., Shabbir, W., Bove-Fenderson, E., Araman, C., Lemmens-Gruber, R., Harris, D. A., and Becker, C. F. W. (2014) A C-terminal membrane anchor affects the interactions of prion proteins with lipid membranes. J. Biol. Chem. 289, 30144-60

100. Jiayu, W., Zhu, H., Ming, X., Xiong, W., Songbo, W., Bocui, S., Wensen, L., Jiping, L., Keying, M., Zhongyi, L., and Hongwei, G. (2010) Mapping the interaction site of prion protein and Sho. Mol. Biol. Rep. 37, 2295-2300

101. Young, K., Clark, H. B., Piccardo, P., Dlouhy, S. R., and Ghetti, B. (1997) GerstmannSträussler-Scheinker disease with the PRNP P102L mutation and valine at codon 129. Brain Res. Mol. Brain Res. 44, 147-50

102. Telling, G. C., Haga, T., Torchia, M., Tremblay, P., DeArmond, S. J., and Prusiner, S. B. (1996) Interactions between wild-type and mutant prion proteins modulate neurodegeneration in transgenic mice. Genes Dev. 10, 1736-1750

103. Monaco, S., Fiorini, M., Farinazzo, A., Ferrari, S., Gelati, M., Piccardo, P., Zanusso, G., and Ghetti, B. (2012) Allelic origin of protease-sensitive and protease-resistant prion protein isoforms in gerstmann-str??ussler-scheinker disease with the p1021 mutation. PLoS One. 10.1371/journal.pone.0032382

104. Steele, A. D., Lindquist, S., and Aguzzi, A. (2007) The prion protein knockout mouse: a phenotype under challenge. Prion. 1, 83-93 


\section{Appendix}

\begin{tabular}{|c|c|}
\hline Oligo Name & DNA sequence \\
\hline Delta105-125for & AACAAGCCCAGCAAACCAGGCTACATGCTGGGGAG \\
\hline Delta105-125rev & CTCCCCAGCATGTAGCCTGGTTTGCTGGGCTTGTT \\
\hline XhoImutator5 & CGGCCGCGGAGGCGCACGAGGCAGTGCCCGG \\
\hline XhoImutator3 & CCGGGCACTGCCTCGTGCGCCTCCGCGGCCG \\
\hline ApoICMV5 & CGCGCGAAATTTCTGCTTCGCGATGTACGGG \\
\hline ApoIBGH3 & GGCCCGAAATTTCCACCGCATCCCCAGCATG \\
\hline PrPNheI5 & GCCGGGCTAGCCACCATGGCGAACCTTGGCTACTG \\
\hline PrPBamHI3 & TACCACGGATCCTCATCCCACGATCAGGAAGATG \\
\hline mShoBamHI5 & CCCGAAGGATCCGCCACCATGAACTGGACTGCTGCCACG \\
\hline XhoISho3 & GGCGCGCTCGAGCTAAGGCCGAAGCAGTTCTAG \\
\hline Linker2-3048-fwd & GTACAAGTGAGGGCGCGCCAAACATATGAAACGTACGAA \\
\hline Linker2-3048-rev & TCGATTCGTACGTTTCATATGTTTGGCGCGCCCTCACTT \\
\hline V-CMV-PrP fw & TTTGCAGGCGCGCCCGATGTACGGGCCAGATATACG \\
\hline V-CMV-PrP rev & CACTATTGTACAGGGCCCTCTAGATGCATGCTCGAGC \\
\hline V-CMV-PA rev & ATAGAGTGTACAACATCCCCAGCATGCCTGC \\
\hline Sho-epi1-fwd & GTACAGGCTCTGGCTGGAGGAGGACCTCAGGGCCTGGAGAGCTA \\
\hline Sho-epi1-rev* & AGGCCCTGAGGTCCTCCTCCAGCCAGAGCCT \\
\hline Sho-epi2-fwd* & GGCCTGGAGGACGATGAGAATGGGGCAATGGGAGGC \\
\hline Sho-epi2-rev* & TGCCCCATTCTCATCGTCCTCCAGGCCTAGCTCTCC \\
\hline Sho-epi3-fwd* & AACGGAACCGACCGAGGAGTCTACAGCTACA \\
\hline Sho-epi3-rev & GTACTGTAGCTGTAGACTCCTCGGTCGGTTCCGTTGCCTCCCAT \\
\hline Sho $\Delta$ HDfor & TACGGCTCCTCTCTGCGCGGCCTTGCTACCGGCTCT \\
\hline Sho $\Delta$ HDrev & AGAGCCGGTAGCAAGGCCGCGCAGAGAGGAGCCGTA \\
\hline V-dHD-fwd & TTTCCCTCATGAACGTTATCCCCTGATTCTGTG \\
\hline V-dHD-rev & AGCTCTGCTCTTCCTGATGTCCTCCTCCAGCCAGAGCC \\
\hline
\end{tabular}

Table 2: The DNA oligos used in the cloning processes. Asterisks mark 5' phosphorylation. 


\begin{tabular}{|c|c|c|c|}
\hline Cell culture name & Introduced transgenes & Parental Cell name & Vector used \\
\hline Zpl/GFP & EGFP & Zpl2-1 & $\mathrm{pSB} / \mathrm{GFP}$ \\
\hline $\mathrm{Zpl} / \mathrm{PrP}$ & mPrP and EGFP & Zpl2-1 & $\mathrm{pSB} / \mathrm{PrP}$ \\
\hline $\mathrm{Zpl} / \Delta \mathrm{CR}$ & $\mathrm{mPrP} \Delta \mathrm{CR}$ and EGFP & Zpl2-1 & $\mathrm{pSB} / \triangle \mathrm{CR}$ \\
\hline SH/GFP & EGFP & SH-SY5Y & $\mathrm{pSB} / \mathrm{GFP}$ \\
\hline $\mathrm{SH} / \mathrm{PrP}$ & $\mathrm{mPrP}$ and EGFP & SH-SY5Y & $\mathrm{pSB} / \mathrm{PrP}$ \\
\hline $\mathrm{SH} / \Delta \mathrm{CR}$ & $\mathrm{mPrP} \Delta \mathrm{CR}$ and EGFP & SH-SY5Y & $\mathrm{pSB} / \triangle \mathrm{CR}$ \\
\hline $\mathrm{SH} / \mathrm{mCh}$ & mCherry & SH-SY5Y & $\mathrm{LV} / \mathrm{mCh}$ \\
\hline SH/Sho & mSho and mCherry & SH-SY5Y & LV/Sho(R) \\
\hline $\mathrm{SH} / \Delta \mathrm{CR}+\mathrm{mCh}$ & mCherry & $\mathrm{SH} / \Delta \mathrm{CR}$ & $\mathrm{LV} / \mathrm{mCh}$ \\
\hline $\mathrm{SH} / \Delta \mathrm{CR}+\mathrm{PrP}$ & mPrP and mCherry & $\mathrm{SH} / \Delta \mathrm{CR}$ & $\mathrm{LV} / \operatorname{PrP}(\mathrm{R})$ \\
\hline $\mathrm{SH} / \Delta \mathrm{CR}+\mathrm{Sho}$ & mSho and mCherry & $\mathrm{SH} / \Delta \mathrm{CR}$ & LV/Sho(R) \\
\hline SH/Sho+GFP & EGFP & SH/Sho & LV/GFP \\
\hline SH/Sho+PrP & $\mathrm{mPrP}$ and EGFP & SH/Sho & $\mathrm{LV} / \operatorname{PrP}(\mathrm{G})$ \\
\hline SH/Sho $\Delta$ RXXX8 & mSho $\Delta 26-61$ and mCherry & SH-SY5Y & $\mathrm{LV} / \mathrm{Sho}^{\Delta \mathrm{RX}}(\mathrm{R})$ \\
\hline SH/ShoQXXX8 & mSho $(\mathrm{QXXX})_{8}$ and mCherry & SH-SY5Y & $\mathrm{LV} / \mathrm{Sho}^{\mathrm{RQ}}(\mathrm{R})$ \\
\hline SH/Sho $\Delta \mathrm{HD}$ & mSho $\Delta 62-77$ and mCherry & SH-SY5Y & $\mathrm{LV} / \mathrm{Sho}^{\Delta \mathrm{HD}}(\mathrm{R})$ \\
\hline SH/Sho(PrPHD) & $\begin{array}{l}\mathrm{mSho} \Delta 62-77 \operatorname{PrP} 113-133 \text { and } \\
\text { mCherry }\end{array}$ & SH-SY5Y & $\mathrm{LV} / \mathrm{Sho}^{\mathrm{PrPHD}}(\mathrm{R})$ \\
\hline $\mathrm{HEK} / \mathrm{mCh}$ & mCherry & HEK293 & $\mathrm{LV} / \mathrm{mCh}$ \\
\hline HEK/Sho & mSho and mCherry & HEK293 & LV/ Sho(R) \\
\hline HEK/Sho+GFP & EGFP & HEK/Sho & $\mathrm{LV} / \mathrm{GFP}$ \\
\hline HEK/Sho+PrP & $\mathrm{mPrP}$ and GFP & HEK/Sho & $\mathrm{LV} / \operatorname{PrP}(\mathrm{G})$ \\
\hline
\end{tabular}

Table 3. Cells with stable transgene expression used in these studies. The given abbreviated names and the specifics for each type of transformant cell are listed in the columns. 
Figure 17: Overexpression of Shadoo causes Zeocin and G418 hypersensitivity in HEK293 cells could be eliminated by WT PrP coexpression. $(A, B)$ Western blot analysis of Shadoo expression (A) and $\operatorname{Pr} P$ expression $(B)$ in $P N G a s e F$ treated extracts from HEK cells. * marks a nonspecific band. $\beta$-actin was used as loading control. $(C, D)$ Cytotoxicity assays by Presto blue after 48 hours of Zeocin treatment. (C) Concentration dependence of Zeocin cytotoxicity is shown in a representative experiment in HEK293 cell types as indicated. (D) Differences in the viability of compared cell types was characterized at a selected concentration of Zeocin. Columns show the means $\pm S . D$ in 3 independent experiments. $(E, \quad F)$ Cytotoxicity assays by Presto Blue after 48 hours of G418 treatment. (E) Concentration dependence of $G 418$ cytotoxicity is shown in a representative experiment in cell types as indicated $(F)$ Differences in the viability of compared cell types was characterized at a selected concentration of G418.

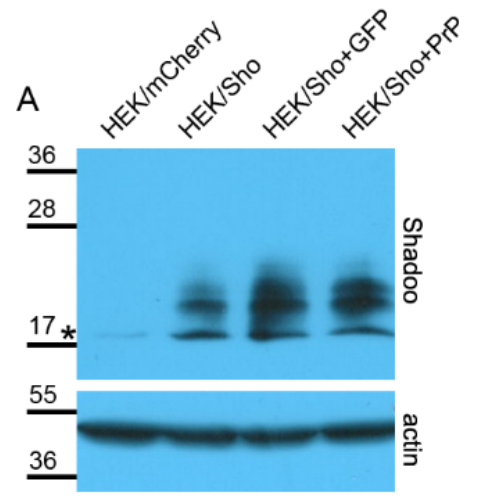

C
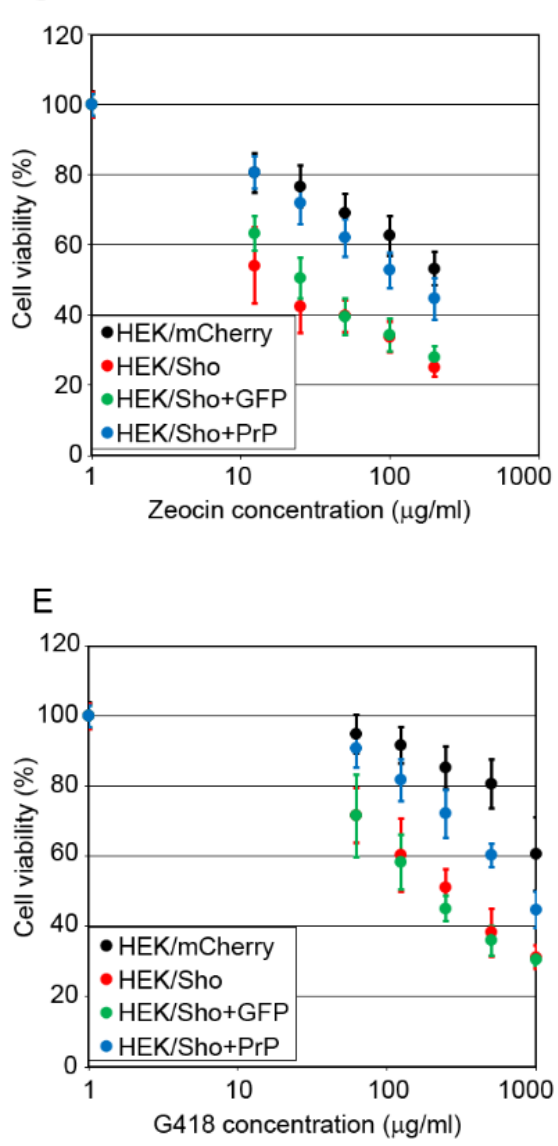

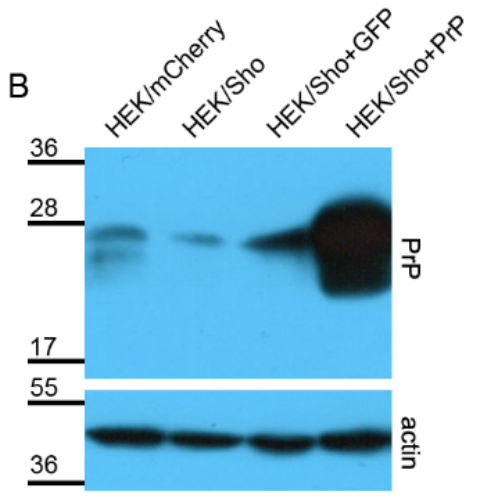

D Zeocin $(50 \mu \mathrm{g} / \mathrm{ml})$

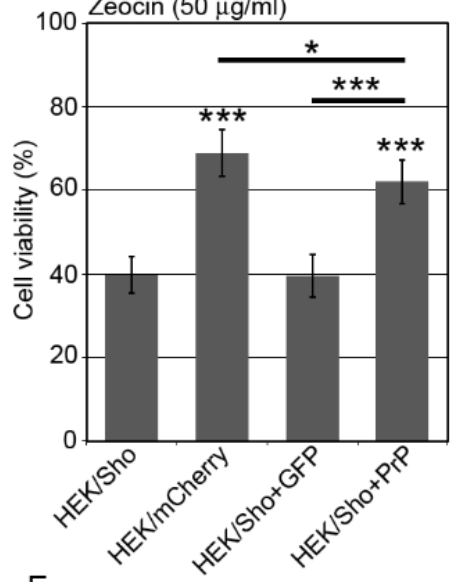

$\mathrm{F}$

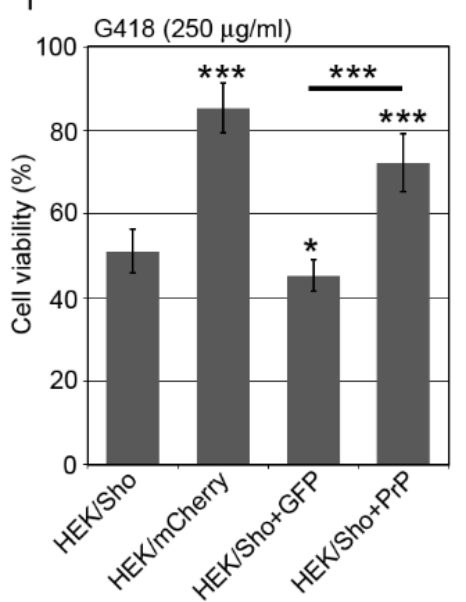

Columns show the means \pm S.D. in 3 independent experiments. (C-F) Viability is given as percentage of non-treated controls. $* p<0.05, * * p<0.01, * * * p<0.001$. 